\title{
High-potential Working Fluids for Next \\ Generation Binary Cycle Geothermal Power
}

\section{Plants}

Phase 3 \& Final Report: Fluid/Cycle Downselection and Experimental Validation

$\begin{array}{ll}\text { Authors } & \text { Phone } \\ \text { Jalal Zia } & 8^{\star} 833-7097 \\ \text { Edip Sevincer } & 8^{\star} 833-4151 \\ \text { Huijuan Chen } & 8^{\star} 833-4793 \\ \text { Ajilli Hardy } & 8^{\star} 833-7849 \\ \text { Paul Wickersham } & 8^{\star} 833-3552 \\ \text { Chiranjeev Kalra } & 8^{\star} 833-7927 \\ \text { Anna Lis Laursen } & \mathbf{8}^{\star} 833-5206 \\ \text { Thomas Vandeputte } & \mathbf{8}^{\star} 833-5370\end{array}$

Contract no. DE-EE0002769

Number of $\quad 105$

Pages

Class Class 1

Key Words Organic rankine cycle (ORC), subcritical, supercritical, trilateral flash, dual pressure, working fluid, geothermal, EGS, enhanced geothermal system 


\section{Contents}

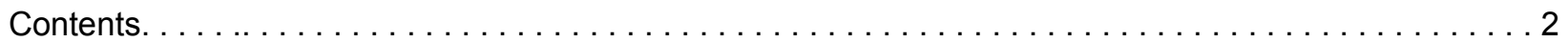

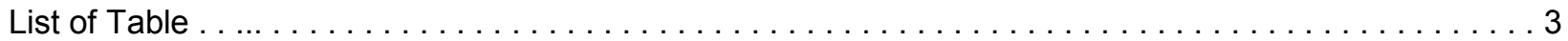

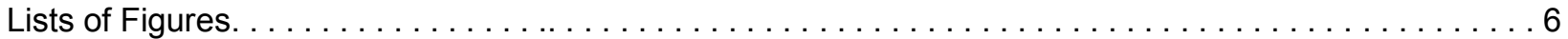

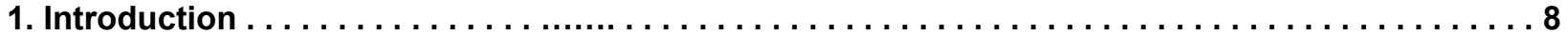

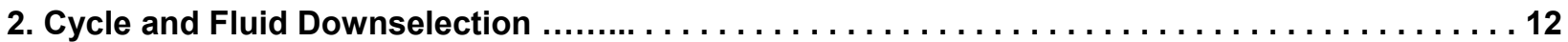

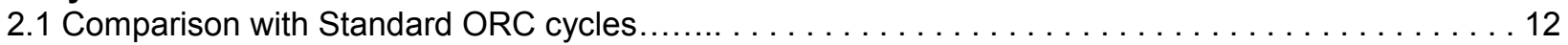

2.2 Downselected Cycle and Fluid for Experimental Validation $\ldots \ldots \ldots \ldots \ldots \ldots \ldots$

3. Organic Fluid Thermal Stability and Compatibility at Relatively High Temperatures............. 14

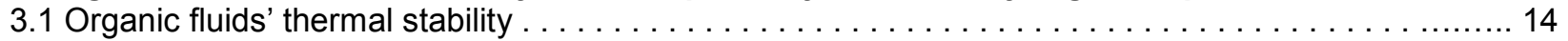

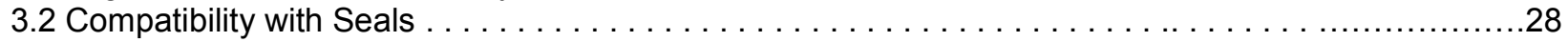

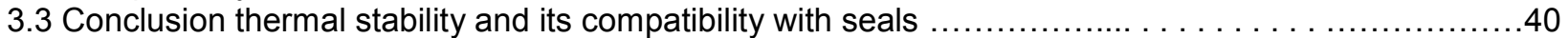

4. Experiment Objectives and Design Rationale. . . . . . . . . . . . . . . . . . . . . . . . . . . . 42

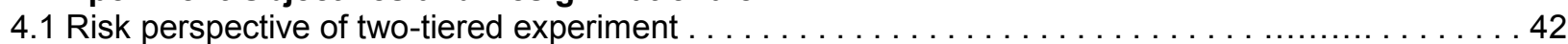

4.2 Teaming with business to conduct subcritical experiment $\ldots \ldots \ldots \ldots$

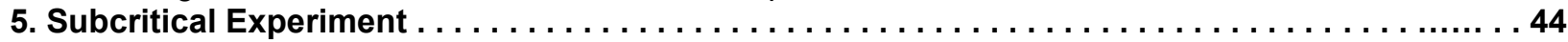

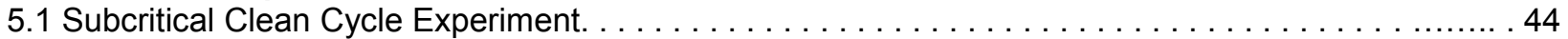

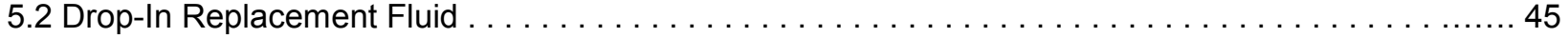

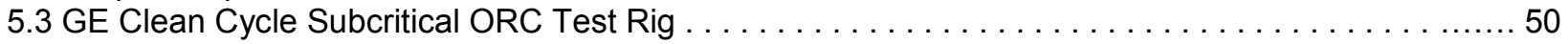

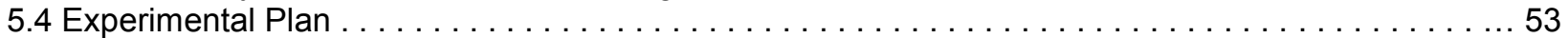

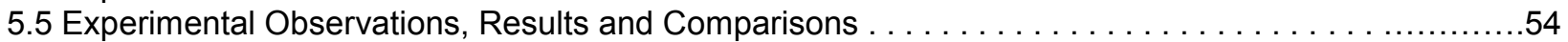

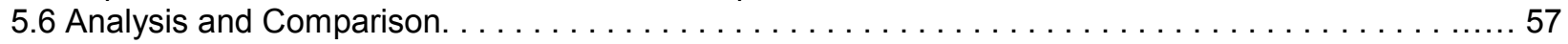

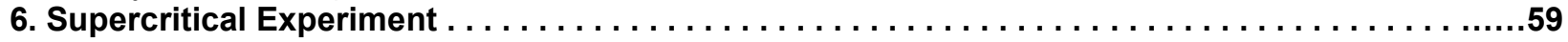

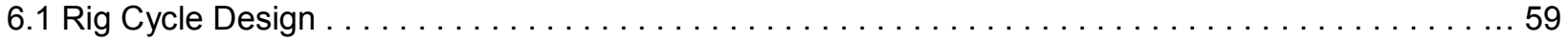

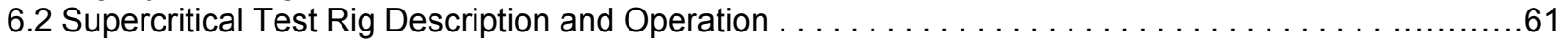

6.3 Heat Exchanger Sizing for the Supercritical NEW FLUID ORC Test Rig. . . . . . . . . . . . . . . . . 67

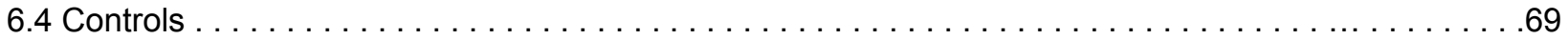

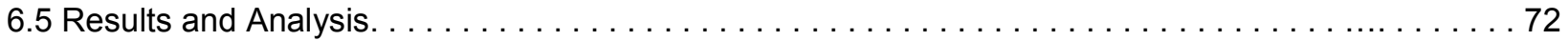

6.6 Method for Estimation of Measurement Uncertainty $\ldots \ldots \ldots \ldots \ldots \ldots$

7. Supercritical Turboexpander Design Study. . . . . . . . . . . . . . . . . . . . . . . . . . 80

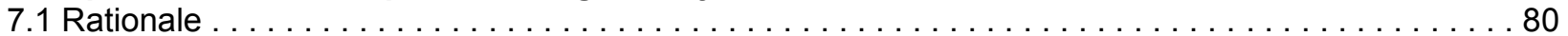

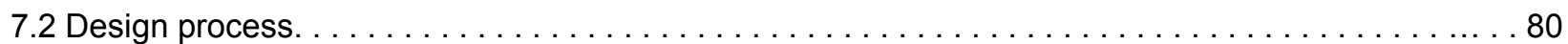

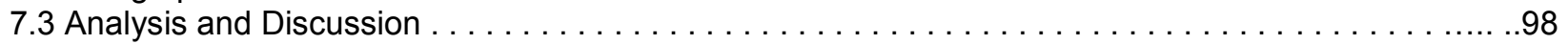

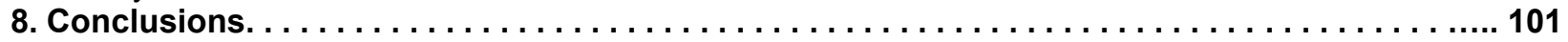

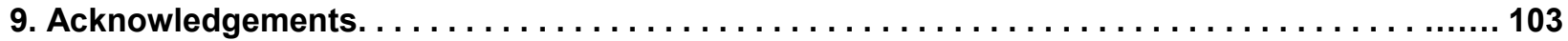

References. . . . . . . . . . . . . . . . . . . . . . . . . . . . . . . . . . . . . . 104 


\section{Lists of Tables}

Table 1. The properties of cyclopentene. ……………….................................................................... 15

Table 2. Estimated amount of products formed from heating cyclopentene at $300^{\circ} \mathrm{C} \ldots \ldots \ldots . .22$

Table 3. Physical and environmental properties of NEW FLUID......................................................... 24

Table 4. Test data on silicone O-rings' compatibility with NEW FLUID. .......................................... 29

Table 5. Test data on silicone O-rings' compatibility with R245fa................................................... 30

Table 6. Comparison between silicone O-rings tested in NEW FLUID and R245fa. .................................................................................. 30

Table 7. Young's modulus of silicone O-rings tested with NEW FLUID.......................................... 32

Table 8. Young's modulus of silicone O-rings tested with R245fa............................................ 32

Table 9. Test data on neoprene O-ring's compatibility with NEW FLUID. ..................................... 33

Table 10. Test results summary on NEW FLUID's compatibility

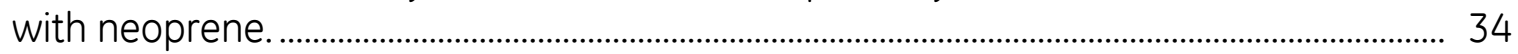

Table 11. Young's Modulus of neoprene O-rings tested with NEW FLUID.................................... 35

Table 12. Thermal-physical properties of R245fa and NEW FLUID............................................ 40

Table 13. R245fa and NEW FLUID test matrix for the subcritical Clean Cycle. ...................................................................................................... 46

Table 14. Design heat exchanger information.[25,26] ........................................................................ 48

Table 15. Data used in the 2-sample T-test...................................................................................... 49

Table 16. Error analysis for NEW FLUID and R245fa............................................................... 50

Table 17. NEW FLUID supercritical state points................................................................................... 53

Table 18. Heat transfer coefficient comparison between R245fa and NEW FLUID. .................. 60

Table 19. Comparison of measured and Hysys predicted state points......................................... 64

Table 20. Comparison of calculated and Hysys predicted energy balance parameters......... 66

Table 21. Repeatability of supercritical runs with NEW FLUID ........................................................... 69

Table 22. Final conceptual flowpath-geometric and aerodynamic properties.......................... 87

Table 23. Final conceptual flowpath corner point table (all coordinates in inches). .................. 89

Table 24. Two-stage and single-stage design details......................................................................... 93

Table 25. Comparative cost analysis at $5 \mathrm{MWe}$......................................................................... 94

Table 26. Comparative cost analysis at $15 \mathrm{MWe}$............................................................................. 94

Table 27. Comparison of various designs completed in the current study................................... 95

Table 28. Impact of the turbine on the power block............................................................................ 95 
Table 29. Comparison of model predictions for supercritical NEW FLUID versus R245fa....... 97 


\section{List of Figures}

Figure 1. 2009 global spending on renewable energy technologies

Figure 2. Total potential capacity and potential annual production for some renewable power sources

Figure 3. Comparison of the optimum LCOE versus resource temperature and cycle type ......................................... 10

Figure 4. Comparison of the optimum LCOE versus resource temperature and cycle type ........................................ 11

Figure 5. Chemical structures of cyclopentane and cyclopentene ……………………......................................................... 12

Figure 6. Possible pathways for cyclopentane decomposition and oxidation …….............................................................. 13

Figure 7. Possible pathways for cyclopentene decomposition and oxidation ......................................................................... 14

Figure 8. NMR spectra of cyclopentene before (red) and after (blue) 90 hours at $300^{\circ} \mathrm{C}$............................................ 17

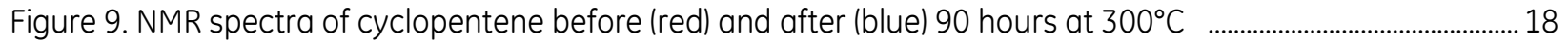

Figure 10. NMR spectra of cyclopentene before (pink) and after (blue) 90 hours

at $300{ }^{\circ} \mathrm{C}$

Figure 11. NMR spectrum of residue after room temperature evaporation of the

$90 \mathrm{hr} / 300^{\circ} \mathrm{C}$ sample

Figure 12. Schematic of GC-MS analysis provided by Hans Grade

Figure 13. GC-MS data for a sample of heated cyclopentene. (Hans Grade) 20

Figure 14. GC-MS data for a sample of heated cyclopentene (Hans Grade)

Figure 15. Increase in the amount of residue after room temperature evaporation after heating cyclopentene at $300^{\circ} \mathrm{C}$ .22

Figure 16. Photograph of evaporated cyclopentene 23

Figure 17. Chemical structures of NEW FLUID and R245fa .24

Figure 18. Possible pathways for NEW FLUID degradation .25

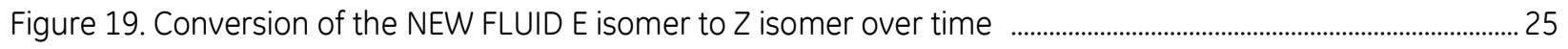

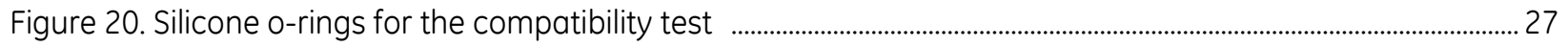

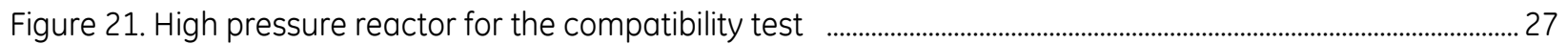

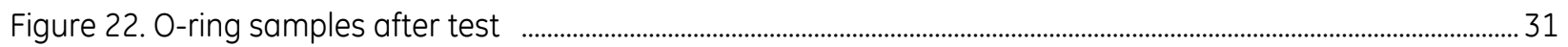

Figure 23. Elasticity test of the O-rings ………………………………………………………………………………………………... 31

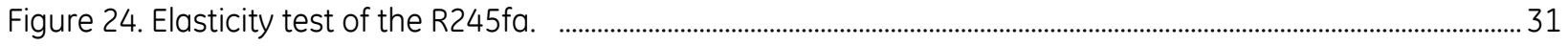

Figure 25. Neoprene O-rings tested with NEW FLUID .............................................................................................................. 34

Figure 26. Elasticity test results of the neoprene O-ring specimens reacted with NEW FLUID ………........................ 35

Figure 27. Ripped Viton diaphragms showing that Viton is not compatible with NEW FLUID ..................................... 36 
Figure 28. Solid lines show the thermodynamic pathway for the supercritical experiment

Figure 29. Global warming and lifetime data for R245fa and NEW FLUID …………………………...................................... 39

Figure 30. Guidelines for selecting the EOS .............................................................................................................................. 40

Figure 31. Pressure-temperature phase diagram for R245fa and NEW FLUID ................................................................ 41

Figure 32. Temperature-entropy phase diagram for R245fa and NEW FLUID ................................................................ 41

Figure 33. Pressure-enthalpy phase diagram for R245fa and NEW FLUID ………………………….................................. 41

Figure 34. Screen shot of the Clean Cycle HYSYS model ………………………….................................................................. 42

Figure 35. State points overlapping the T-S phase diagram for (A) R245fa and (B) NEW FLUID ............................... 42

Figure 36. Predicted performance using NEW FLUID ............................................................................................................ 43

Figure 37. 3D Schematic of the Clean Cycle ………………………………………………………………………………………..... 44

Figure 38. Clean Cycle breakdown of components: ...................................................................................................................... 44

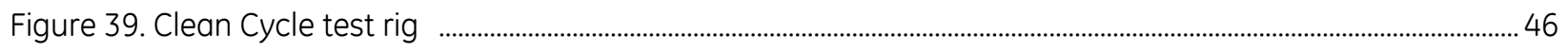

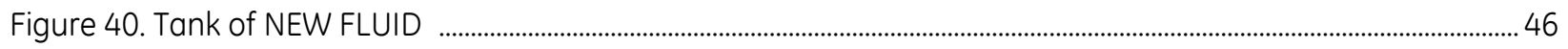

Figure 41. Turbine efficiency versus pressure ratio of R245fa and NEW FLUID .............................................................. 47

Figure 42. Efficiency versus heat for (A) pre-evaporator and (B) evaporator ...................................................................48

Figure 43. Generated power versus (A) pressure ratio and (B) evaporator inlet power for

R245fa and NEW FLUID ................................................................................................................................................. 48

Figure 44. Efficiency versus generated Power for R245fa and NEW FLUID ......................................................................... 49

Figure 45. Pressure-temperature plot. .................................................................................................................................... 51

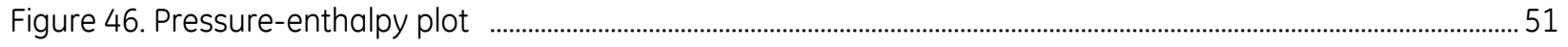

Figure 47. T-s diagram of the supercritical NEW FLUID demonstration cycle ……………………………………………......52

Figure 48. Sketch of the major components in the refrigerant loop ................................................................................... 54

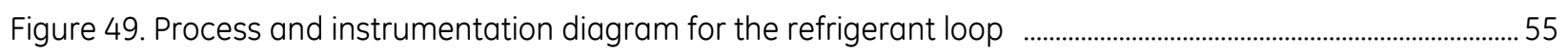

Figure 50. Process and instrumentation diagram for the heating oil loop ........................................................................ 56

Figure 51. Process and instrumentation diagram for the cooling water loop ……………………………………………….... 57

Figure 52. Process and instrumentation diagram indicating how the refrigerant lines

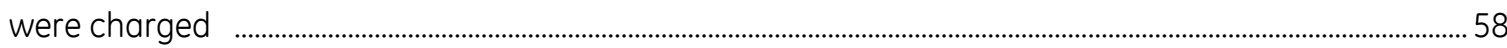

Figure 53. process and instrumentation diagram indicating how the refrigerant was

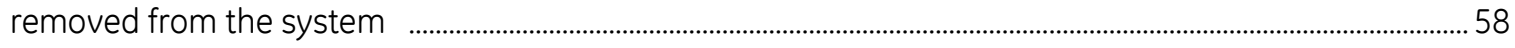

Figure 54. Heater of the supercritical ORC rig and the thermal oil heating loop …............................................................59

Figure 55. False load heat exchanger and condenser of the supercritical ORC rig and the

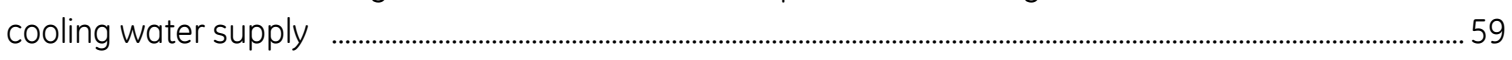

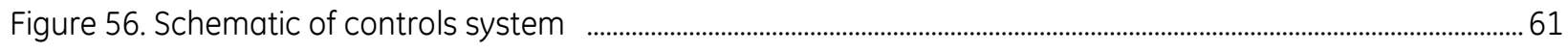


Figure 57. Piping and instrumentation diagram for the $5 \mathrm{~kW}$ supercritical test rig

Figure 58. Graphical summary of percent difference between measured and predicted state points

Figure 59. Graphical summary of percent difference between calculated and predicted energy balance parameters

Figure 60. Generic flowpath aerodynamic design process ……………………………………………………………………......

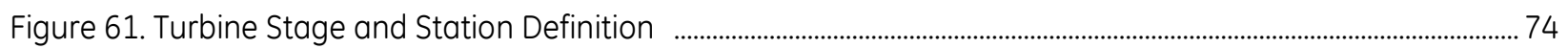

Figure 62. Turbine stage velocity triangles and flow angle definition .......................................................................... 74

Figure 63. Zwiefel coefficient definition ……………………………………………………………………………………….... 77

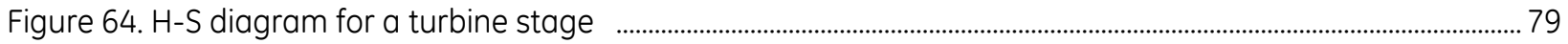

Figure 65. Geothermal loss model benchmark: Four-stage GE P\&W gas turbine .............................................................. 80

Figure 66. Geothermal loss model benchmark two-stage gas turbine design of

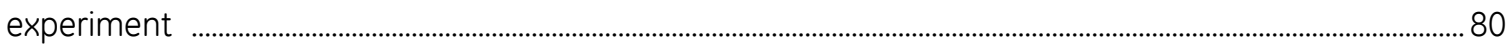

Figure 67. Count screening study-stage properties ................................................................................................................... 83

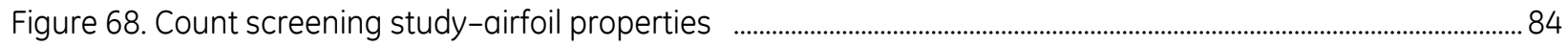

Figure 69. Count screening study-wall slopes ……………………………………………………………………………………...... 85

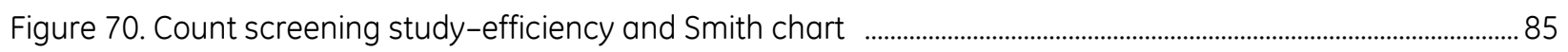

Figure 71. Count screening study-flowpath overlay ……………………………………………………………………….............. 85

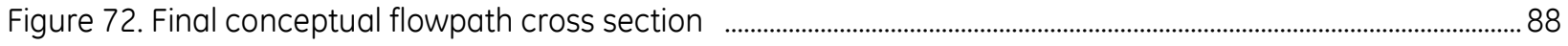

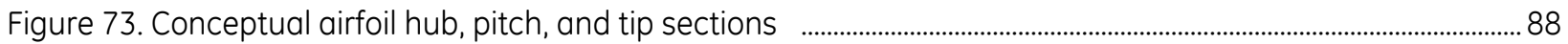

Figure 74. Entropy-enthalpy curves illustrating constant enthalpy, isentropic (ideal),

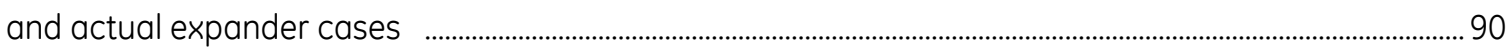

Figure 75. Photo image of the impeller wheel for the radial turboexpander ..................................................................... 91

Figure 76. Digitized graphs for the calculation of tip speed based on specific speed and the composition of inlet fluid in the expander design process ...................................................................................... 92

Figure 77. Predicted efficiency as a function of RPM and the wheel diameter ..................................................................... 92

Figure 78. Graphical summary of percent difference between measured and predicted state points 


\section{Introduction}

Geothermal energy is the only baseload renewable source of power. Every other source of renewable energy is cyclic and/or relies on weather, tidal, and seasonal phenomena.

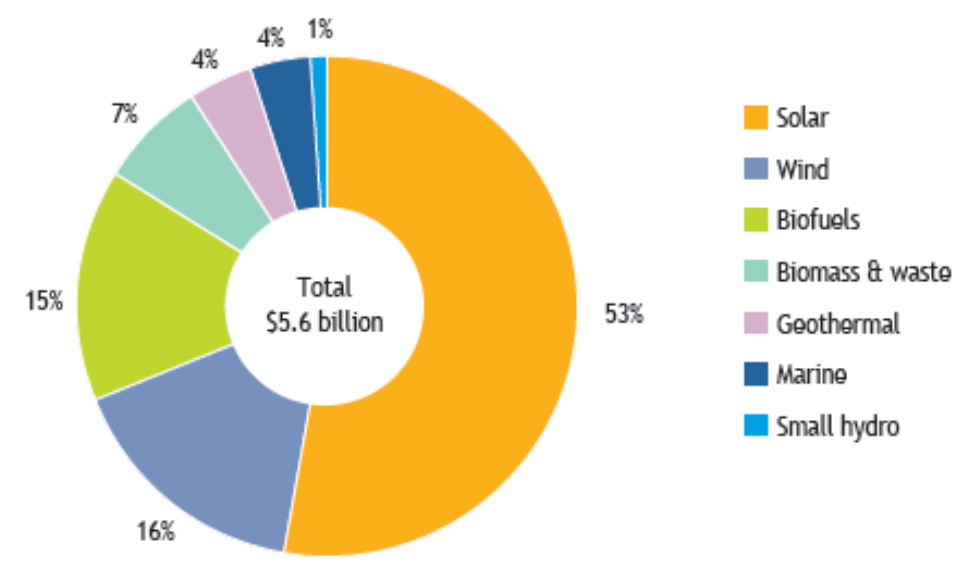

Source: Bloomberg New Energy Finance databases.

Figure 1: 2009 Global spending on renewable energy technologies

Figure 1 shows the global spending on research and development in renewable energy technologies. The leading beneficiary of funding, as seen in Figure 1, is solar power, followed by wind, biofuels, biomass/waste heat, geothermal, small marine and hydro. Despite receiving less than one tenth of the R\&D funding support, geothermal sources produced more than twice the electricity of solar sources in 2010.[1]

One of the biggest drawbacks of geothermal energy has traditionally been the geographical location of hydrothermal resources. These are often found in geologically "hot" areas where underground heat coincides with naturally occurring aquifers. Drilling is done to intersect such aquifers, thus raising the risk of a "missed well" and the cost of unsuccessful drilling.

A new technology, called enhanced geothermal, promises to dramatically reduce this risk. It does so by drilling a well and creating a network of passages in the hot rock underground. A unique approach to EGS has been developed by AltaRock Energy. The process is called hydroshearing. Once the formation has been hydrosheared, a low permeability biodegradable polymer is pumped into the formation and the passages are blocked. This allows the next formation to be hydrosheared in the same well. The process is repeated until several hydrosheared zones are created. These zones are then intersected by drilling one or more producer wells. Water is pumped into one well from above ground; it then gathers enthalpy from the underground "heat exchanger" and it flows out of the other well. A surface based power plant recovers this enthalpy and generates useful power. The technology to create this underground network of passages has recently been validated by Altarock Inc. at their Newberry, OR site.[2]

Enhanced geothermal energy holds tremendous potential in the USA because it is largely free of the requirement of locating an underground aquifer. All that is needed is an underground temperature gradient. Work by google.org (www.google.org/egs) has shown that economically attractive temperature gradients are ubiquitous in the USA, particularly west of the continental divide. According to a report by NREL,[3] the potential nameplate capacity for enhanced 
geothermal systems (EGS) in the USA is $>3900 \mathrm{GW}$ with a potential annual production of over 31 million GW-hours. These numbers are compared and contrasted with other renewables in Figure 2.

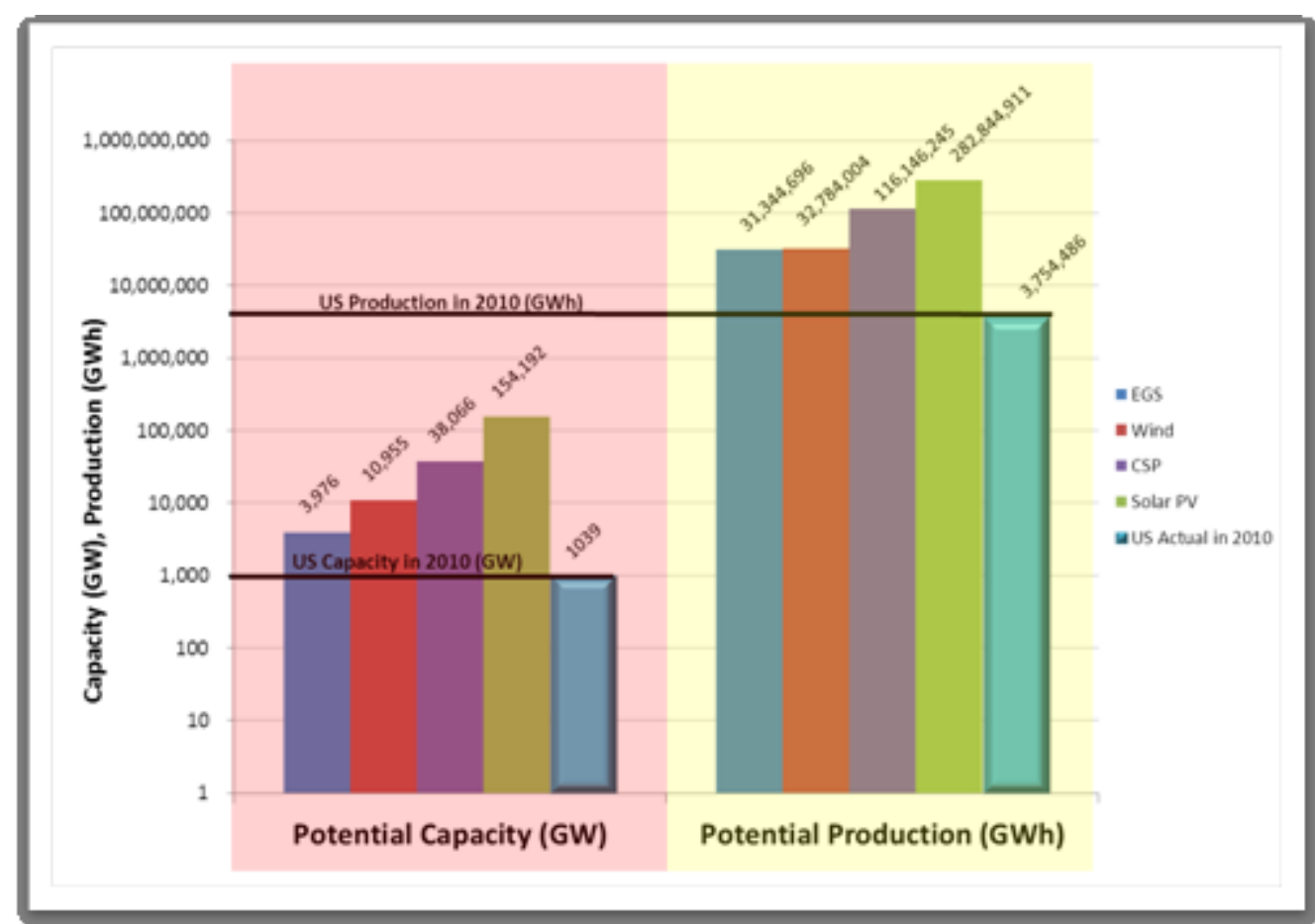

Figure 2: Total Potential Capacity $(G W)$ and Potential Annual Production (GWh) for some renewable power sources

A barrier to EGS is the high up front cost of drilling. This can often be a barrier since high temperature hot rocks tend to be 3-6 km deep on the West Coast and 6-10 km deep on the East Coast. Therefore the cost of drilling can be very high. Once the reservoir has been created, the power generation hardware also tends to be a significant cost. In a typical EGS project, the wellfield will cost between $50-60 \%$ of the total project, the rest being the cost of the power plant. It therefore becomes critically important that the power plant be optimized to produce the maximum amount of power for the lowest capital cost. The DOE has set its goal for the levelized cost of electricity (LCOE) of EGS power to be 6 cents $/ \mathrm{kWh}$ by the year 2030 .

This program intends to address the need for improved energy conversion technology by identification and characterization of binary power plant working fluids in conjunction with innovative thermodynamic cycles for greater energy conversion efficiency than conventional systems. As a result, groups of working fluid/advanced cycle combinations will be proposed for the temperature range of interest. The evaluation of working fluids is complimented by evaluation of hardware requirements and performance of such fluids using different thermodynamic cycles. Such improvement would greatly impact the performance of current and future EGS systems and accelerate the acceptance and development of EGS.

The design capability for optimal energy conversion efficiency at the plant are combined with drilling cost models to find an optimal design point between drilling depth and energy conversion 
plant investment. In addition, such models allow for the evaluation of system performance under a range of boundary conditions.

If geothermal source temperature variation over time can be predicted, the energy conversion system can be designed to have optimal efficiency over a range of source temperatures. A similar analysis can also be used to improve output performance under heat sink night and day temperature variation. By providing for optimization over the lifetime of the complete EGS system, it is expected that further economic and output performance benefits can be realized. Besides EGS, completion of this program has the potential to impact power generation from other waste heat sources such as drilling and industrial processes.

The current program is set up in three phases:

- Phase 1: Screen for high-potential working fluids and develop performance model

- Phase 2: Determine required accuracy of fluid property data and build plant economic model

- Phase 3: Downselect high-potential working fluid, determine fluid properties, and build validation rig

In Phase 1 of the program, an analysis was performed for a combination of advanced power cycles and high-potential working fluids for a range of different resource temperatures. For each cycle, a set of different working fluids was identified that maximizes the cycle power output for a given resource temperature. Overall, the proper cycle/fluid combination showed the promise of a net power output increase of at least 30-50\%, as predicted in the proposal [29].

On the basis of net output power alone, it was found that at lower temperatures the supercritical and the dual pressure cycles had an advantage over the subcritical and the trilateral flash cycles. At higher temperatures, the subcritical and supercritical cycles were competitive. The trilateral flash cycle clearly lost ground at the higher temperatures.

Phase 1 of this program was solely focused on the technical aspects of geothermal power generation with special attention paid to fluid selection, fluid validation, different cycles (subcritical, supercritical, trilateral flash), and different cycle configurations (dual pressure). A lot of assumptions in the models, like pinch points or efficiencies, were taken as constants across all models.

In Phase 2, a thermo-economic model was built to calculate and optimize the LCOE for EGS power projects. Various parameters affecting power plant equipment costs were identified. Wellfield costs, auxiliaries, operating and maintenance costs, and financing and transmission line access were taken into consideration when building the thermo-economic model. The most significant finding was that drilling deep to access high temperature hot rocks allowed the cost of power to come down to $\sim 7$ cents $/ \mathrm{kWh}$ without the need for any additional technological breakthroughs [30].

This report focuses on Phase 3. In this final phase of the project, the predictions made by the thermo-economic model were subjected to experimental verification. More specifically, at a chosen heat source temperature of $200^{\circ} \mathrm{C}$, the most optimum organic rankine cycle (ORC) working fluid predicted by the thermo-economic model was thoroughly analyzed for thermal and chemical stability (see Chapter 3).

Then a two-tiered experiment was designed to test and verify the thermophysical behavior of the fluid and contrast it to the predictions of the thermo-economic model (see Chapter 4). Chapters 5 and 6 give detailed descriptions of the experimental rigs, the data collected and offer analysis to demonstrate consistency between the experimental results, and the predictions of the model.

Chapter 7 studies in greater detail the prospective design and cost of a turbo-expander to fit the power plant cycle conditions in the model. Finally, Chapter 8 summarizes the findings of the 
experiments and draws the significant conclusion that achieving an LCOE of 7 cents $/ \mathrm{kWh}$ with a deep EGS reservoir is possible today with careful and complimentary design of the power plant and wellfield. 


\section{Cycle and Fluid Downselection}

\subsection{COMPARISON WITH STANDARD ORC CYCLES}

A key premise in the calculation of the overall LCOE of the geothermal power project was that combinations of fluids and cycles can be found that offer a LCOE advantage over conventional/standard fluids and cycles. Figure 3 shows a comparison of the best LCOE obtained for each resource temperature and cycle versus the LCOE for subcritical isobutane (a conventional fluid and cycle) for the same resource conditions. Several interesting observations can be made about this result.

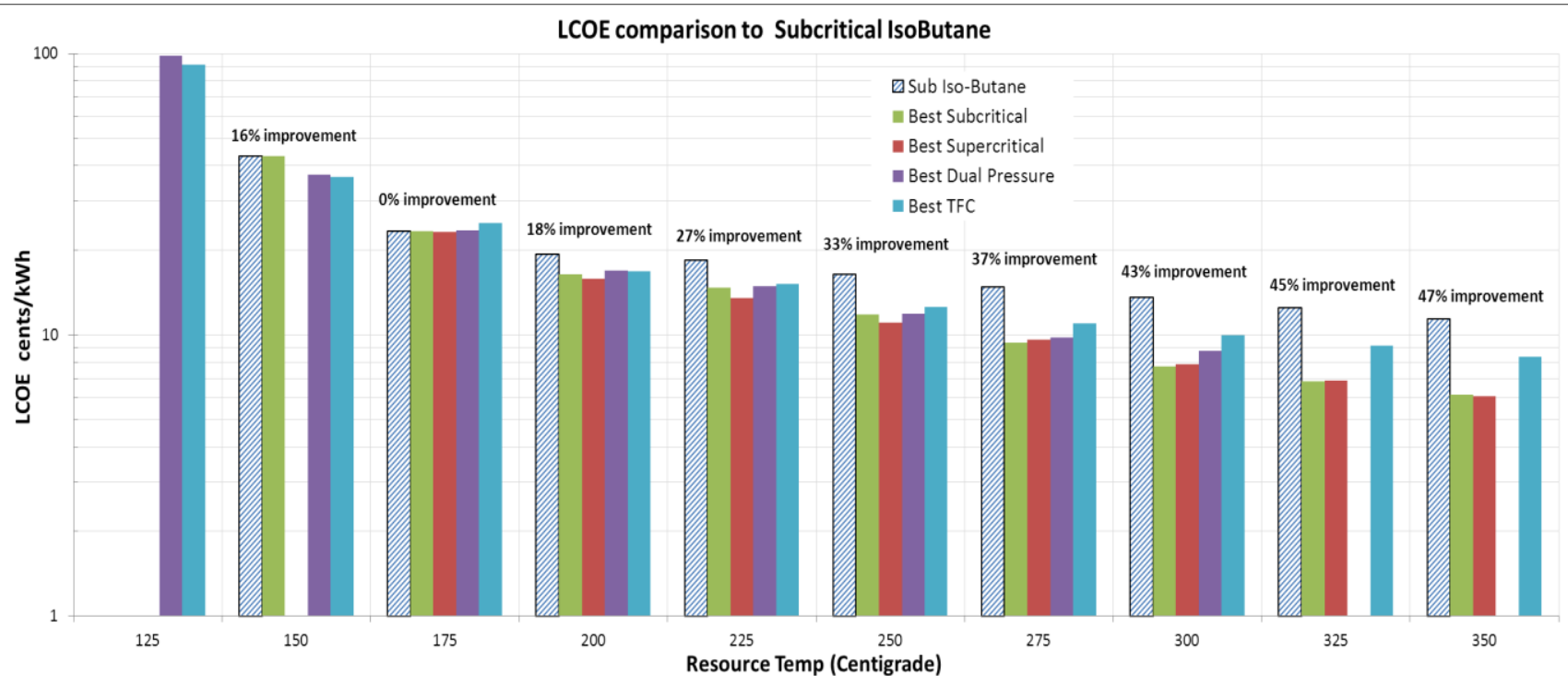

Figure 3: Comparison of LCOE vs. resource temperature range and cycle type

In general, it is seen that the LCOE falls as the resource temperature rises. This result is expected and provides a superficial validation of the thermo-economic model.

It is clear that at a resource temperature of $175^{\circ} \mathrm{C}$ there is no other cycle and fluid combination that can beat subcritical isobutane in LCOE. It remains the best cycle at that temperature within the constraints and boundary conditions used in this study.

At temperatures lower than $175^{\circ} \mathrm{C}$, the trilateral flash cycle shows the lowest LCOE among the four cycles investigated. Nevertheless, power produced at such low resource temperatures remains relatively expensive ( 36.5 cents $/ \mathrm{kWh}$ for the optimum trilateral flash cycle at a resource temperature of $150^{\circ} \mathrm{C}$ ). Note that the thermo-economic model allows for inclusion of government incentives and credits, but they are not included in these results.

At resource temperatures higher than $175^{\circ} \mathrm{C}$ the supercritical and subcritical cycles become the most attractive choices. The dual pressure cycle does not seem to perform well in terms of LCOE due to the cost burden of extra hardware required for the low pressure loop without significant extra power benefit from the second loop.

There is an interesting comparison between the supercritical and subcritical cycles at moderate and high resource temperatures. At moderate temperatures above $175^{\circ} \mathrm{C}$, the supercritical cycle performs better than the subcritical cycle in terms of overall LCOE. However at high temperatures (above $275^{\circ} \mathrm{C}$ ) the supercritical cycle loses its advantage over the subcritical cycle. This is due to increasing working pressures in the cycle required to maintain supercritical conditions inside an 
ORC loop that require thicker walls and, therefore, more expensive equipment. Above $275^{\circ} \mathrm{C}$, it seems the extra power produced by the supercritical cycle is unable to compete in LCOE with a subcritical cycle with lower pressure equipment.

\subsection{DOWNSELECTED CYCLE AND FLUID FOR EXPERIMENTAL VALIDATION}

A fluid and cycle downselect for experimental state point validation needs to address the needs of the geothermal and waste heat industry (two of the largest consumers of ORC power plants today). It seems, however, that the resource conditions for both industries are vastly different. The geothermal industry today needs a more efficient solution for low temperature resources $\left(200^{\circ} \mathrm{C}\right.$ and below), whereas the waste heat industry often deals with much higher temperatures $\left(300^{\circ} \mathrm{C}\right.$ and above).

From the findings in this report, it seems an optimum solution for geothermal resources at $175^{\circ} \mathrm{C}$ already exists in the form of the subcritical cycle with isobutane as the working fluid. However, at $200^{\circ} \mathrm{C}$, an $18 \%$ improvement can be made in the LCOE by utilizing supercritical R245fa. Furthermore, by using a proprietary vendor fluid that is non-flammable, non-toxic, low GWP replacement for R245fa in a supercritical cycle - a truly unique, value added solution can be found to improving the safety and cost effectiveness of ORC geothermal power plants today. This seems like an attractive proposition; however, it requires further investigation of the properties of the new fluid to determine the accuracy and suitability for use in a supercritical cycle.

In addition, at higher temperatures (above $250^{\circ} \mathrm{C}$ ), milestone report $\# 2$ showed the optimum fluids to be supercritical cyclopentane and subcritical cyclopentene [30].

Therefore, the next chapter will focus on thorough investigation of the thermal and chemical stability of this new experimental fluid. 


\section{Organic Fluid Thermal Stability and Compatibility at Relatively High Temperatures}

\subsection{ORGANIC FLUIDS' THERMAL STABILITY}

ORC technology has matured over the years for low temperature applications $\left(<200^{\circ} \mathrm{C}\right)$. The drive for maximizing cycle efficiency has made engineers and researchers consider ORC for higher temperature applications. However, many organic working fluids are not stable at high temperatures. Therefore, finding an organic working fluid that has good thermodynamic performance in an ORC and remains stable at relative high temperatures has become an import topic. An earlier GE internal study considered the thermal stability of several candidate fluids [4]. A conclusion of that report was that cyclopentane would likely have acceptable stability under the envisioned conditions. A recent paper from workers at Idaho National Laboratories came to the same conclusion.[5]

\subsubsection{Thermal Stability of Cyclopentene as ORC Working Fluid}

\section{Introduction}

Calculations done by workers at GE Global Research have shown that cyclopentene could provide a lower LCOE than cyclopentane in an ORC system operating under subcritical conditions and relatively high temperatures.[30,7] It is therefore meaningful to study the thermal stability of cyclopentene to see if it can be used in ORC at $300^{\circ} \mathrm{C}$. The difference between cyclopentane and cyclopentene is that cyclopentene has a carbon-carbon double bond in the five-membered ring of carbons while cyclopentane only has single bonds (see Figure 5).
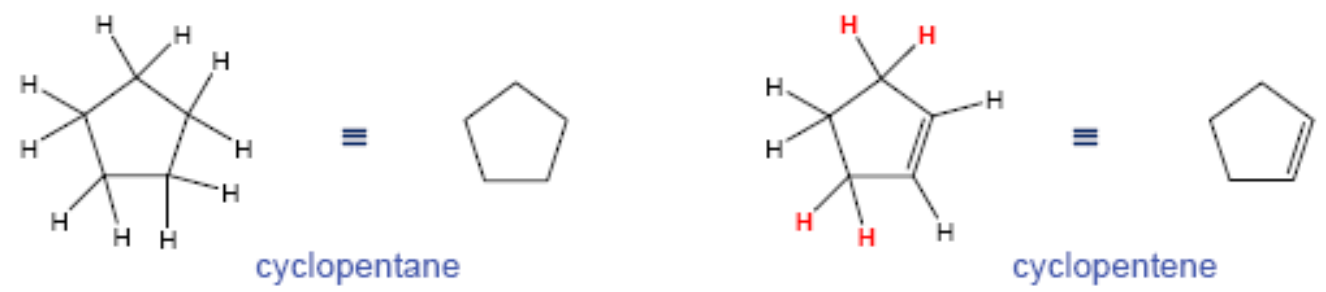

Figure 5. Chemical structures of cyclopentane and cyclopentene.

By convention, chemists draw structures showing the carbon framework and assume that each carbon has a total four bonds available to it. These bonds connect carbon to hydrogen atoms unless shown otherwise. To the organic chemist, cyclopentene immediately raises questions about thermal stability since chemistry is available to cyclopentene that is not available to cyclopentane. 
Possible degradation chemistry for cyclopentane is shown in Figure 6.

a)

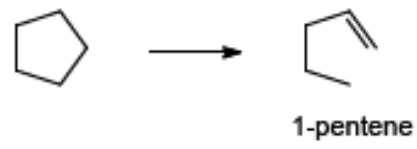

b)

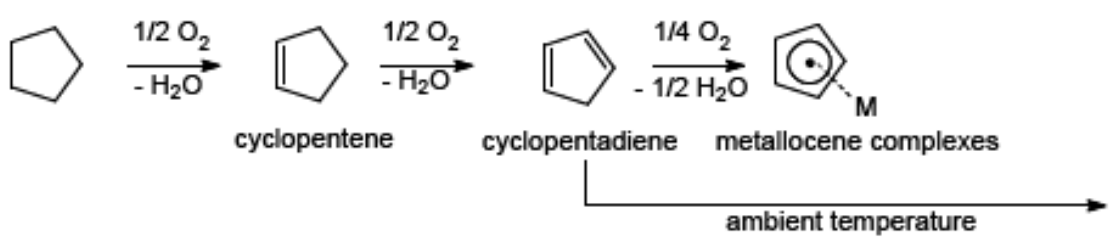

c)

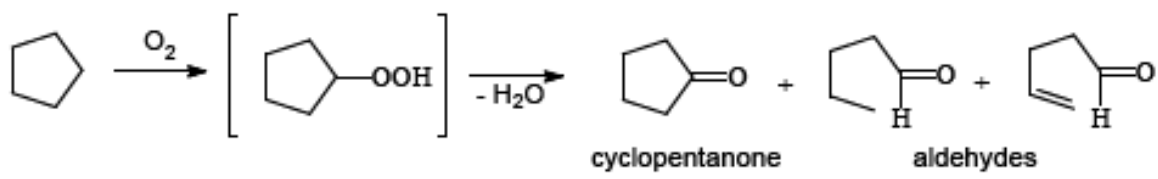

Figure 6. Possible pathways for cyclopentane decomposition and oxidation.

Pathway a) can occur only at very high temperature and is not likely at temperatures less than $300^{\circ} \mathrm{C}$. We did not observe products from this reaction in our previous work. Pathway b) could occur in the presence of oxygen as well as purely thermally, and we did see small amounts of cyclopentene when cyclopentane was heated at $300^{\circ} \mathrm{C}$ in the presence of a little oxygen. No cyclopentene was detected in the absence of air. We saw no cyclopentadiene or evidence of metal complexes. Pathway c) occurs very quickly in the presence of oxygen, but only cyclopentanone was found as the oxidation product. Any oxygen in an ORC system would be expected to end up oxidizing some cyclopentane, but we concluded that cyclopentane was otherwise likely to be sufficiently stable for ORC applications.

Cyclopentene is fundamentally different from cyclopentane for two reasons. The first is that the carbon-hydrogen bonds shown in red in Figure 5 are weaker than similar bonds that are not adjacent to a carbon-carbon double bond. These are called "allylic" positions and are quite susceptible to chemical reactions. For example, oxidation of unsaturated fats and oils occurs at allylic positions. If a hydrogen atom is abstracted from this position, one electron from the bond goes with the hydrogen and one remains on the carbon. Such an orphaned electron is shown by a dot and is called a free radical. Free radicals are very reactive toward oxygen, but can also do other chemistry. Among their reaction repertoire is adding to double bonds to make a new carbon-carbon bond and a new free radical. This is the second reason cyclopentene is different: it provides the way to link rings together to make long chains. This is the way many polymers (plastics) are made.

Some of the possible degradation chemistry for cyclopentene is shown in Figure 7. 
a)

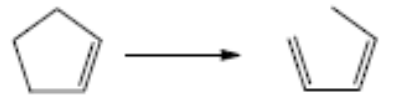

b)

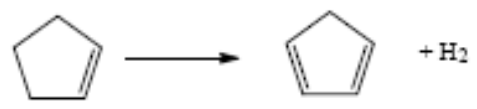

c)
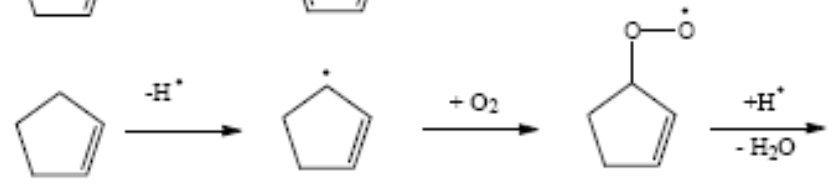<smiles>O=C1C=CCC1</smiles>

d)

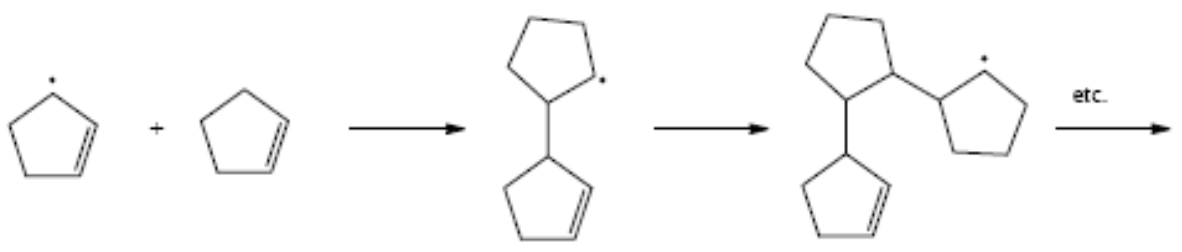

Figure 7. Possible pathways for cyclopentene decomposition and oxidation.

Pathway a) should be unfavored for the same reasons as for cyclopentane. Pathway b) is known in the chemical literature to occur at temperatures $>400^{\circ} \mathrm{C}$ under low pressure conditions. [8-14] Kinetic parameters have been published for the Arrhenius equation that allow us to calculate that the rate of this reaction should be about $1 \times 10^{-10} \mathrm{sec}^{-1}$ at $300^{\circ} \mathrm{C}$.[11] This translates to about $0.00004 \%$ per hour. So, if the Arrhenius equation holds over this extrapolation, this reaction should be detectable, but not terribly important.

The oxidation pathway c) is expected to be very fast and will probably give a complex mixture of products.[15] We can expect that essentially every molecule of oxygen in the system will be consumed. All ORC fluids will react with oxygen at these temperatures. Whether or not oxidation is important will depend on how much oxygen gets into the system. Pathway d) is polymerization. Catalyzed polymerization of cyclopentene is known.[16] Polymers (or oligomers, which are very short polymers) would not be expected from the low-pressure gas phase pyrolysis experiments described above, but could be very possible at high pressure. The rings can link together in several ways - only one is shown in Figure $7 \mathrm{~d}$ - so that a family of products can be formed. In addition, the primary oxidation products are unlikely to be stable at this temperature and can be expected to decompose to a variety of products. 


\section{Cyclopentene Experimentation}

The following experiments were done to test cyclopentene's decomposition and oxidation at $300^{\circ} \mathrm{C}$.

\section{Chemicals}

A bottle of cyclopentene (Aldrich 344508; 96\% purity) was used without further purification. The bottle was stored in the laboratory refrigerator and transferred using a gas-tight syringe. The properties are shown in

Table 1. The properties of cyclopentene.

\begin{tabular}{l|c}
\multicolumn{1}{c}{ Property } & \multicolumn{1}{c}{ Value } \\
CAS number & $142-29-0$ \\
\hline Molecular weight & 68.11 \\
\hline Density & $0.744 \mathrm{~g} / \mathrm{cm}^{3}$ \\
\hline Melting point & $-135^{\circ} \mathrm{C}$ \\
\hline Boiling point & $44^{\circ} \mathrm{C}$ \\
\hline Vapor pressure & $0.416 \mathrm{~atm}\left(20^{\circ} \mathrm{C}\right)$ \\
\hline Critical temperature & $238.6^{\circ} \mathrm{C}$ \\
\hline Critical pressure & $44.5 \mathrm{bar}$ \\
\hline
\end{tabular}

Table 1.

\section{Vial and Valve Assembly}

Stainless steel $10 \mathrm{~cm}^{3}$ sample vials (Swagelok SS-4CS-TW-10; 3/8" o.d. tube end 316 grade stainless) were fitted with a stainless steel 3/8" to 1/16" reducing adaptors (Swagelok SS-600-6-1), $\sim 12$ " of 1/16" stainless steel tubing, stainless steel 2-way ball valves (Swagelok SS41GS1), and $1 / 16$ " stainless steel caps. The threads of the $3 / 8$ " side of the adaptor were lightly lubricated with a high-temperature lube to facilitate disassembly after heat aging. The assemblies were numbered and weighed both evacuated and when filled with air.

\section{Typical Procedure}

Cyclopentene $(0.46 \mathrm{~mL}, 0.344 \mathrm{~g}, 0.005$ mole) was added to a stainless steel sample vial using a gas tight syringe. Optionally, steel witness coupons could be added to the vial. The vial was immediately attached to the adaptor/tubing/valve assembly and tightened with wrenches in a vice. The assembly was then placed in a Dewar flask of liquid nitrogen and attached to a vacuum rack equipped with a nitrogen purge. After freezing, the vial was evacuated to $<0.1$ torr and refilled with nitrogen at least four times to remove air from the headspace. The assembly was finally evacuated to $<0.1$ torr, the valve closed, removed from the vacuum rack, capped, and allowed to warm to room temperature. Weighing the assembly gave the mass of the final charge, typically very close to the expected $0.34 \mathrm{~g}$. The assembly was then suspended in a forced air oven equilibrated to $300^{\circ} \mathrm{C}$ through a hole in the top of the oven. The hole was packed with glass wool and covered with a piece of slotted stainless steel allowing passage of the tubing and isolation of the valve. The vial and most of the tubing were in the oven at $300^{\circ} \mathrm{C}$, there was a transition zone of $\sim 2$ ", and the valve outside the oven was only slightly warm. It was estimated that the $0.34 \mathrm{~g}$ charge 
will result in a pressure of about 20 bar in the sample vial. ${ }^{1}$ [17] The assemblies were removed, cooled, and weighed after 24 hours to ensure minimal loss of sample due to leakage. If the assembly appeared tight, it was returned to the oven. After the full heating time, the assembly was cooled to room temperature, weighed, and disassembled. Samples were removed for analysis. Some portion was allowed to evaporate at room temperature in the fume hood to measure the amount of high molecular weight material that was formed.

\section{Nuclear Magnetic Resonance (NMR) Analysis}

Proton NMR spectra are generated from hydrogen atoms present in the molecules. The spins of the protons are oriented in a strong magnetic field and perturbed with a radio frequency pulse. Radio frequency signals are generated by the spins that are knocked out of alignment. Fourier transform of this signal gives a frequency spectrum. Information is gained from the position of the peaks (the chemical shift) given as parts per million (ppm) from the tetramethylsilane internal standard assigned as 0 . Additional structural information can be obtained from the splitting pattern of the peaks; each proton on adjacent carbons split the signal into two. The carbon- $13\left({ }^{13} \mathrm{C}\right)$ isotope has spin $1 / 2$ and can also split signals, although the predominant carbon- 12 has no spin and cannot split signals. Since ${ }^{13} \mathrm{C}$ is present at $\sim 1 \%$ abundance, small "satellite peaks" at approximately \pm 63 $\mathrm{Hz}( \pm 0.16 \mathrm{ppm}$ for a $400 \mathrm{MHz}$ spectrometer) flank each strong signal. In addition, the rotation of the sample tube within the probe couples with the signal to make "spinning side bands" at multiples of $\pm 20 \mathrm{~Hz}(0.05 \mathrm{ppm}$ for a $400 \mathrm{MHz}$ spectrometer) from the main signal. Spectra usually are taken in deutrochloroform $\left(\mathrm{CDCl}_{3}\right.$; deuterium has no spin) solvent which contains small amounts of regular chloroform $\left(\mathrm{CHCl}_{3}\right)$, water, and $\mathrm{HCl}$ that give weak signals in the spectrum. All these signals become important when looking for small product peaks near the starting material. NMR can be especially useful to find small amounts of products if they can be detected in regions well away from the starting material. In addition, it is fast and requires no sample preparation.

Fourier transform NMR spectra were taken in deuterochloroform solution using a Bruker 400MHz spectrometer and analyzed using GE Net NMR 2.10.0. The spectra were usually obtained using 16 pulses (sometimes 128). Some of the signals could be quantified by integration and comparison to the starting material peak. The threshold of detection varied with the number of hydrogens attributed to a particular signal, but the values given are probably accurate to within $\pm 50 \mathrm{ppm}$. The amount is reported as ppm based on moles, not weight.

\section{Results and Discussion \\ Product Identification}

The working fluid in an ORC system encounters the highest temperatures for only a relatively small fraction of the total operation time due to high velocities in the hot zone as well as the excess volume of fluid. Estimates are that a particular molecule of fluid encounters temperatures as high as $270-300^{\circ} \mathrm{C}$ for as little as 40 hours per year of operation. Thus, continual exposure to $300^{\circ} \mathrm{C}$ for a few weeks is sufficient to test the stability of the fluid for the equivalent of many years of operation.

Traces of oxygen are very likely to be present during operation, particularly at start-up. Air ingress is much less likely during operation because the pressure in the loop is higher than atmospheric and any leakage should be outward. In our experiments, we removed as much air as

${ }^{1}$ For cyclopentene, the critical temperature and pressure are $T_{c}=238.6^{\circ} \mathrm{C}, P_{c}=44.5$ bar, respectively. At 20 bar and $300^{\circ} \mathrm{C}$, the reduced pressure and reduced temperature are 0.45 and 1.12, respectively. Based on generalized correlations, the compressibility factor (z) under these conditions is 0.86 . 
possible from the headspace of the vial, but deliberately did not degas the cyclopentene itself. This left a very small amount of oxygen that would make oxidized products and could serve to initiate free radical reactions that would surely occur in a real system.

NMR spectra of the starting cyclopentene after $\sim 90$ hours of heating at $300^{\circ} \mathrm{C}$ are shown in Figure 8.

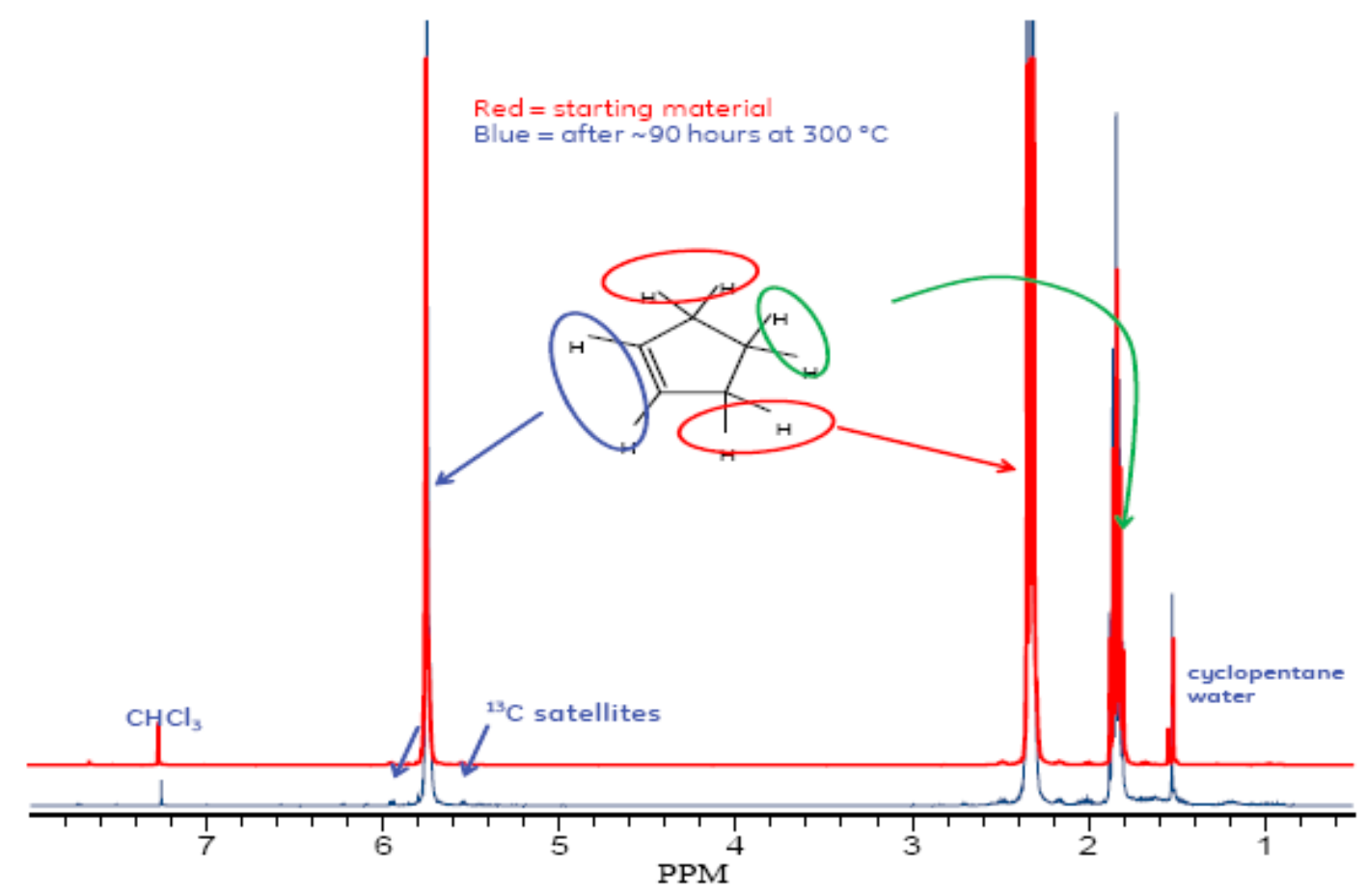

Figure 8. NMR spectra of cyclopentene before (red) and after (blue) 90 hours at $300^{\circ} \mathrm{C}$.

The heated sample was dark amber in color. The positions of the various protons are noted, and some of the impurity peaks are identified. These spectra are "on scale" and show little change after heating. A blown-up portion of the spectra is shown in Figure 8. The red line shows signals at 6.18 and $7.65 \mathrm{ppm}$ in the starting cyclopentene that are due to an unknown impurity as well as a trace of cyclopentadiene that has two sets of signals between 6.4 and $6.6 \mathrm{ppm}$. Spectrum matches that taken of freshly distilled cyclopentadiene formed by cracking the dimer. The blue line shows that, after heating, the impurity signals disappear, more cyclopentadiene is formed, and signals at 6.23 and $6.72 \mathrm{ppm}$ due to the oxidized product 2-cyclopentenone grow in.[18] Other minor signals also appear that we have not identified.

A middle region of the spectra is shown in Figure 9, which also shows the disappearance of unknown impurities and the appearance of 2-cyclopentenone and cyclopentadiene. In addition, a complex new signal appears at $2.55 \mathrm{ppm}$. 


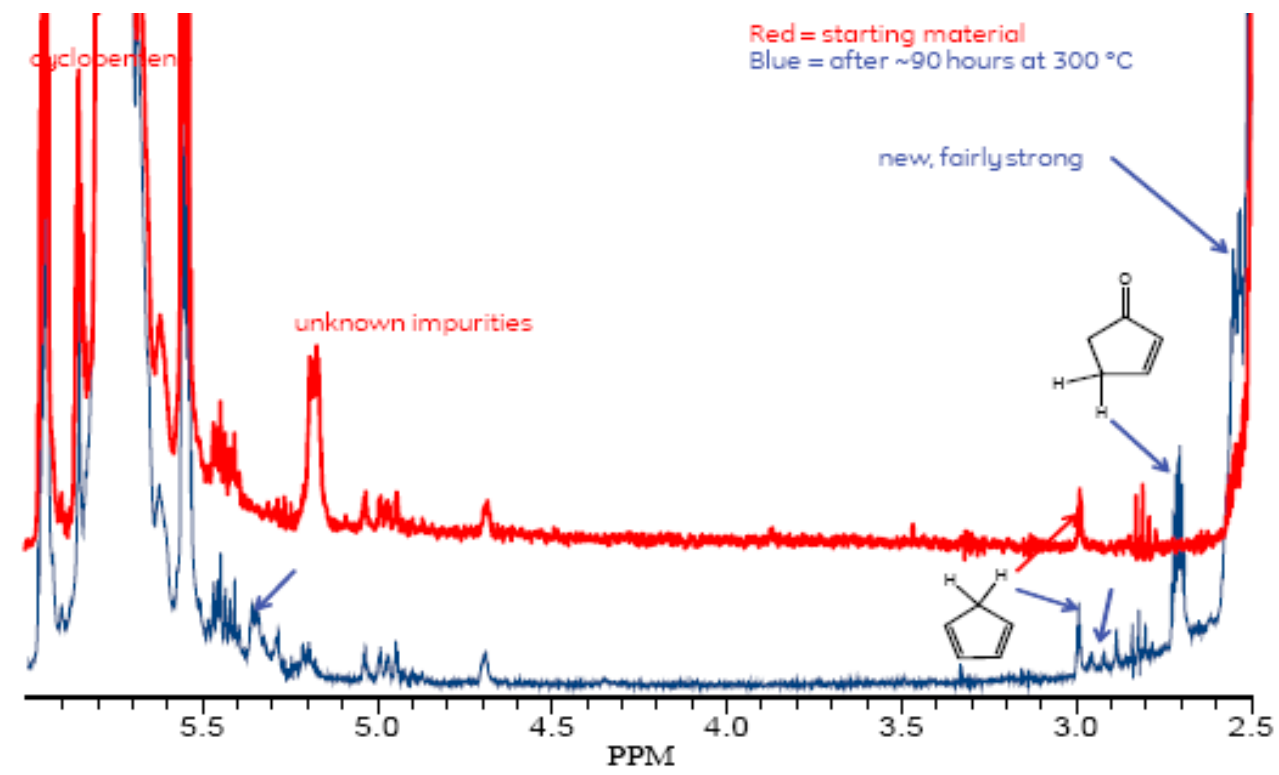

Figure 9. NMR spectra of cyclopentene before (red) and after (blue) 90 hours at $300^{\circ} \mathrm{C}$.

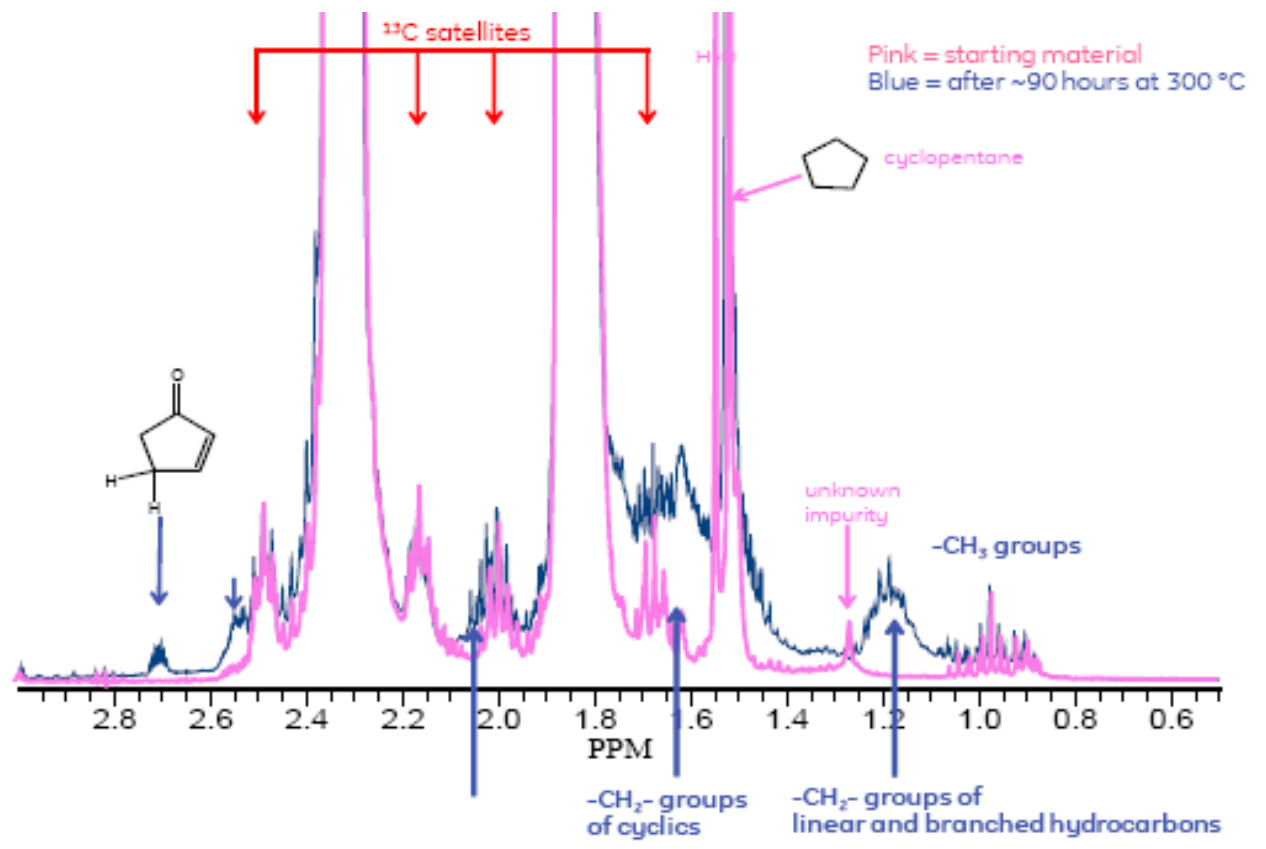

Figure 10. NMR spectra of cyclopentene before (pink) and after (blue) 90 hours at 300

Figure 10 shows the most upfield region less blown up. One sees the formation of the new signals at $2.55 \mathrm{ppm}$ as well as new signals at 2.05, 1.65, and $1.17 \mathrm{ppm}$. Also evident are signals due to cyclopentane at $1.50 \mathrm{ppm}$ (strong singlet) and several triplets around $1.0 \mathrm{ppm}$ that are due to the $-\mathrm{CH}_{3}$ ends of non-cyclic hydrocarbon impurities. (Cyclopentene is made by adding hydrogen to cyclopentadiene, so some residual cyclopentadiene and some doubly hydrogenated cyclopentane are inevitable impurities. The origin of the non-cyclic hydrocarbons is not known.). 
A portion of the sample was allowed to evaporate in the hood at room temperature leaving approximately $4 \%$ of dark residue. The NMR spectrum in Figure 11 shows that the signals from the residue correspond to the new signals in Figure 10. No residue is found in fresh cyclopentene.

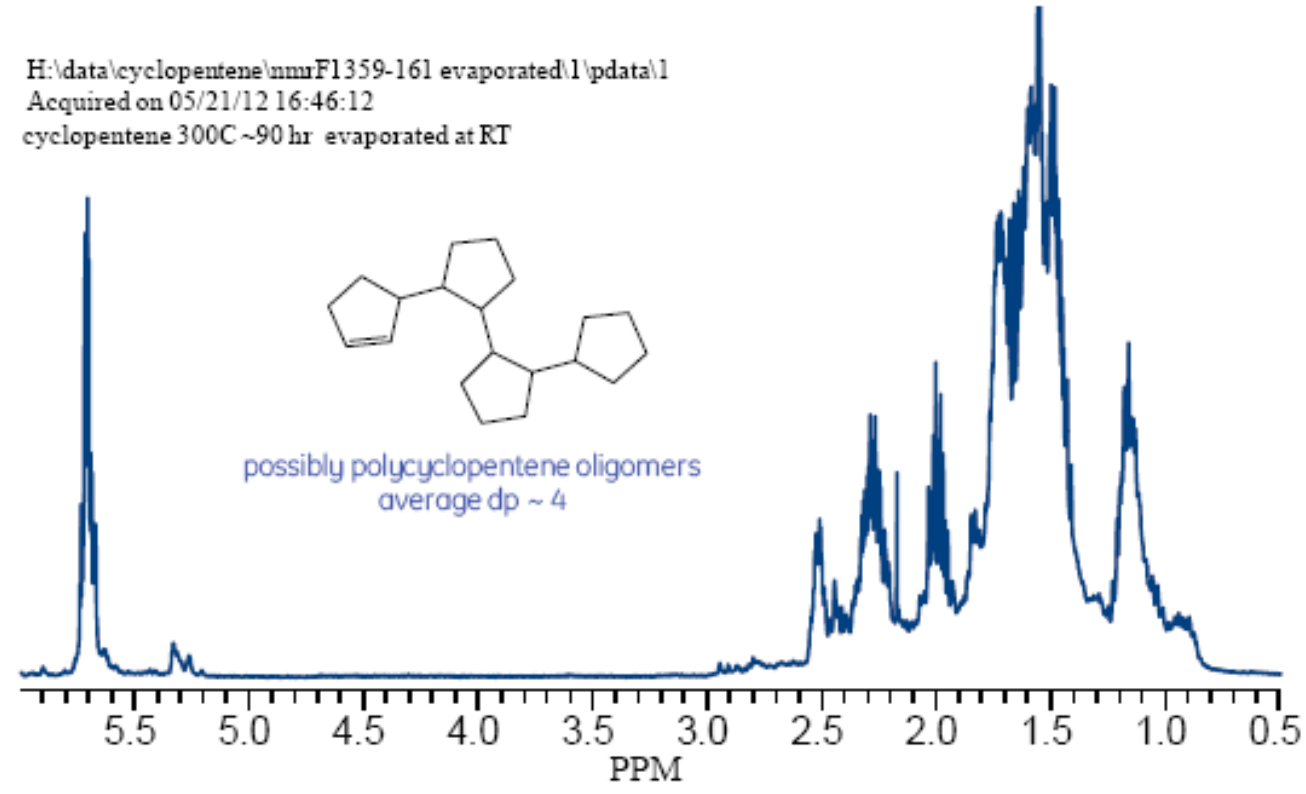

Figure 11. NMR spectrum of residue after room temperature evaporation of the $90 \mathrm{hr} / 300^{\circ} \mathrm{C}$ sample.

The most likely explanation for the residue is the formation of oligomers as shown in pathway d) of Figure 7. This will produce products with some signals between 5 and 6 ppm arising from the protons on the double bond and strong signals arising from various other protons.

Confirmation of this assignment came from dynamic headspace gas chromatography-mass spectrometry (GC-MS) analysis. shown in Figure 12.

\section{Dynamic Headspace GC-MS}

1. GC oven at $-70 \mathrm{C}$, load sample into heated desorption device.

2. Volatiles produced by the sample are trapped at the head of the column.

3. Remove sample.

4. Program GC oven temperature while scanning the mass spectrometer.

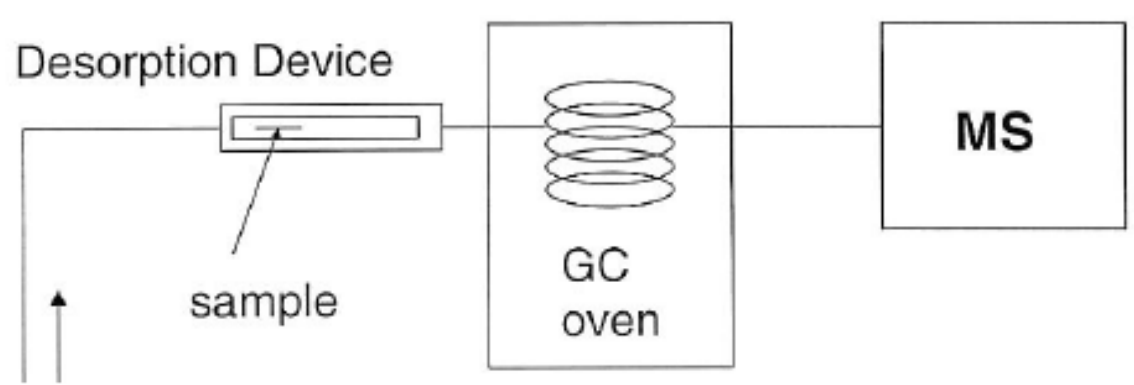

Figure 12. Schematic of GC-MS analysis provided by Hans

The sample is dissolved in methylene chloride $\left(\mathrm{CH}_{2} \mathrm{Cl}_{2}\right)$ and injected onto clean glass wool in the sample desorption tube. The tube is heated to $300^{\circ} \mathrm{C}$ under helium flow while the GC oven is 
kept at $-70{ }^{\circ} \mathrm{C}$. This deposits all volatile material at the head of the column. After desorption is complete, the column is heated while helium is flowing. This causes separation of the components of the sample, usually with the smaller, more volatile components emerging from the column before the heavier ones. Effluent from the column is fed into a mass spectrometer that ionizes the sample and gives (usually) the molecular weight of whatever is coming off the column as well as information about the structure arising from the way the parent ions fragment. An experienced eye and comparison to a database often allows identification of the components.

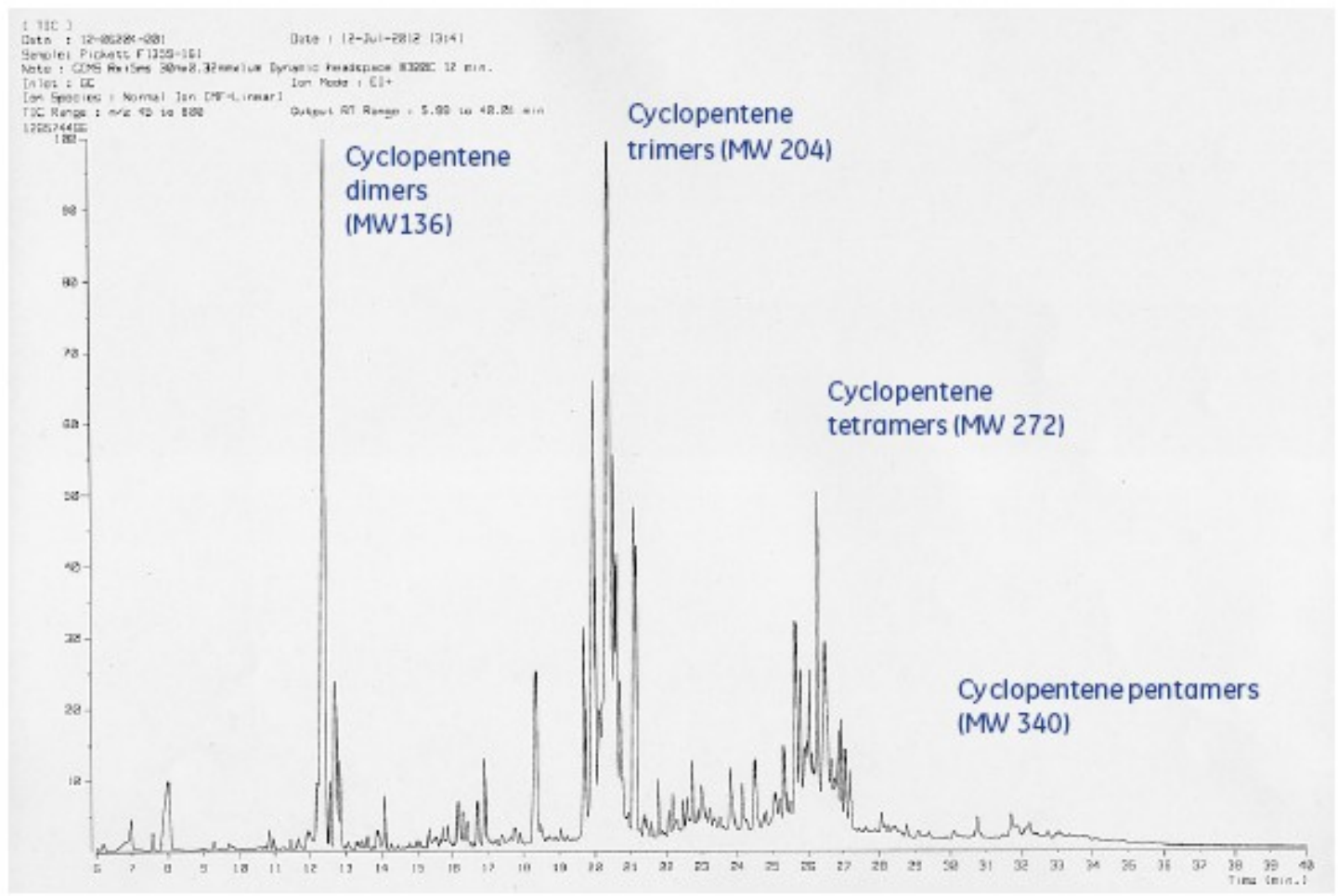

Figure 13. GC-MS data for a sample of heated cyclopentene. (Hans Grade).

Figure 13 shows a chromatogram of cyclopentene after 90 hours at $300{ }^{\circ} \mathrm{C}$. The horizontal axis is time, so progressively less volatile components emerge going from left to right. [what are units of y axis?] The first few minutes of the chromatogram containing the most volatile components, including cyclopentene and similarly very low boiling compounds, are not monitored to avoid overloading the mass spectrometer. We see families of products corresponding to dimers, trimers, tetramers, and pentamers of cyclopentene. Several components are seen at each molecular weight increment because there are multiple structural isomers possible as the number of rings increase. Analysis of another sample that had been evaporated at room temperature gave similar results except that it was depleted in dimer. 


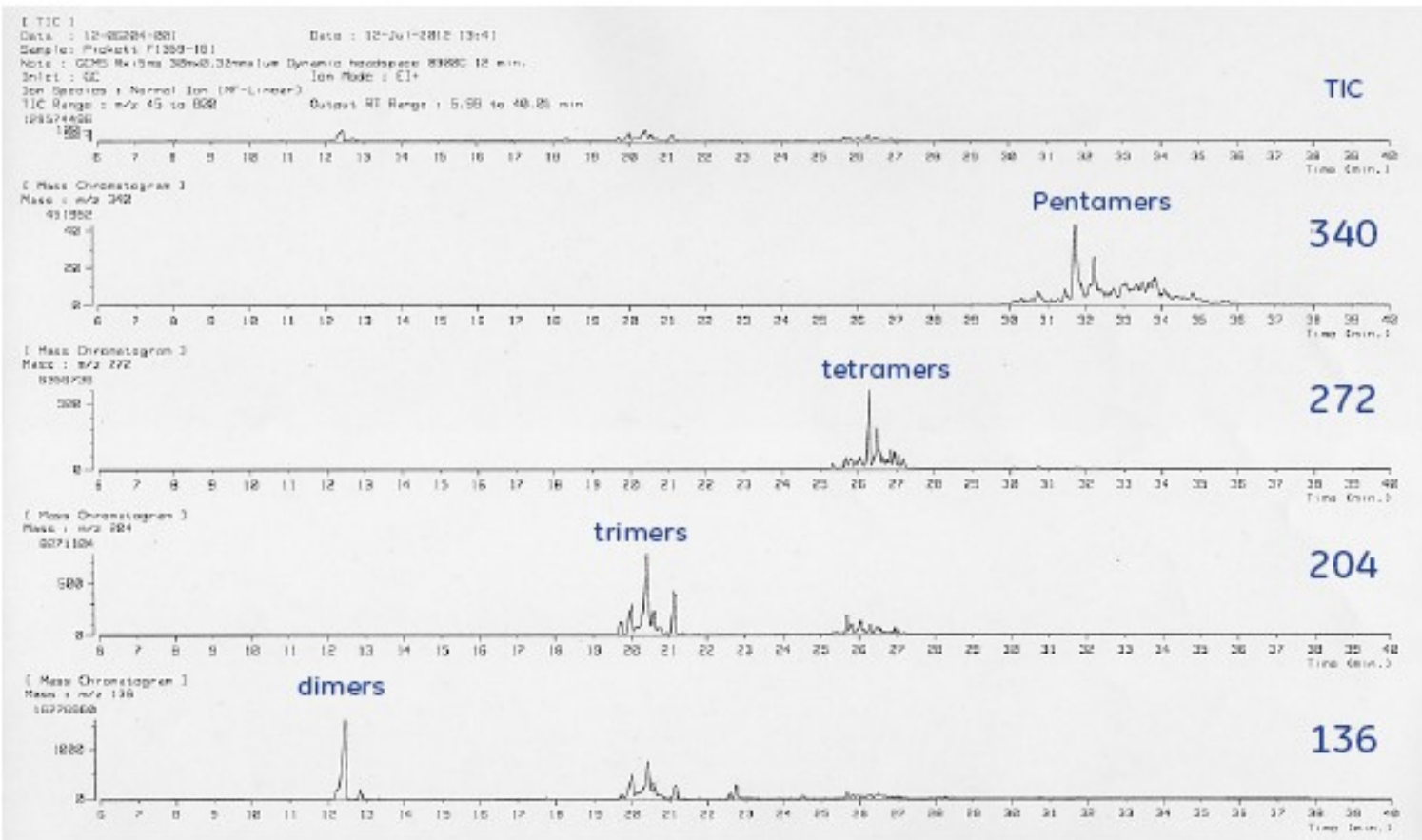

Figure 14. GC-MS data for a sample of heated cyclopentene (Hans Grade).

Another look at the data is shown in Figure 14. The data are analyzed by looking at the amount of a particular ion mass $(\mathrm{m} / \mathrm{e})$ from the mass spectra as a function of time. It shows ions of molecular weight 340 corresponding to pentamers coming out at times between 30 and 36 minutes. The ions with molecular weight 272, corresponding to the tetramers, are seen at between 25 and 28 minutes. Note that some trimer ion $(\mathrm{m} / \mathrm{e}=204)$ and even a little dimer $(\mathrm{m} / \mathrm{e}=136)$ are seen at the same time. This is because of fragmentation of the tetramers into smaller pieces. The smaller fragments are not visible for the pentamer because there is not much pentamer and the fragment signals from it are very weak.

The oligomers are problematic because of their high boiling points. Reported boiling points are $185-186^{\circ} \mathrm{C}(760 \mathrm{~mm})$ for the dimer, $140-141^{\circ} \mathrm{C}(10 \mathrm{~mm})$ for the trimer, and $183-185^{\circ} \mathrm{C}(3 \mathrm{~mm})$ for the fully saturated tetramer.[19] An isomeric trimer had a boiling point of $300-301^{\circ} \mathrm{C}(760$ $\mathrm{mm}$ ). Obviously, these will accumulate somewhere on the hot surfaces and probably eventually form coke. 


\section{Semi Quantitative Results}

The quantity of cyclopentadiene and 2-cyclopentenone can be estimated by integrating the NMR signals and comparing with the strength of the cyclopentene signals. The results are shown in Table 2.

Table 2. Estimated amount of products formed from heating cyclopentene at $300^{\circ} \mathrm{C}$.

\begin{tabular}{r|c|c|c}
$\begin{array}{r}\text { Time } \\
(\mathrm{hr})\end{array}$ & $\begin{array}{r}\text { Cyclopentadiene } \\
\text { (ppm) }\end{array}$ & $\begin{array}{r}\text { 2-cyclopentenone } \\
\text { (ppm) }\end{array}$ & $\begin{array}{r}\text { Evaporation Residue } \\
(\%)\end{array}$ \\
\hline 0 & $\sim 100$ & 0 & -- \\
\hline 68 & $\sim 600$ & 1500 & ca. 4 \\
\hline 90 & $\sim 300$ & 1500 & 7.5 \\
\hline 160 & $\sim 300$ & 1400 & $13.7^{* *}$ \\
\hline $255^{*}$ & $\sim 400$ & 950 & 14.0 \\
\hline 260 & $\sim 300$ & 1050 & 21.0 \\
\hline 390 & $\sim 900$ & 450 & \\
\hline * with steel coupons & & \\
** by NMR integration & & \\
\hline
\end{tabular}

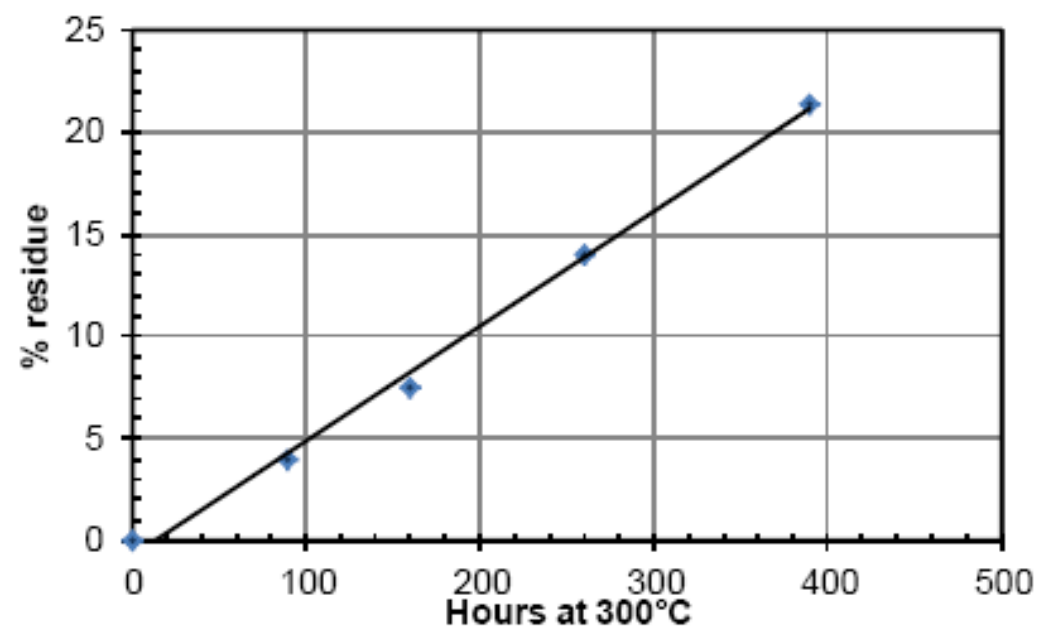

Figure 15. Increase in the amount of residue after room temperature evaporation after heating cyclopentene at $300^{\circ} \mathrm{C}$.

As expected, 2-cyclopentenone oxidation product is formed immediately and may decrease with extended time as it is decomposed. There is also not a good trend with cyclopentadiene because it also might be formed and decomposed and thereby reach a steady state. In any case, there is $<0.1 \%$ present even after nearly 400 hours. By contrast, the residue after evaporation 
steadily increases with time as shown in Figure 15, reaching over $20 \%$ by mass after 400 hours of heating. The actual amount of oligomerization is probably higher because most of the dimer is lost during evaporation. Experiments with cyclopentane heated at $300^{\circ} \mathrm{C}$ for 160 and 303 hours gave colorless fluids that had the same amount of evaporation residue $(0.4 \%)$ as unheated cyclopentane.

\section{Color Generation}

In contrast to our previous work with cyclopentane and other saturated hydrocarbons, cyclopentene generated a great deal of color during heating as shown in the photograph in Figure 16.

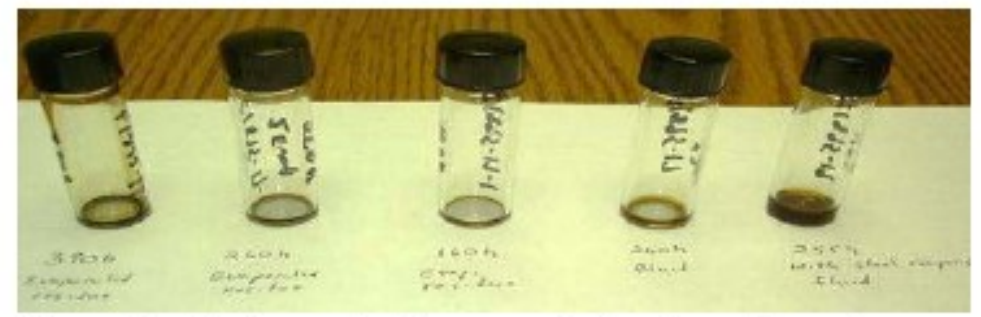

Figure 16. Photograph of evaporated cyclopentene. Samples after 390,260 , and 160 hours at $300^{\circ} \mathrm{C}$ (left 3 vials) and non-evaporated cyclopentene after 260 and 255 hours (right 2 vials).

The origin of the color is not known. In addition to this color, a black sooty residue was found inside the sample vial and the inner surface of the adaptor that could be removed with a cotton swab moistened with toluene. Only a very small amount of black residue was found in vials and adaptors in which cyclopentane had been heated for 160 and 303 hours.

\section{Steel Witness Coupons}

Rectangular coupons were cut of 2205 alloy (22\% chromium, 3\% molybdenum, 5-6\% nickel), stainless steel $(1.25 \times 4 \times 38 \mathrm{~mm}, \sim 1.4 \mathrm{~g})$, and 1060 plain-carbon steel $(3 \times 3.5 \times 38 \mathrm{~mm}, \sim 2.9 \mathrm{~g})$ and placed in the sample vials along with cyclopentene during some $300^{\circ} \mathrm{C}$ aging experiments. A pair of coupons was heated for 304 hours at $300^{\circ} \mathrm{C}$ in a nitrogen-filled assembly. The stainless steel appeared bronzed and the carbon steel had a sooty black residue on the surface. There was no detectable change in mass within $0.0001 \mathrm{~g}$. Coupons heated in cyclopentene for 39 and 255 hours exhibited less bronzing of the stainless steel while the carbon steel coupon looked about the same as the nitrogen control. There were no detectable changes in mass within $0.0001 \mathrm{~g}$. Coupons heated in cyclopentane for 160 and 303 hours gave similar results. There was no evidence of corrosion of the steel surfaces beyond the migration of carbon to the surface of the carbon steel that also occurred in nitrogen.

\section{Conclusions}

Cyclopentene degradation under ORC conditions comes from two sources: 1) reaction with any residual oxygen and 2) reaction with itself to produce higher molecular weight products. The reaction with oxygen occurs with all organic fluids and is limited by the amount of oxygen present. Presumably, these reactions with oxygen could be nearly eliminated by careful degassing of the system prior to operation or by the use of sacrificial getters. Loss of hydrogen to form cyclopentadiene, which is the major pathway $>400^{\circ} \mathrm{C}$ at low pressure, does not seem to be a major concern at $300^{\circ} \mathrm{C}$. 
The addition of a free radical formed on one cyclopentene molecule to the double bond of another cyclopentene molecule is indeed a problem. It occurs because radicals are easily formed at the carbons adjacent to the double bond and because the concentration of cyclopentene is high at 20-40 bar. This reaction seems capable of consuming as much as $2 \%$ of the cyclopentene per year (assuming 40 hours per year exposure to 300C) to make a dark, high-boiling residue if the fluid reaches temperatures as high as $300^{\circ} \mathrm{C}$. Accurate predictions of the amount formed at lower temperature would require additional experiments at lower temperature in order to find an activation energy.

Because of the high reactivity of cyclopentene, we do not recommend its use in an ORC system at the temperatures we tested. 


\subsubsection{Thermal Stability of the new vendor fluid in a Supercritical ORC}

Cyclopentene is not recommended for use in an ORC system at relatively high temperatures. At lower temepratures, other fluids are considered. R245fa (1,1,1,3,3-Pentafluoropropane) is a fluid with promising performance, but its environmental impact is a concern. An alternative to R245fa is the new vendor fluid. The fluid has similar or slightly better thermodynamic performance than R245fa, but a lot lower global warming and ozone depletion potential. Therefore, it is the target of this section to investigate its thermal stability as a working fluid of ORC and supercritical ORC at temperatures around $200^{\circ} \mathrm{C}$ and pressures greater than its critical pressure of $\sim 40$ bar.

\section{Introduction}

The new Vendor fluid is a liquid halogenated olefin, which has been developed as a blowing agent for polymer foams. It is a non-flammable liquid having a room temperature boiling point.

\section{Experimentation}

The following experiments were done to test the new fluid's thermal stability.

\section{Chemicals}

A pound of the new fluid in a small tank was obtained from the vendor and used for this test without further purification. The tank was stored in the laboratory at atmospheric temperature and transferred using a gas-tight syringe.

\section{Test Procedure}

Samples of the new fluid were injected in stainless steel vials and heated to $200^{\circ} \mathrm{C}$ and $40 \mathrm{bar}$ for up to 400 hours. Samples were pulled out at approximately 62, 94, 168, and 400 hours to test the trace of degradation. All of the samples have both stainless steel and carbon steel witness coupons. Refer to the cyclopentene thermal stability experiments discussed in Section 3.1.1 for details about the vial and vial assembly.

\section{Headspace GC-MS}

Headspace GC-MS is a technique to analyze volatile compounds. With this technique, a sample is placed in a closed sampling vessel, heated using a certain temperature profile, and the vapor in the vessel is sampled for analysis of the composition.

\section{Results and Discussion}

With the headspace GC-MS analysis, it is estimated that the conversion to an isomer was less than $3 \%$ after 399 hours of heating at $200^{\circ} \mathrm{C}$, and the dimer was less than $25 \mathrm{ppm}$. The graph below shows that the conversion to isomer is approximately linear over this period. As explained earlier, the formation of isomer does not significantly impact the ORC performance, as long as no other compounds are derived.

Given the fact that less than 25ppm of dimer was formed after 399 hours of cooking, the fluid is considered to be thermally stable at the condition tested, which is $200^{\circ} \mathrm{C}$ and $40 \mathrm{bar}$. It is recommended that it can be used in the supercritical ORC cycle from the thermal stability standpoint. 


\subsection{COMPATIBILITY WITH SEALS}

Since thermal stability of the new fluid is not a concern, the next thing to consider is its compatibility with seals. In the commercially available waste heat recovery product, known as GE Clean Cycle II"M: Waste-to-Electric Generator System (referred to as "Clean Cycle"), silicone O-rings have been used for the seals when the working fluid is R245fa. Silicone has not been found to have any issues with R245fa. So it is our first choice to test silicone's compatibility with the new fluid. R245fa was tested at the same condition for comparison.

\subsubsection{Compatibility with Silicone O-rings}

\section{Test Design}

Test subjects: Compatibility of the new fluid and R245fa (1,1,1,3,3-Pentafluoropropane) with silicone O-ring.

Test Condition: $30 \mathrm{bar}, 150^{\circ} \mathrm{C}$. The fluid is in liquid condition, in contact with the silicone O-ring. It is know that it is more aggressive in liquid phase than vapor.

Test period: 48 hours. This is long enough for the seals to react (if at all).

Test materials and apparatus preparation: Twenty-four silicon O-rings from GE Heat Recovery Solutions ( 1.2" in diameter). Refrigerants R245fa and the new fluid, 1lb each (shipped from vendor without any further purification). High pressure reactor from GE Global Research's high pressure lab, glass liner with $\sim 2.25$ " diameter. Twenty-four fender washers with $1.5 "$ diameter, twelve bolts, twelve nuts for O-ring compression.

Test Methods: ASTM D395 methods for compressed seal test. Other methods refer to test procedure.

\section{Test Procedure}

For each O-ring compatibility test, six O-rings were used. Each O-ring was labeled with a unique ID and measured before and after the test. O-rings 1-3 were compressed and O-rings 4-6 were not.

1. Pre-measurement. Weight, thickness, diameter, hardness (Shore), and elasticity of each O-ring sample were measured before the test.

2. O-rings' compression set. O-rings 1-3 were compressed by placing them between 4 fender washers and tightened with bolts and nuts. The compression set was $29 \%$, controlled by the lock washer placed between the fender washers. In the Clean Cycle ORC system, the O-rings were compressed $17-30 \%$ during operation, which is how the $29 \%$ compression set was decided. Refer to Figure 20 for the samples.

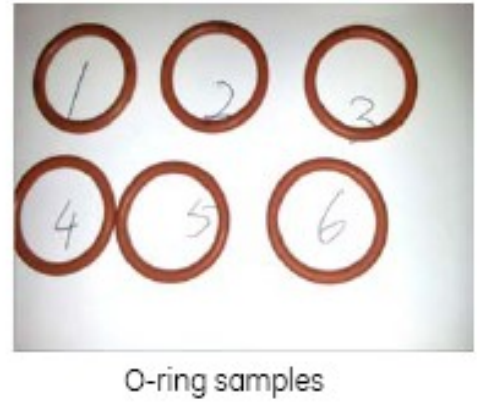

Figure 20. Silicone o-rings for the compatibility test.
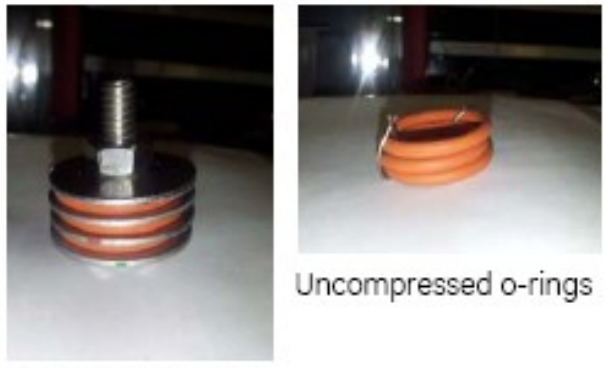

Compressed o-rings

uncompressed o-rings 
A.

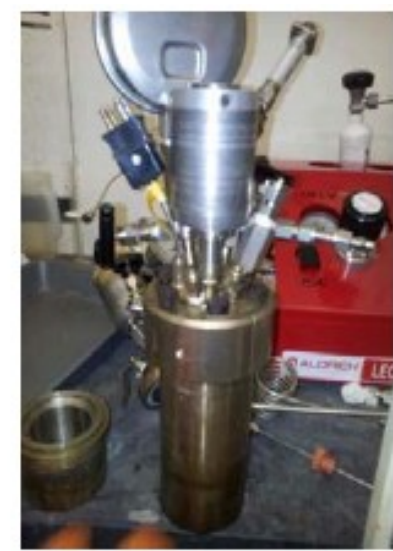

B.

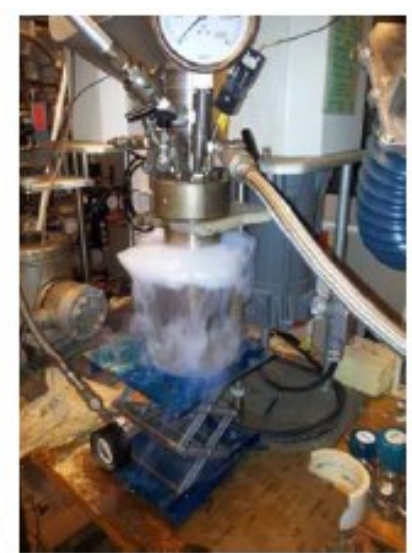

Figure 21. High pressure reactor for the compatibility test. A. High pressure reactor with test samples inside. B. Cooling the reactor with liquid nitrogen.

3. Charging fluid to the reactor. The saturation temperatures of both fluids at atmospheric pressure are $18.6^{\circ} \mathrm{C}$ and $14.8^{\circ} \mathrm{C}$, respectively. In order to keep the fluids in liquid phase during charging, the fluid tanks were placed in an ice water bath for a number of hours before charging. The reactors were vacuumed first, and then connected to the fluid tank for charging. An adaptor was used when it was found that the fitting of the fluid tank did not match that of the reactor. Based on the volume of the tank and the reaction temperature, grams of the fluid need to be charged were calculated. On top of that, 10-20\% excessive fluid was charged for fine turning.

4. Submerge silicone O-rings in the fluid, seal, and apply heat to the reactors to reach $150^{\circ} \mathrm{C}$ and stay constant. Let it react for 48 hours for each fluid at the specified temperature and pressure. For each test, both compressed and non-compressed O-rings were placed in the reactor. Refer to Figure 21 for the high pressure reactor used for this test.

5. Post-measurement. Weight, thickness, diameter, hardness (Shore), and elasticity of each O-ring sample were post-measured after the test. The post-measurement should be done right after the samples are taken out of the reactor. For this test, the first round of the post-measurements were done within 10 minutes of the samples being taken out of the reactor. 


\section{Data Processing}

\section{Weight variations}

Weight gain $(\mathrm{WtGn})=[(\mathrm{wt}$ of specimen + sorbed liquid $)$ - wt of specimen $]$; percent weight-gain $(\% \mathrm{WtGn})=\mathrm{Wt}$ gain $(100) / \mathrm{Wt}$ of dry specimen

\section{Thickness and diameter variations}

Thickness increase $(\mathrm{TkIn})=(\mathrm{Tk}$ of specimen after the reaction $-\mathrm{Tk}$ of the specimen before the reaction)

Percent thickness increase $(\% \mathrm{TkIn})=$ thickness increase $(\mathrm{TkIn})(100) /$ thickness of the specimen before the reaction

Diameter increase $(\mathrm{DiIn})=[(\mathrm{Di}$ of specimen after the reaction $-\mathrm{Di}$ of the specimen before the reaction)

Percent diameter increase $(\%$ DiIn $)=$ diameter increase $($ DiIn $)(100) /$ Diameter of the specimen before the reaction

\section{Hardness (Shore) variations}

Material's hardness could be defined as a material's resistance to permanent indentation. Shore Durometer was used to measure the hardness of the specimen. It measures the depth of an indentation in the material created by a given force on a standardized presser foot. Hardness increase $(\mathrm{HdIn})=($ hardness of the specimen before the reaction - hardness of the specimen after the reaction). Percent hardness increase $(\% \mathrm{HdIn})=$ hardness increase $(\mathrm{HdIn}) /$ hardness of the specimen before the reaction.

\section{Elasticity variations}

When an external force is applied on an elastic material, an internal force is created that opposes the deformation. When the external force is applied longer, the elastic material restores to its original state. The elasticity of materials is normally described by a stress-strain curve. The curve shows relation between stress (the restorative internal force per unit area) and strain (the relative deformation).[21] The relationship between stress $(\sigma)$ and strain $(\varepsilon)$ can be expressed as: $\sigma=\mathrm{E} \varepsilon$ where $\mathrm{E}$ is known as the Young's modulus. For this test, forces were gradually applied on the O-ring specimens increasing from $0 \mathrm{lb}$ to $0.3 \mathrm{lb}$, and the displacement (strain) the O-rings was measured.

\section{Test Results Discussion}

\section{Thickness, diameter, hardness, and weight variations}

Table 4 and Table 5 are the test data of the silicone O-ring's compatibility with the new fluid and R245fa, respectively. 


\begin{tabular}{|c|c|c|c|}
\hline \multirow[t]{2}{*}{ Subject: } & O-ring \#1 & & \\
\hline & $\begin{array}{l}\text { Measure } \\
\text { count }\end{array}$ & Before test & After test \\
\hline \multirow[t]{4}{*}{ Thickness } & & Inch & Inch \\
\hline & 1 & \begin{tabular}{|r|}
0.13950 \\
\end{tabular} & 0.15950 \\
\hline & 2 & 0.13800 & 0.13800 \\
\hline & 3 & 0.13850 & \\
\hline \multirow[t]{4}{*}{ Diameter } & & Inch & Inch \\
\hline & 1 & 1.3055 & 1.4295 \\
\hline & 2 & 1.2960 & 1.3440 \\
\hline & 3 & 1.3155 & 1.2820 \\
\hline \multirow[t]{4}{*}{ Hardness } & & $5 A$ & SA \\
\hline & 1 & 64 & 54 \\
\hline & 2 & 64 & 60 \\
\hline & 3 & 64 & \\
\hline \multirow[t]{4}{*}{ Weight } & & gram & gram \\
\hline & 1 & \begin{tabular}{|r|}
1.2758 \\
\end{tabular} & $\begin{array}{r}1.7550 \\
\end{array}$ \\
\hline & 2 & & 1.3040 \\
\hline & 3 & & \\
\hline
\end{tabular}
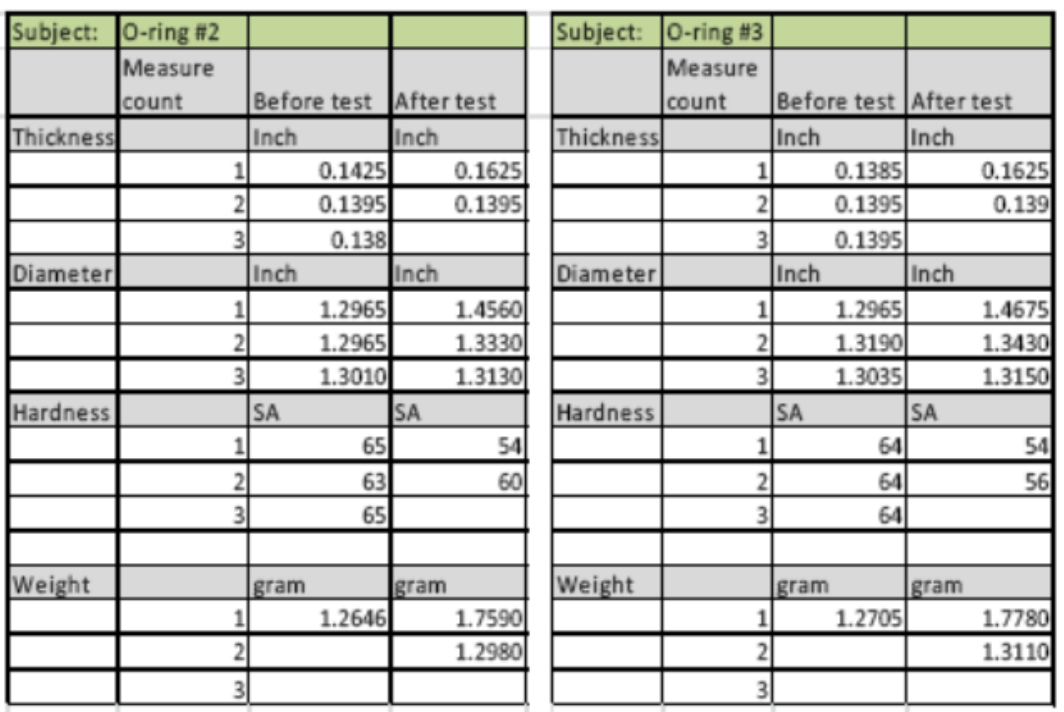

\begin{tabular}{|l|r|r|r|}
\hline Subject: & O-ring H4 & & \\
\hline & $\begin{array}{l}\text { Measure } \\
\text { count }\end{array}$ & Before test & After test \\
\hline & 1 & 0.1385 & 0.1650 \\
\hline & 2 & 0.1390 & 0.1395 \\
\hline & 3 & 0.1400 & \\
\hline & & Inch & Inch \\
\hline & 1 & 1.3035 & 1.4400 \\
\hline & 2 & 1.3185 & 1.3120 \\
\hline & 3 & 1.3210 & 1.3110 \\
\hline Diameter & & $5 A$ & SA \\
\hline & 1 & & \\
\hline & 2 & & 54 \\
\hline & 3 & & \\
\hline & & gram & gram \\
\hline Weight & 1 & 1.2700 & 1.8210 \\
\hline & 2 & & 1.3320 \\
\hline & 3 & & \\
\hline & & & \\
\hline
\end{tabular}
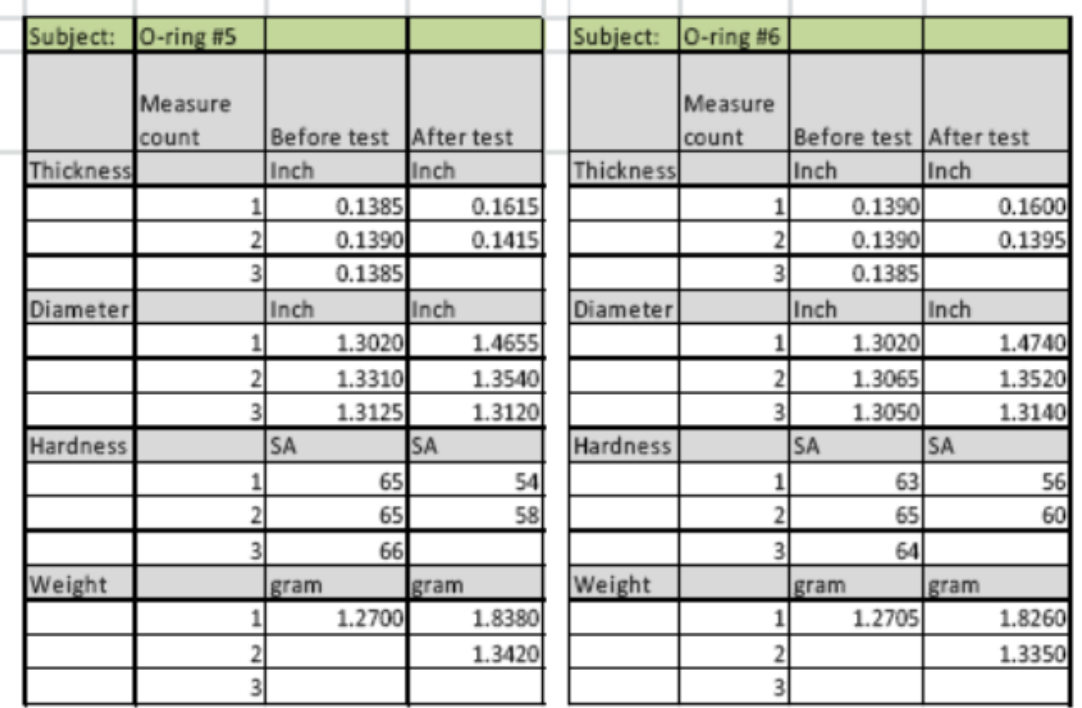

Table 4. Test data on silicone O-rings' compatibility with the new fluid 


\begin{tabular}{|c|c|c|c|}
\hline \multirow[t]{2}{*}{ Subject: } & O-ring \#1 & & \\
\hline & $\begin{array}{l}\text { Measure } \\
\text { count }\end{array}$ & Before test & After test \\
\hline \multirow[t]{4}{*}{ Thickness } & & Inch & Inch \\
\hline & 1 & 0.1390 & \begin{tabular}{|l}
0.1410 \\
\end{tabular} \\
\hline & 2 & 0.1385 & 0.1405 \\
\hline & 3 & 0.1395 & \\
\hline \multirow[t]{4}{*}{ Diameter } & & Inch & Inch \\
\hline & 1 & 1.3205 & $\begin{array}{r}1.3270 \\
\end{array}$ \\
\hline & 2 & 1.3190 & 1.3225 \\
\hline & 3 & 1.3200 & 1.3350 \\
\hline \multirow[t]{4}{*}{ Hardness } & & Shore & Shore \\
\hline & 1 & 66 & 55 \\
\hline & 2 & 66 & \\
\hline & 3 & 67 & \\
\hline \multirow[t]{4}{*}{ Weight } & & gram & gram \\
\hline & 1 & 1.3038 & 1.3800 \\
\hline & 2 & & 1.3219 \\
\hline & 3 & & \\
\hline
\end{tabular}
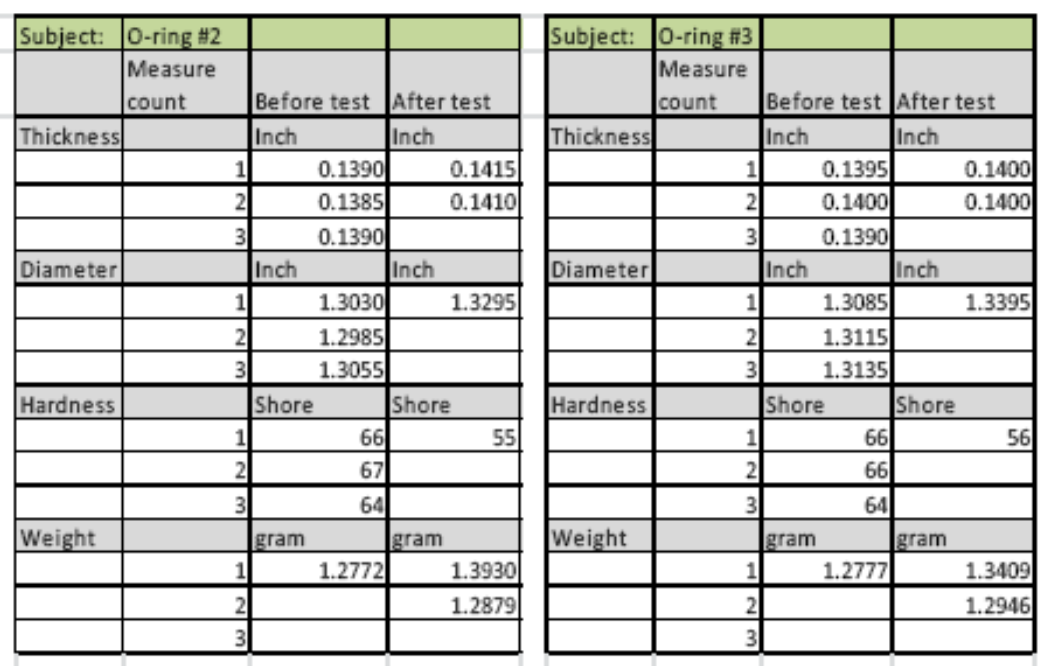

\begin{tabular}{|c|c|c|c|}
\hline \multirow[t]{2}{*}{ Subject: } & O-ring $\# 4$ & & \\
\hline & $\begin{array}{l}\text { Measure } \\
\text { count }\end{array}$ & Before test & After test \\
\hline \multirow[t]{4}{*}{ Thickness } & & Inch & Inch \\
\hline & 1 & 0.1400 & 0.1465 \\
\hline & 2 & 0.1395 & 0.1445 \\
\hline & 3 & 0.1395 & \\
\hline \multirow[t]{4}{*}{ Diameter } & & Inch & Inch \\
\hline & 1 & 1.3035 & 1.3565 \\
\hline & 2 & 1.3185 & 1.3360 \\
\hline & 3 & 1.3210 & \\
\hline \multirow[t]{4}{*}{ Hardness } & & \begin{tabular}{|l|} 
Shore \\
\end{tabular} & Shore \\
\hline & 1 & 65 & 57 \\
\hline & 2 & 66 & \\
\hline & 3 & 64 & \\
\hline \multirow[t]{4}{*}{ Weight } & & gram & gram \\
\hline & 1 & 1.2853 & $\begin{array}{r}1.4550 \\
\end{array}$ \\
\hline & 2 & & 1.3229 \\
\hline & 3 & & \\
\hline
\end{tabular}
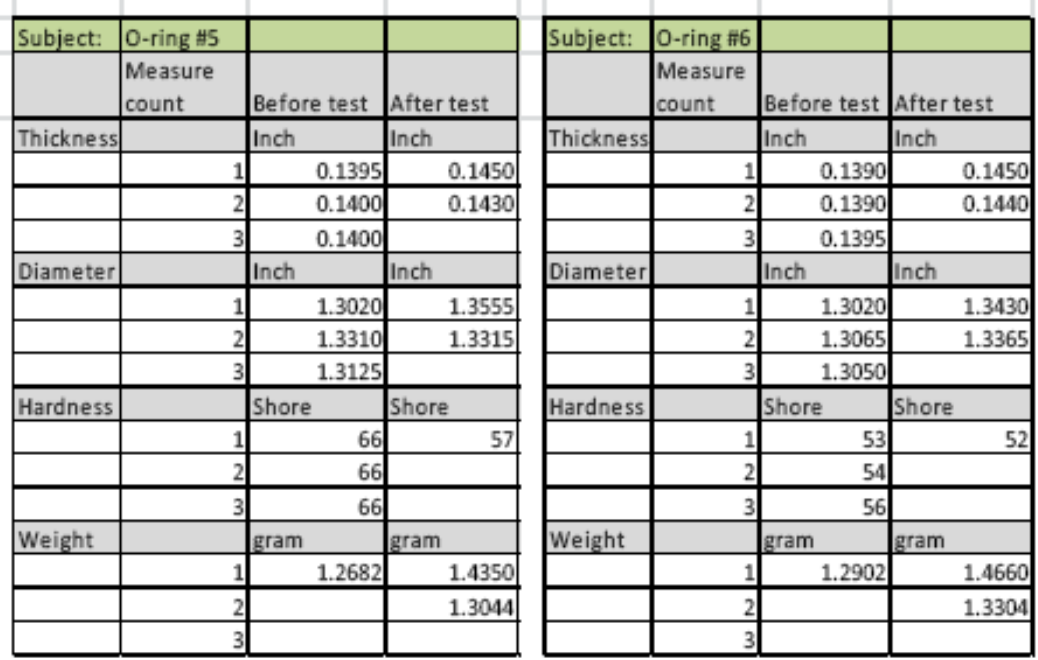

Table 5. Test data on silicone O-rings' compatibility with R245fa. 
Table 6. Comparison between silicone O-rings tested in new fluid and R245fa.

\begin{tabular}{|c|c|c|}
\hline Test Fluid & New Fluid & $R 245 \mathrm{fa}$ \\
\hline & \multicolumn{2}{|c|}{ Average Delta } \\
\hline \multicolumn{3}{|c|}{ Compressed O-rings } \\
\hline Thickness & $16 \%$ & $1 \%$ \\
\hline Diameter & $11 \%$ & $2 \%$ \\
\hline Hardness & $-16 \%$ & $-16 \%$ \\
\hline Weight & $39 \%$ & $7 \%$ \\
\hline \multicolumn{3}{|c|}{ Uncompressed O-rings } \\
\hline Thickness & $17 \%$ & $4 \%$ \\
\hline Diameter & $11 \%$ & $3 \%$ \\
\hline Hardness & $-15 \%$ & $-10 \%$ \\
\hline Weight & $44 \%$ & $13 \%$ \\
\hline
\end{tabular}

Table 6 summarizes the comparison. Note that in Table 4 and Table 5 the redundant measurements "before the test" are mainly for error minimization. However, the redundant measurements "after the test" were taken to see the property changes over time as the specimens were taken out of the reactor. The first measurement of each parameter of the specimens was taken approximately within $15 \mathrm{~min}$ of them taken out of the reactor. These measurements are most important in terms of investigating the changes before and after the test. The summary in Table 6 is based on the average measurement of the data before the test and the first measured data after the test. 
When comparing the silicone O-rings tested in the new fluid and R245fa (see Table 6), it is evident that the new fluid has changed the silicone O-rings' properties much more significantly than R245fa, except for the hardness. Hardness change is mainly due to the temperature difference of the specimens before and after the test. The $16 \%$ growth in thickness and $11 \%$ growth in diameter cannot be accepted for seals in many cases. Figure 22 shows silicone O-rings in the new fluid and R245fa after the test. It is visible that the O-rings have "grown out of" the plates that were used for O-ring compression.

A.

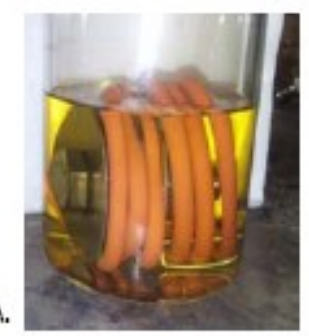

B.

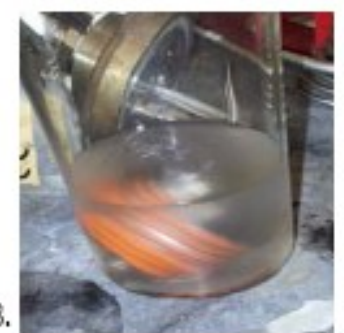

Figure 22. O-ring samples after test. (A) Silicone O-rings in HDR14 and (B) silicone O-rings in R245fa.

\section{Elasticity changes}

The elasticity of the O-ring specimens changes when they react with the working fluid. Figure 23 and Figure 24 show the elasticity test results of the silicone O-ring specimens reacted with the new fluid and R245fa, respectively. All the results are shown in a position (deformation) versus load manner. The curves are labeled with the O-rings' ID numbers, the numbers without " ' " are the O-rings measured before reacting with the fluids, and the numbers with " ' " are measured after reacting with the fluid. The fitting line of each curve represents the relationship between the load that was applied on the O-ring and the deformation of the O-ring due to the load. Strictly, Young's modulus does not apply to non-linear materials, including rubber. But since the load is small, it is a close enough approximation for the purpose of this study. The slope of the fitting line represents the O-ring specimen's Young's modulus. 

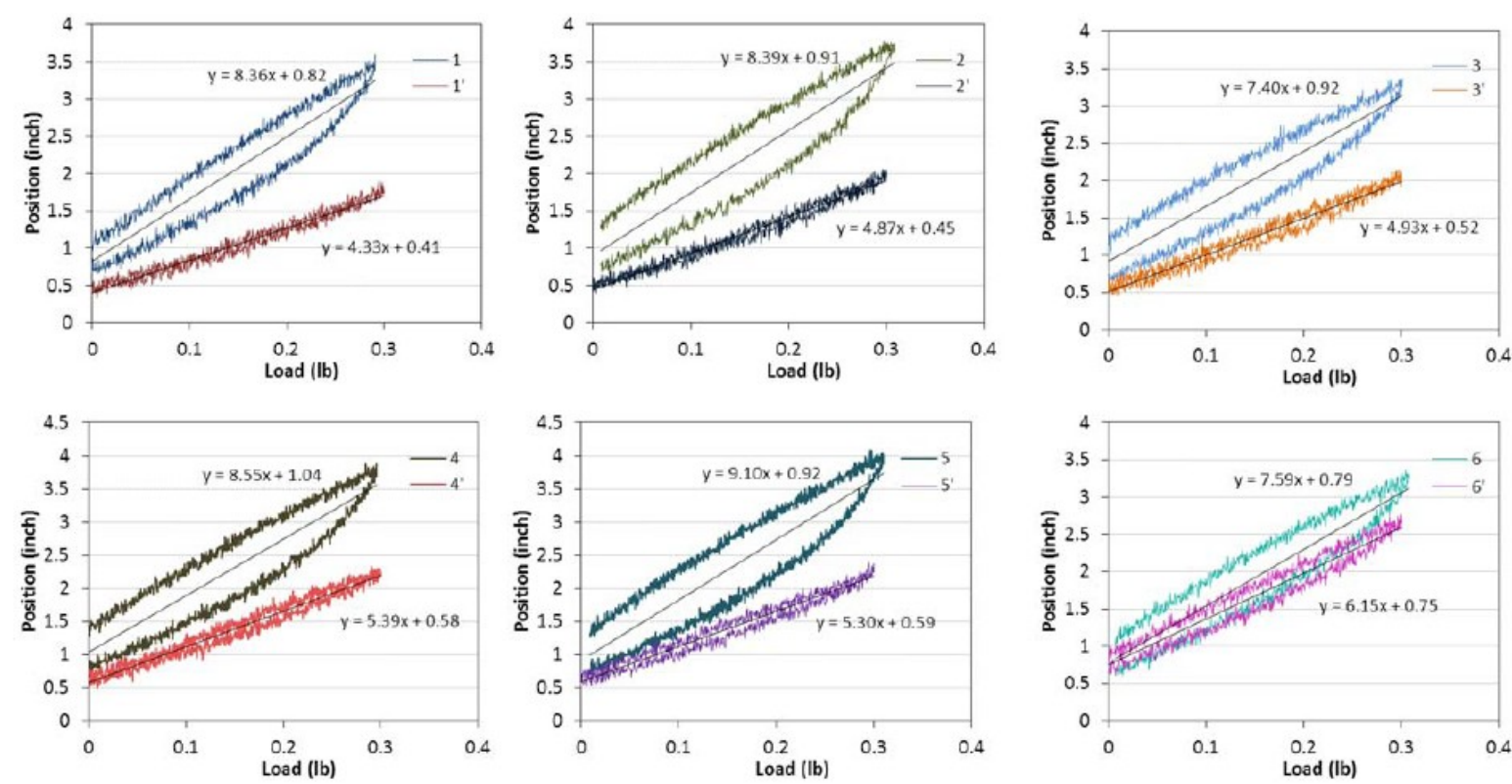

Figure 23. Elasticity test of the O-rings.
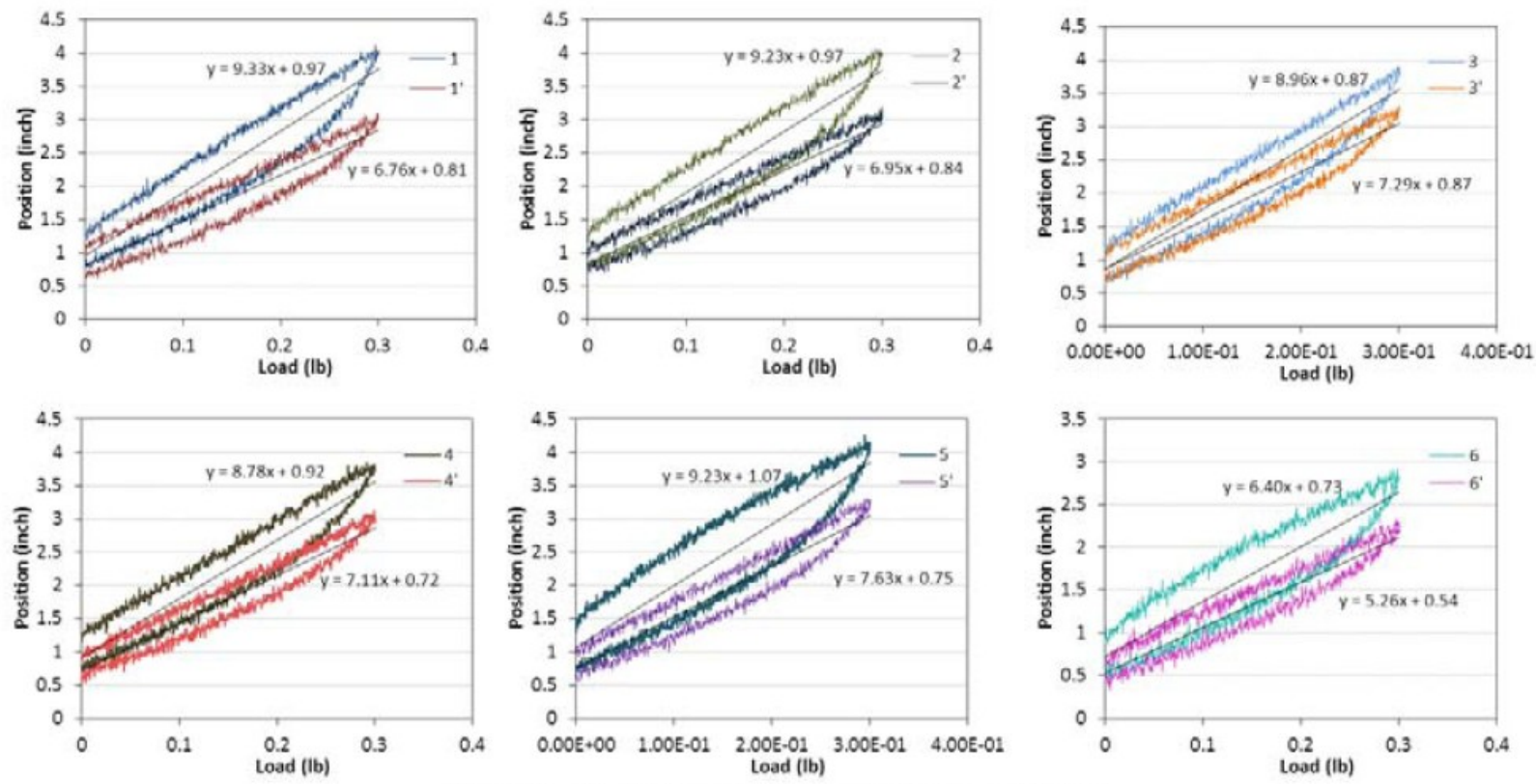

Figure 24. Elasticity test of the R245fa. 
Table 7. Young's modulus of silicone O-rings tested with the new fluid.

\begin{tabular}{|c|c|c|c|c|c|c|}
\hline O-ring ID & 1 & 2 & 3 & 4 & 5 & 6 \\
\hline Before reaction & 8.36 & 8.39 & 7.4 & 8.55 & 9.1 & 7.59 \\
\hline After reaction & 4.33 & 4.87 & 4.8 & 5.39 & 5.3 & 6.15 \\
\hline Difference & $48 \%$ & $42 \%$ & $35 \%$ & $37 \%$ & $42 \%$ & $19 \%$ \\
\hline
\end{tabular}

Table 8. Young's modulus of silicone O-rings tested with R245fa.

\begin{tabular}{l|c|c|c|c|c|c|c}
\multicolumn{1}{c}{ O-ring ID } & 1 & 2 & 3 & 4 & 5 & 6 \\
\hline Before reaction & 9.33 & 9.23 & 8.96 & 8.78 & 9.23 & 6.4 \\
\hline After reaction & 6.76 & 6.95 & 7.29 & 7.11 & 7.63 & 5.26 \\
\hline Difference & $28 \%$ & $25 \%$ & $19 \%$ & $19 \%$ & $17 \%$ & $18 \%$ \\
\hline
\end{tabular}

Table 7 and Table 8 show the elasticity changes of the O-rings reacted with the new fluid and R245fa, respectively. On average, the elasticity of the O-rings reacted with the new fluid reduces by $37 \%$, and that of the O-rings reacted with $\mathrm{R} 245$ fa reduces by $21 \%$.

The compatibility test of the new fluid with various plastics and elastomers were also done and published by the vendor. Commonly used plastics, such as ABS, HDPE, nylon, polycarbonate, polypropylene, polyethylene terephthalate, poly-vinyl chloride, high-impact polystyrene, acrylic, and elastomers, such as Viton B, epichlorohydrin rubber, Buna N (nitrile butadiene rubber), butyl rubber, buna-nitrile, polyurethane 390 , neoprene, silicone rubber, perfluoroelastomer (Kalrez $\left.{ }^{\circledR}\right)$, and ethylene propylene diene M-class rubber, were immersed in the new fluid for two weeks at room temperature in enclosed cells for the compatibility test. Weight change and dimensional change were carried out along with visual observation for cracks or other degradation. The results show that, except for high-impact polystyrene and acrylic, all plastics have minimal or no effect. The new fluid completely dissolved acrylic material; for the elastomers, significant changes were observed for Buna-nitrile, ethylene propylene diene M-class rubber, and for others the changes observed are minimal.

Note that the compatibility tests done by the vendor were conducted at room temperature. Silicone rubber tested by the vendor at room condition was found to have no significant changes. However, the tests done by GE Global Research at $150^{\circ} \mathrm{C}$ showed different results. The silicone O-ring had serious swell and other properties have also changed significantly. In an ORC or supercritical ORC system, seals in a lot of places "see" high temperatures. Therefore, the test done by the vendor at room temperature cannot be used directly to guide the selection of seals for ORC system or supercritical ORC system.

Based on the tests conducted by GE Global Research, it is not recommended that silicone seals to be used in ORC systems with the new fluid where the temperature can reach $150^{\circ} \mathrm{C}$ or higher. 


\subsubsection{Compatibility With Neoprene}

\section{Introduction}

Similar to the test done with silicone O-rings, the compatibility test of neoprene with the new fluid was conducted in the same conditions. Without going through the test procedure, which one can refer to the silicone test, the follow section shows the test results and analysis directly.

\section{Test Results Discussion}

\section{Thickness, diameter, hardness, and weight variations}

Table 9 shows the test data of the neoprene O-ring's compatibility with the new fluid, and Table 10 summaries the test results.

\begin{tabular}{|c|c|c|c|}
\hline \multirow{2}{*}{ Subject: } & O-ring \#1 & & \\
\hline & $\begin{array}{l}\text { Measure } \\
\text { count }\end{array}$ & Before test & After test \\
\hline \multirow[t]{4}{*}{ Thickness } & & Inch & Inch \\
\hline & 1 & 0.1390 & \begin{tabular}{|r}
0.1410 \\
\end{tabular} \\
\hline & 2 & 0.1385 & 0.1405 \\
\hline & 3 & 0.1395 & \\
\hline \multirow[t]{4}{*}{ Diameter } & & Inch & Inch \\
\hline & 1 & 1.3205 & $\begin{array}{r}1.3270 \\
\end{array}$ \\
\hline & 2 & 1.3190 & 1.3225 \\
\hline & 3 & 1.3200 & 1.3350 \\
\hline \multirow{4}{*}{ Hardness } & & Shore & Shore \\
\hline & 1 & 66 & 55 \\
\hline & 2 & 66 & \\
\hline & 3 & 67 & \\
\hline \multirow[t]{4}{*}{ Weight } & & gram & gram \\
\hline & 1 & 1.3038 & 1.3800 \\
\hline & 2 & & 1.3219 \\
\hline & 3 & & \\
\hline
\end{tabular}

\begin{tabular}{|l|r|r|r|}
\hline Subject: & O-ring \#4 & & \\
\hline & $\begin{array}{l}\text { Measure } \\
\text { count }\end{array}$ & Before test & After test \\
\hline & & Inch & Inch \\
\hline & 1 & 0.1400 & 0.1465 \\
\hline & 2 & 0.1395 & 0.1445 \\
\hline & 3 & 0.1395 & \\
\hline Thickness & & Inch & Inch \\
\hline & 1 & 1.3035 & 1.3565 \\
\hline & 2 & 1.3185 & 1.3360 \\
\hline & 3 & 1.3210 & \\
\hline Hardness & & Shore & Shore \\
\hline & 1 & 65 & \\
\hline & 2 & 66 & \\
\hline & 3 & 64 & \\
\hline Weight & & gram & gram \\
\hline & 1 & 1.2853 & 1.4550 \\
\hline & 2 & & 1.3229 \\
\hline & 3 & & \\
\hline
\end{tabular}
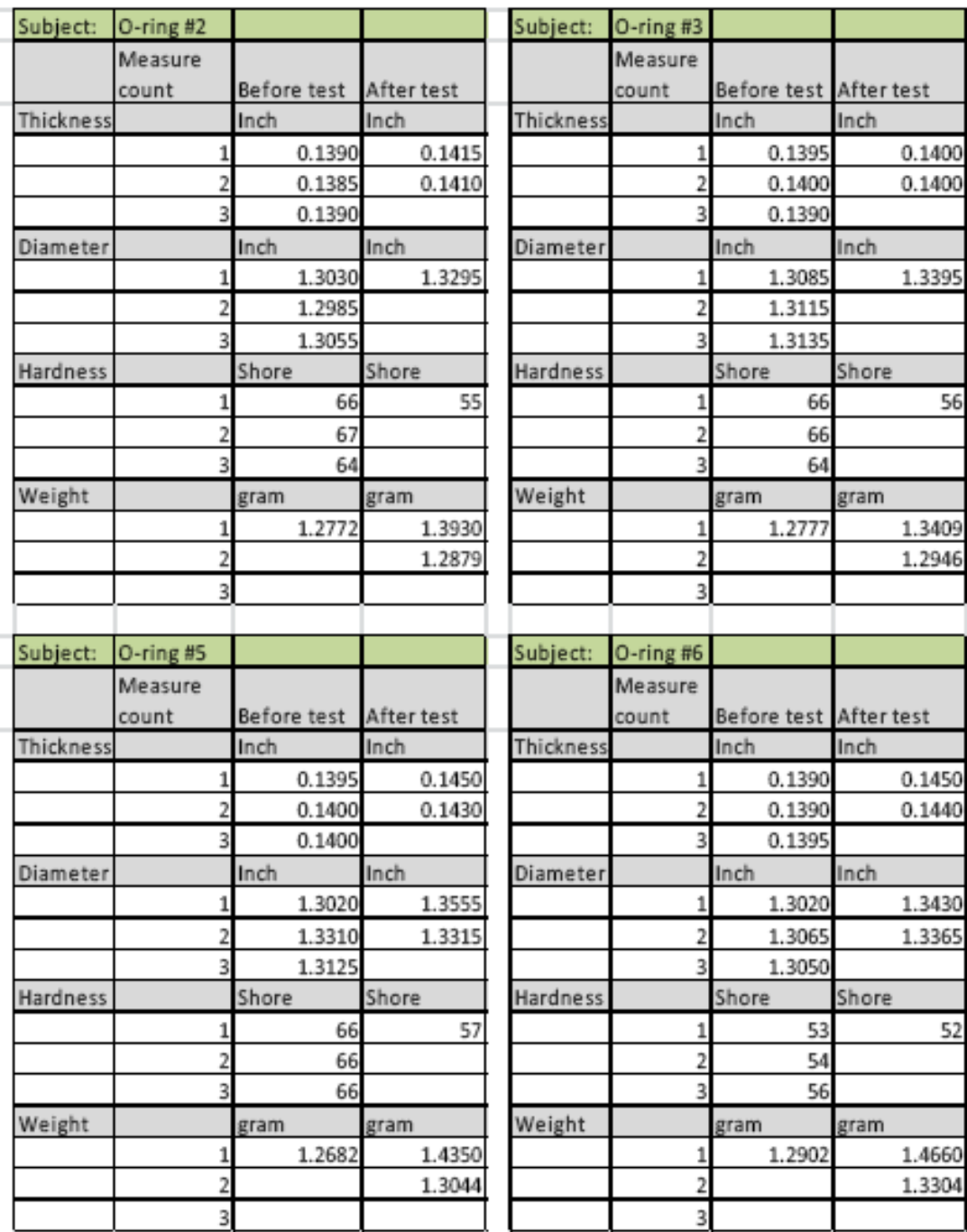

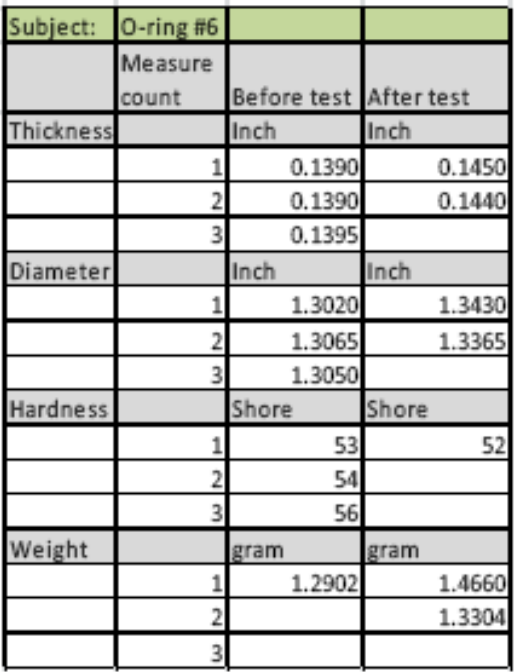

Table 9. Test Data on Neoprene O-Ring compatibility with the new fluid 
Table 10. Test results summary on compatibility

of the new fluid with neoprene.

\begin{tabular}{l|c|c}
\multirow{2}{*}{ Test Fluid } & \multicolumn{2}{|c}{ New Fluid } \\
& \multicolumn{2}{|c}{ Average Delta } \\
\cline { 2 - 3 } & Compressed O-rings & Uncompressed O-rings \\
\hline Thickness & $-30.3 \%$ & $1.1 \%$ \\
\hline Diameter & $3.4 \%$ & $0.0 \%$ \\
\hline Hardness & $33.3 \%$ & $32.1 \%$ \\
\hline Weight & $6.8 \%$ & $6.6 \%$ \\
\hline
\end{tabular}

Like the test with silicone O-rings, the redundant measurements "before the test" are mainly for error minimization. The redundant measurements "after the test" were taken to see the property changes over time as the specimens were taken out of the reactor. The first measurement of each parameter of the specimens was taken approximately within 15 minutes of the specimens being taken out of the reactor. These measurements are most important in terms of investigating the changes before and after the test. The summary in Table 10 is based on the average measurement of the data before the test and the first measured data after the test.

Comparing the results of the compressed and uncompressed O-rings in Table 10, it is noticeable that the thickness of the compressed O-rings has decreased by $30.0 \%$ on average, indicating serious compression set. Figure 25 is a snapshot of the neoprene O-ring specimens after being taken out of the reactor.

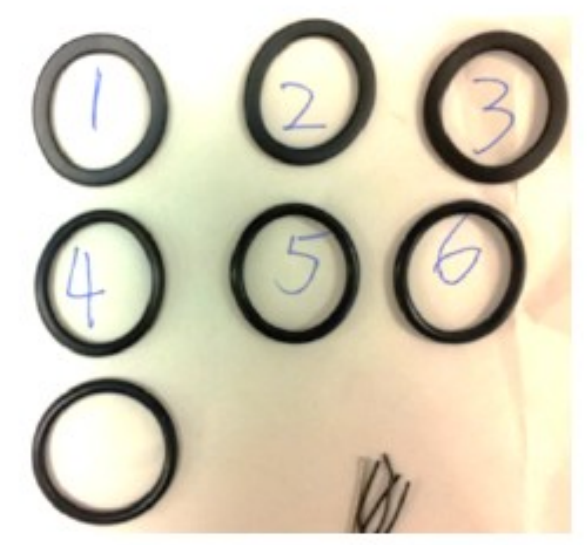

Figure 25. Neoprene O-rings tested with HDR14.

O-rings 1-3 were compressed during the test, and O-rings 4-6 were not compressed. The $\mathrm{O}$-ring not identified is a new sample that was not tested. It is visible that O-rings $1-3$ became "flat" after the test. This compression set of neoprene is mostly permanent, as it can be seen measured over time (refer to Table 9). It was noticed that the neoprene O-rings 1-3 had the same compression set after a month of being placed in the air. Recall that silicone O-rings tested with the 
new fluid experienced serious swell, this compression set of neoprene could be worse as a seal material for an ORC system with this fluid.

\section{Elasticity changes}

Figure 26 shows the elasticity test results of the neoprene O-ring specimens reacted with the new fluid.
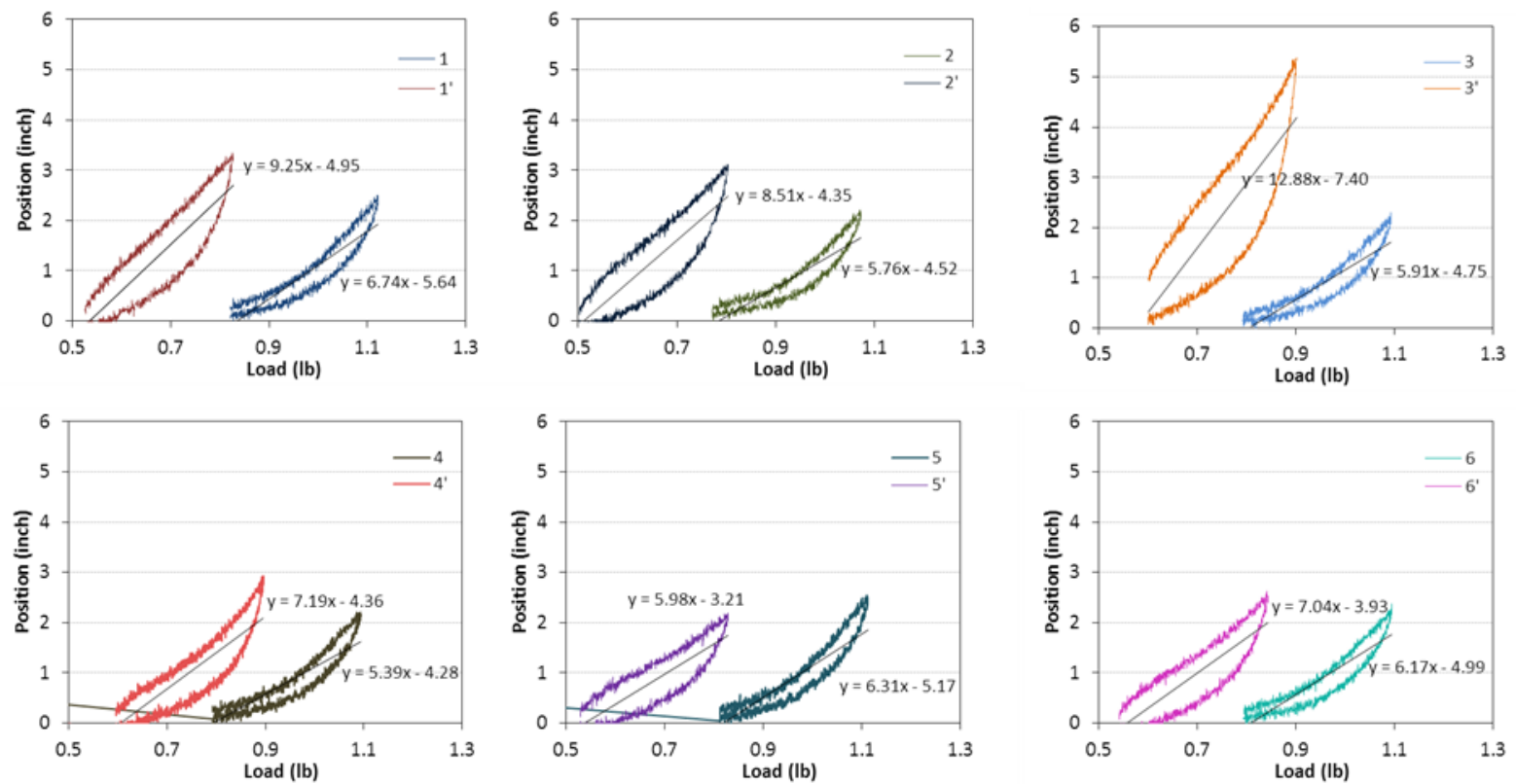

Figure 26. Elasticity test results of the neoprene 0 -ring specimens reacted with the new fluid

All the results are shown in a position (deformation) versus load manner. Like the test with silicone O-rings, the curves are labeled with the O-rings' ID numbers, the numbers without " ' " are the O-rings measured before reacting with the fluid, and the numbers with " " " are measured after reacting with the fluid. The fitting line of each curve represents the relationship between the load that was applied on the O-ring and the deformation of the O-ring due to the load. The slope of the fitting line represents the O-ring specimen's Young's modulus. Table 11 summarizes the elasticity results.

Table 11. Young's Modulus of neoprene O-rings tested with the new fluid.

\begin{tabular}{l|c|c|c|c|c|c|c}
\multicolumn{1}{c}{ O-ring ID } & 1 & 2 & 3 & 4 & 5 & 6 \\
\hline Before reaction & 6.74 & 5.76 & 5.91 & 5.39 & 6.31 & 6.17 \\
\hline After reaction & 9.25 & 8.51 & 12.88 & 7.19 & 5.98 & 7.04 \\
\hline Difference & $-37 \%$ & $-48 \%$ & $\begin{array}{r}-118 \\
\%\end{array}$ & $-33 \%$ & $5 \%$ & $-14 \%$ \\
\hline
\end{tabular}

As seen in Table 11, five out of the six neoprene O-rings tested experience a decrease in Young's modulus after reaction. This is a different direction of change than the silicone O-rings. 
This decrease in Young's modulus indicates reduced elasticity, which results in the compression set we noticed earlier. The average decrease in Young's modulus with the compressed and uncompressed neoprene O-rings are $68 \%$ and $14 \%$, respectively.

Based on the tests conducted with the new fluid and neoprene, it is not recommended that neoprene seals to be used in ORC systems with this fluid where the temperature can reach $150^{\circ} \mathrm{C}$ or higher.

\subsubsection{Compatibility with Viton and Teflon}

Compatibility of the new fluid with Viton and Teflon were not tested in the lab. Instead, they were tested in-situ on the supercritical ORC test rig (described in chapter 6) built for supercritical ORC system testing due to time constraints. In the supercritical ORC test rig, a hydra-cell pump with Viton diaphragms was used. The test rig was charged with the new fluid without applying any pressure or heat to it, yet it was found that the pump had a serious leakage, and the Viton diaphragms were torn even under this room condition. Figure 27 shows the ripped diaphragms that were taken off the test rig. This clearly shows that Viton is not chemically resistant to the new fluid and it cannot be used as a seal material in a system in contact with this fluid, even at room condition.

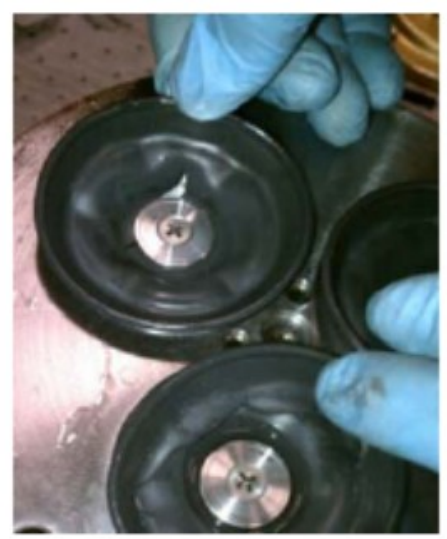

Figure 27. Ripped Viton diaphragms showing that Viton is not compatible with the new fluid.

With Viton out of the question, the pump was sent back to the vendor and Viton diaphragms replaced with Teflon diaphragms. Tests have been conducted with Teflon diaphragms on the pump on the rig for about 2 weeks, and no leakage has been found from the pump. It indicates that Teflon is chemically resistant to the new fluid at the temperature tested. However, it needs to be mentioned that the pump was operating at temperatures between $20-50^{\circ} \mathrm{C}$ and high delta pressures during the test. Whether Teflon is compatible with the new fluid at elevated temperatures is still un-known.

\subsection{CONCLUSION ON THERMAL STABILITY AND COMPATIBILITY WITH SEALS}

In Chapter 2 of this report, best cycles and fluids were downselected for different resource temperatures. To review it briefly, cyclepentene in subcritical ORC and the new fluid in supercritical ORC give the optimal system LCOE at the resource temperatures of $275-350^{\circ} \mathrm{C}$ and $200-225^{\circ} \mathrm{C}$, respectively. ORC fluids have the tendency of degrading at elevated temperatures. Thermal stabilities of the two fluids at $300^{\circ} \mathrm{C}$ and $200^{\circ} \mathrm{C}$ were tested, respectively. Results show that cyclopentene is not thermally stable and degrades at $300^{\circ} \mathrm{C}$, which comes from two sources: 
its reaction with any residual oxygen and reaction with itself to produce higher molecular weight products. The new vendor fluid is thermally stable at $200^{\circ} \mathrm{C}$, which is derived from that fact that after 399 hours of cooking, there was only $25 \mathrm{ppm}$ of dimer and less than $3 \%$ of isomer formed.

When charged into an ORC system, this new fluid needs to be chemically resistant to the seals the fluid is in contact with. Compatibility of the new fluid with seals including silicone O-rings, neoprene O-rings, Viton diaphragm, and Teflon diaphragm were tested. The first two were tested in lab settings, and the latter two were test in-situ on the supercritical ORC rig. Results show that only Teflon is compatible with the new fluid at the condition tested. 


\section{Experiment Objectives and Design Rationale}

Once the fluid stability and compatibility questions had been adequately addressed by experimental studies, empirical data was needed on the validity of the thermo-economic performance models that showed a significant cost/performance advantage of the new working fluid at the target resource temperature $\left(200^{\circ} \mathrm{C}\right)$, as reported in Milestone Report 2.

The overall objectives of the subsequent experiments were therefore twofold:

1. Experimental data on the accuracy of the thermodynamic predictions of the model had to be collected in a representative environment that approximated, as closely as practical, the state points in an ORC cycle.

2. Furthermore, the experimental risk of high pressure in the supercritical cycle had to be systematically retired.

\subsection{RISK PERSPECTIVE OF TWO-TIERED EXPERIMENT}

Due to the risk of high temperature $\left(200^{\circ} \mathrm{C}\right)$ and pressure $(>42$ bar $)$ at supercritical conditions for the new fluid, it was decided to perform a two-stage experimental campaign. In the first stage, the chosen working fluid will be tested under subcritical conditions. In the second stage, the pressure and temperature of the fluid will be brought up to supercritical conditions at the evaporator thus providing a "transcritical" cycle. Coincidentally, the GE Heat Recovery Solutions business offers a commercial ORC unit that uses R245fa as a working fluid at subcritical conditions. Therefore, a subcritical experiment that compared and contrasted the performance of the baseline R245fa versus the new fluid in the production ORC unit was planned. Thermodynamic data collected from this experiment would meet part of the overall objectives laid out above and allow low risk, low pressure characterization of the new working fluid.

A second rig to address the more risky high pressure supercritical conditions was conceived at a smaller scale. Instead of a supercritical expander, this rig employed an isenthalpic valve and heat exchanger in series to accomplish the thermodynamic equivalent of the expander. The isenthalpic valve drops pressure while the downstream heat exchanger removes enthalpy as heat (that would otherwise be removed as work in a real expander). This unique feature allowed the experiment to be performed without undertaking an expensive design selection of a supercritical expander that did not fit the experimental objectives. The solid lines in Figure 28 show the expected thermodynamic pathway for the experiment, while the dotted line shows the expected equivalent of a real (supercritical) turboexpander. 


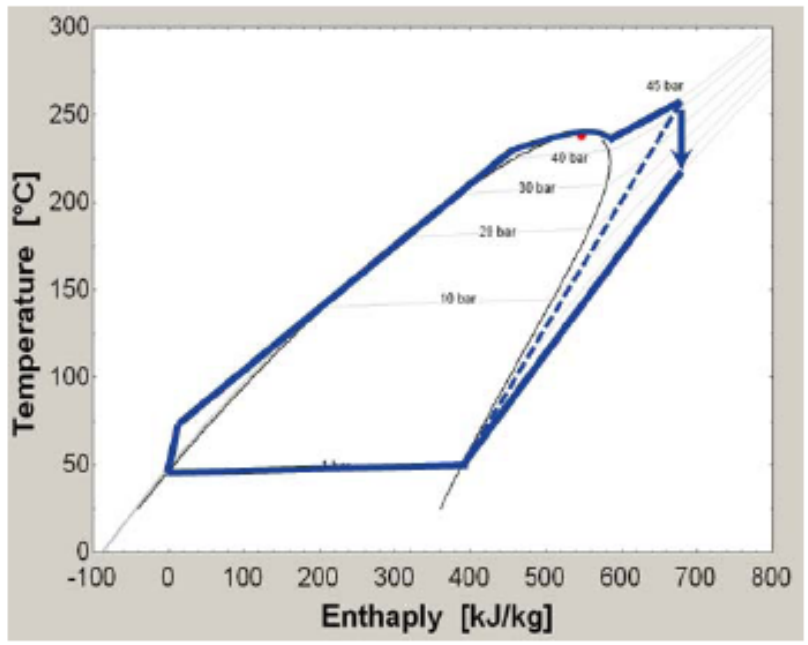

Figure 28. Solid lines show the thermodynamic pathway for the supercritical experiment. The dotted line shows the equivalent with a real expander.

Details of each experimental rig, setup, the data collected, analysis, and funding are provided in Chapters 5 and 6.

\subsection{TEAMING WITH BUSINESS TO CONDUCT SUBCRITICAL EXPERIMENT}

The GE Heat Recovery Solutions business had expressed their interest in finding an alternative low global warming potential, non-flammable working fluid due to regulatory restrictions on the use of R245fa. Their interest was in obtaining, testing, and validating a viable alternative to R245fa that could be made available commercially. The aims of the research experiment and the needs of the business in this case were complimentary and provided the further benefit of bringing the DOE sponsored research closer to a commercial product at an early stage. This was the prime reason for teaming with the GE Heat Recovery Solutions business to conduct the subcritical experiment.

An additional benefit was that the business was able to provide their technical expertise and skilled personnel to help with running the ORC unit and subsequent data analysis. The GE Heat Recovery Solutions site in Florida also served as a convenient test/host site for the subcritical experiment, eliminating the need to build or acquire a similar facility by the project team. 


\section{Subcritical Experiment}

\subsection{SUBCRITICAL CLEAN CYCLE EXPERIMENT}

The team performed a subcritical experiment on the commercially available waste heat recovery product, known as Clean Cycle. The Clean Cycle uses R245fa as its working fluid with a waste heat resource temperature of $160^{\circ} \mathrm{C}$. The main motivation of testing alterative working fluids to R245fa is due to its high global warming potential characteristics. This has led to R245fa being phased out in Europe and it is expected the US will shortly follow.

The new developmental fluid from a vendor has much better global warming potential characteristics. As seen in Figure 29, R245fa has a global warming potential of 930, compared to the new fluid which has a global warming potential of 7. Additionally, the new fluid has a favorable short-lived atmospheric lifetime of 0.1 years.

From a programmatic viewpoint, testing the performance of the new fluid at subcritical conditions was viewed as a risk mitigation strategy, prior to testing at supercritical conditions. Using a waste heat recovery product that has been tested in the field, and is therefore well understood, and working in the subcritical regime (below the critical point-lower temperatures and pressures) was ideal for testing fluid properties and fluid stability. The following performance assessment was conducted on the new fluid:

1. Compared overall system performance between R245fa and the new fluid. The new fluid was treated as a "drop-in replacement fluid". (Drop-in replacement fluid refers to a system that was not optimized for the new fluid.)

2. Compared turbine performance and efficiency.
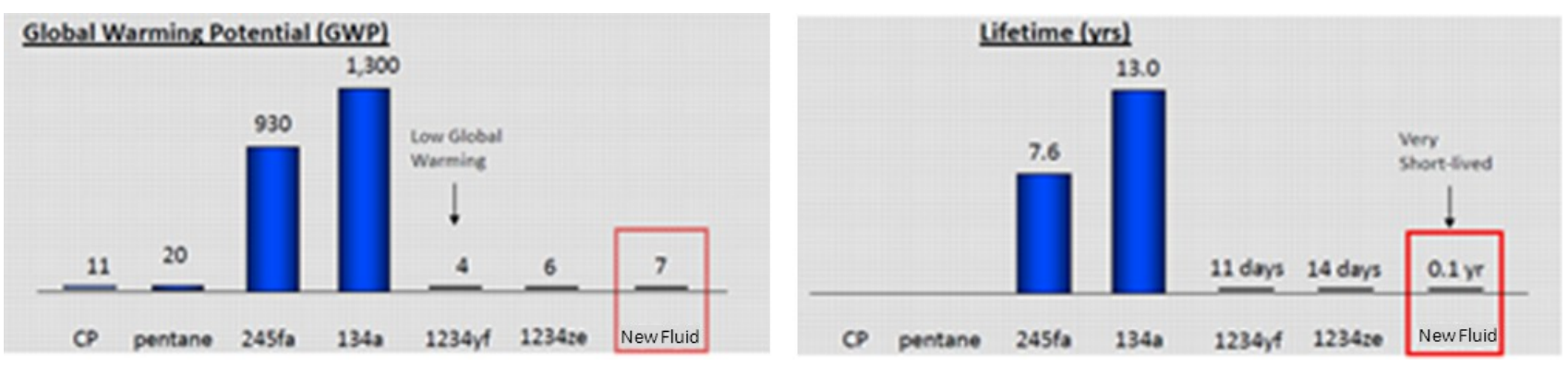

Figure 29. Global warming and lifetime data for R245fa and the new fluid. [22] 


\subsection{DROP-IN REPLACEMENT FLUID}

As mentioned in the previous section, the Clean Cycle subcritical system did not alter its hardware. This is the likely scenario a typical Waste Heat Recovery user will encounter with the phase out of R245fa. It should be noted that performance results with the new fluid will be inherently conservative, since the system has not been optimized for this working fluid.

Several assessments were done to ensure the system would perform safely. First, the properties of R245fa and the new fluid were compared and contrasted. Second, an Aspen HYSYS model was developed to replicate the conditions of the Clean Cycle, to ensure safe performance. Table 12 displays the thermophysical properties of the fluids.

The critical temperature and pressure of the new fluid are $10^{\circ} \mathrm{C}$ and 1 bar higher, respectively. The new fluid also has a lighter molecular weight and density compared to R245fa.

Table 12. Thermal-physical properties of R245fa and the new fluid.

\begin{tabular}{c|c|c|c|c|c}
\multicolumn{2}{c}{ R245fa+ $^{+}$} & \multicolumn{4}{c}{ New Fluid ++} \\
Property & Value & Unit & Property & Value & Unit \\
\hline Critical temperature (Tc) & 154.05 & ${ }^{\circ} \mathrm{C}$ & Critical temperature (Tc) & 165.6 & ${ }^{\circ} \mathrm{C}$ \\
\hline Critical pressure (Pc) & 36.62 & Bar & Critical pressure (Pc) & 37.72 & $\mathrm{Bar}$ \\
\hline Molecular weight (MW) & 134 & $\mathrm{~g} / \mathrm{mol}$ & Molecular weight (MW) & 130.5 & $\mathrm{~g} / \mathrm{mol}$ \\
\hline Density & 1339 & $\mathrm{~kg} / \mathrm{m}^{3}$ & Density & 1260 & $\mathrm{~kg} / \mathrm{m}^{3}$ \\
\hline
\end{tabular}

+ National Institute of Standards and Technology Certified data

++ Developmental Fluid Package data from vendor

\subsubsection{Equations of State}

An important aspect of using a thermophysical simulation, like HYSYS, is selecting the most accurate equation of state (EOS) to apply for to the fluid. The physical properties have uncertainties when phase changes are involved, in particular around the critical point. In the first Milestone Report for the Phase 1 activities, Chapter 4 goes into detail about the various EOS evaluated and the errors associated with them. The challenge with EOS is to determine which of the numerous equations available is valid for a fluid having specific conditions and application.

A result of the Phase 1 activities, benchmarking conducted for the "REFPROP" and "Non-REFPROP" fluids, it was observed that chemical families provide a natural grouping to select fluid-packages. Figure 30 shows a guideline for selecting fluid packages developed to obtain accurate thermodynamic values with small standard deviations. 


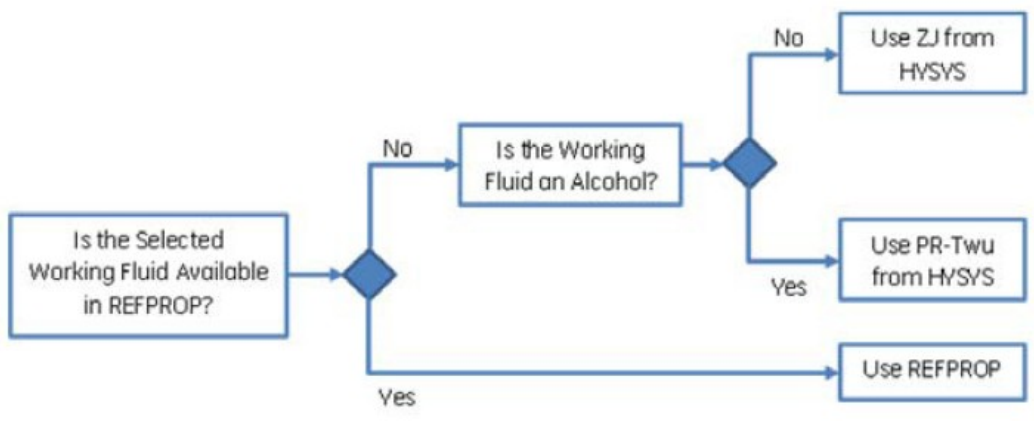

Figure 30. Guidelines for selecting the EOS.

Therefore, the appropriate EOS for R245fa is REFPROP. REFPROP is an EOS system that is certified by National Institute of Standards and Technology, and provides the industry standard for the fluid property information utilized in this study.[23] There are three models for the thermodynamic properties of pure fluids:

- EOS explicit in Helmholtz energy

- Modified Benedict-Webb-Rubin EOS

- Extended corresponding states model

For the new fluid, the situation is more complicated. It falls outside the guidelines of Figure 30, because it is a developmental fluid. It has not been fully tested by the National Institute of Standards and Technology. Therefore, the vendor recommended the use of HYSYS Peng-Robinson EOS. An important detail should also be noted. In HYSYS, there are 2 Peng-Robinson EOSs available: (1) the Aspen Peng-Robinson EOS and (2) the HYSYS Peng-Robinson EOS. It is important to use the HYSYS Peng-Robinson EOS. This provided the most accurate information.

\subsubsection{Phase Diagrams}

Once the EOS was determined, the team compared and contrasted R245fa with the new fluid in several phase diagrams. The pressure-temperature $(\mathrm{P}-\mathrm{T})$ plot shown in Figure 31 revealed that for the new fluid to achieve the same pressure as R245fa, the system would have to be higher in temperature.

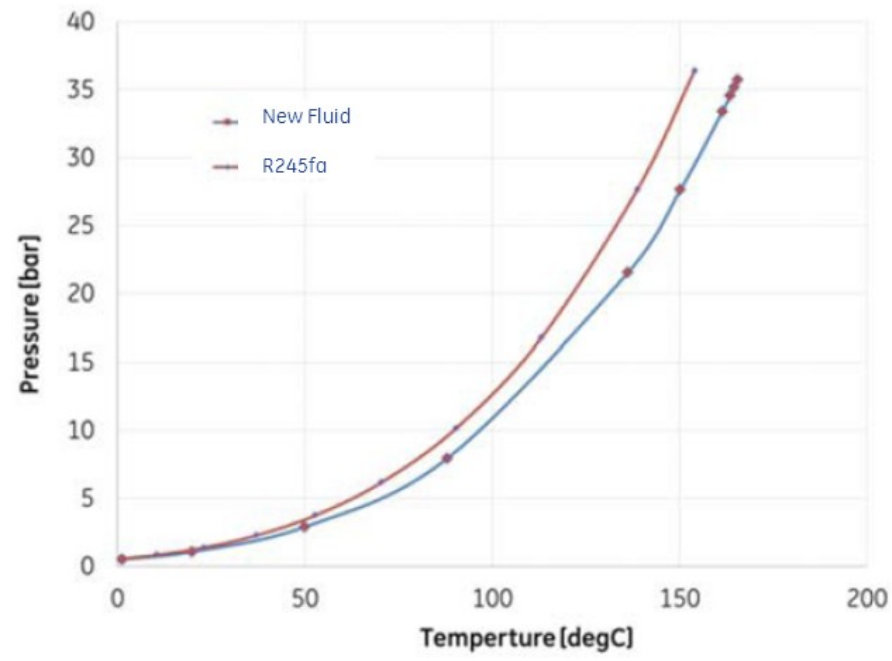

Figure 31. Pressure-temperature phase diagram for R245fa and the new fluid 
This was an important finding, since the controls and alarms in the Clean Cycle control logic was adjusted for the new fluid and anticipated higher temperatures.

The second phase diagram was done for temperature-entropy (T-s), where R245fa and the new fluid were compared. As seen in Figure 32, the vapor-liquid dome has a similar shape, although the reference point is different. The dome shape does come to a higher point, due the critical temperature of the new fluid being $10^{\circ} \mathrm{C}$ higher.

The third phase diagram was done for a pressure-enthalpy (P-h), where R245fa and the new fluid were compared. As seen in Figure 33, the vapor-liquid dome overlapped and had a very similar characteristic shape. The likely reason the top of the dome comes more to a point, is due to lack of available experimental pressure data near the critical pressure.

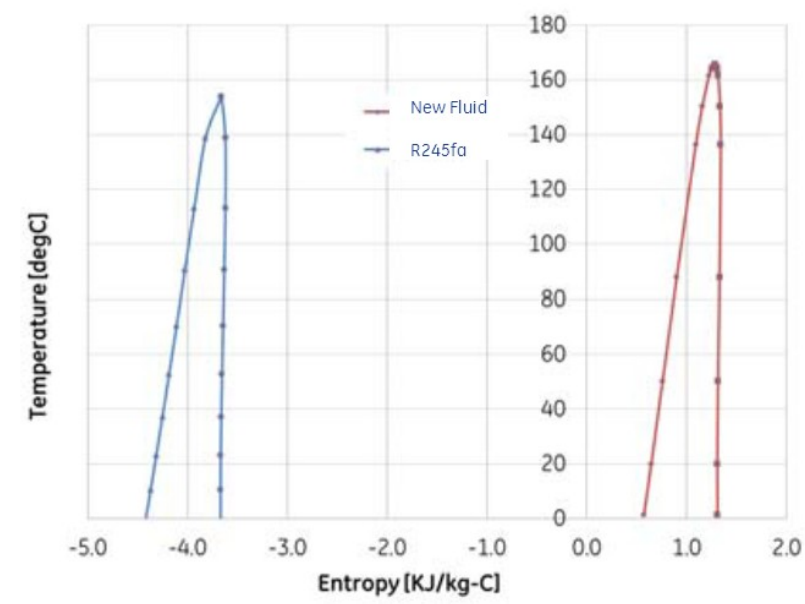

Figure 32. Temperature-entropy phase diagram for R245fa and the new fluid

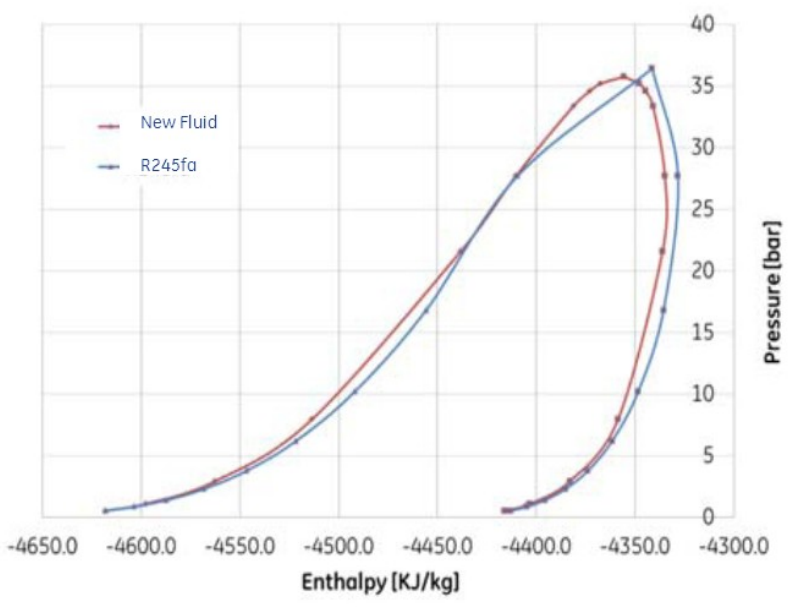

Figure 33. Pressure-enthalpy phase diagram for R245fa and the new fluid

\subsubsection{HYSYS Modeling and State Points}

To compare the state points between the Clean Cycle using R245fa and the new fluid, a model was developed in Aspen HYSYS. Figure 34, shows a screen shot of the HYSYS model that was developed to replicate Clean Cycle system arrangement and conditions.

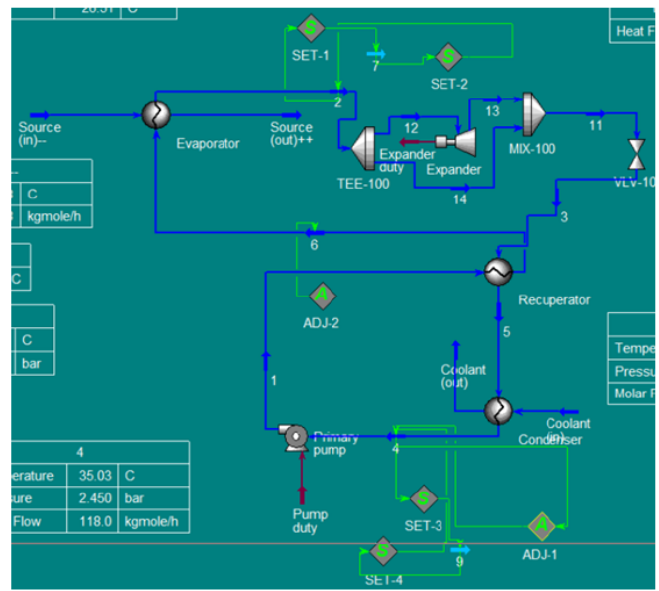

Figure 34. Screen shot of the Clean Cycle HYSYS model. 
From the HYSYS model, the state points where gathered for R245fa and the new fluid. Figure 35 shows the state points on the T-s phase diagrams.

The state points allowed the team to predict the expected performance of the Clean Cycle. Due to the similar thermal-physical properties of the new fluid and R245fa, similar performance could be expected and it would be safe to replace R245fa with the new fluid from a performance view point.
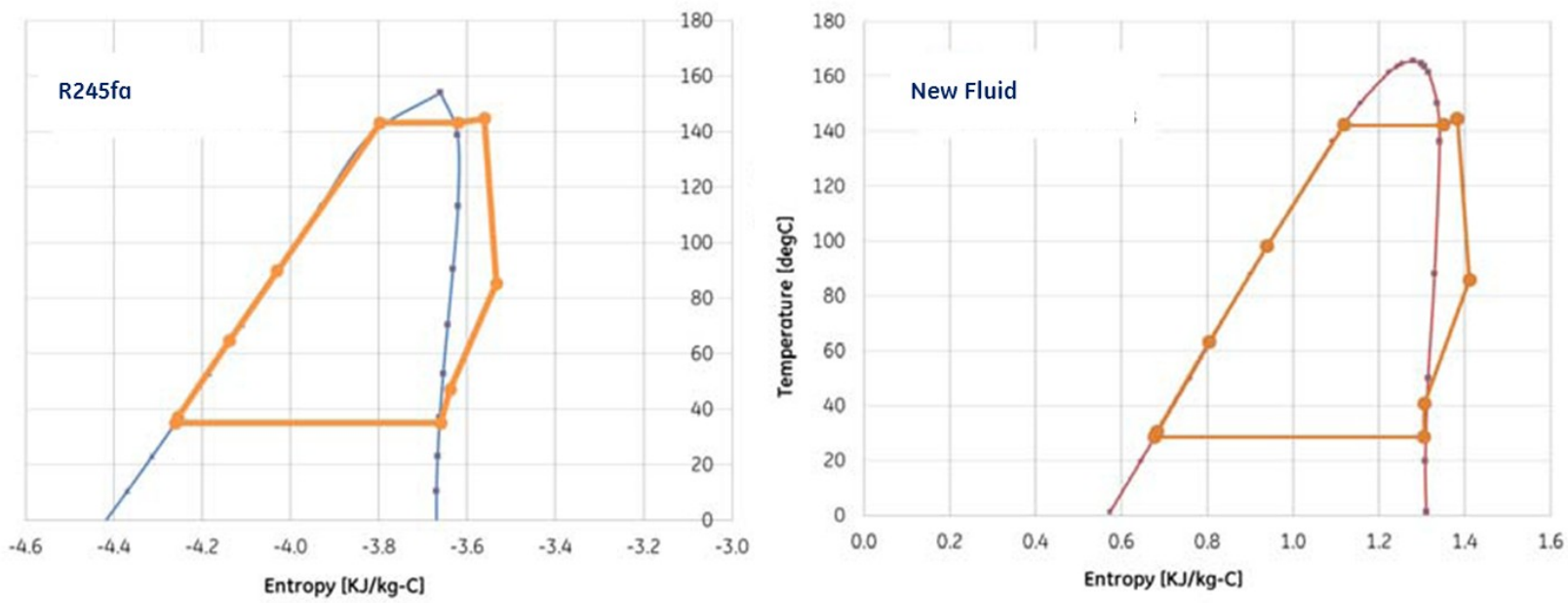

Figure 35. State points overlapping the T-S phase diagram for (A) R245fa and (B) the new fluid.

\subsubsection{Predicted Turbine Performance}

An Aspen model was developed by GE Heat Recovery Solutions and was used to predict turbine and overall system performance for R245fa. For this study, the team used the same model, and replaced the working fluid with a property model of the new fluid. Thus predictions of turbine pressure ratio, power output, and mass flow rates at given turbine speeds were generated. This exercise assessed which experimental parameters were of interest and aided in building a design of experiment. The results are shown in Figure 36, at turbine speeds of 26,000 rpm (start-up turbine speed), 27,500 rpm (normal operating speed), and 29,000 rpm (turbine upper limit speed). 


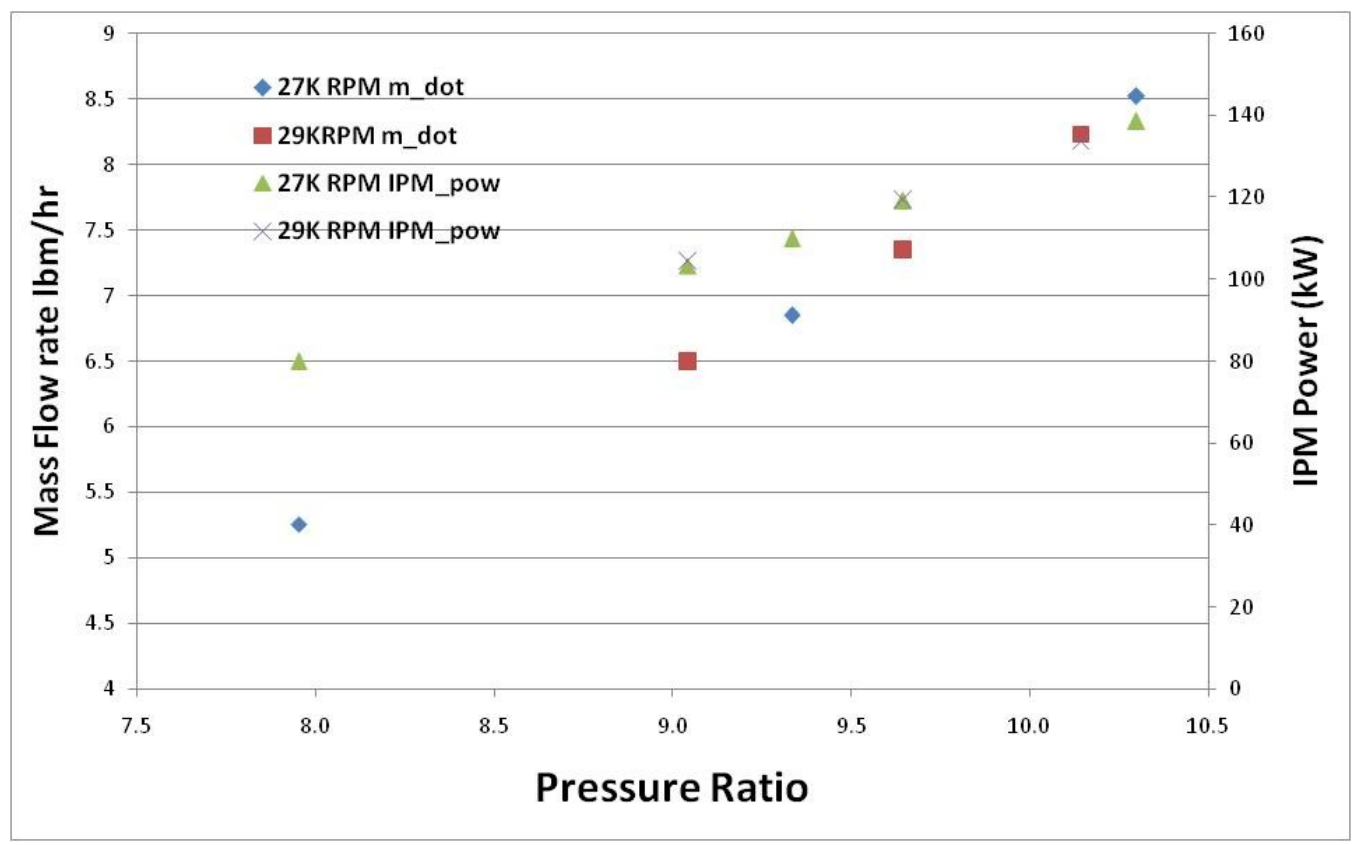

Figure 36. Predicted performance using the new working fluid

Based on Figure 36, it was predicted that by running the new fluid in the Clean Cycle the system would be able to reach the same generated power as R245fa.

\subsubsection{Material Compatibility}

Since the new fluid is developmental, the material compatibility with existing equipment and seals was a concern. The vendor provided GE with a compatibility table with elastomers that were tested at ambient conditions for 2 weeks. Section 3.2 provides a detailed assessment of the material compatibly study that was done at GE.

The material compatibility study that was done at GE with the Clean Cycle conditions, determined that for long-term operation, silicone O-rings in the system should be replaced. Due to the short duration (less than 2 weeks) of the experiment, the O-rings were not replaced and there was no sign of degradation. 


\subsection{GE CLEAN CYCLE SUBCRITICAL ORC TEST RIG}

The subcritical ORC test rig is the Clean Cycle. The Clean Cycle offers optimal ORC performance in the $140 \mathrm{~kW}$ range. The Clean Cycle is optimized specifically for the vast majority of small-scale heat-wasting applications.

The Clean Cycle is able to captures heat in an evaporator that boils the working fluid, producing vapor. The vapor expands, spinning the turbine which drives a generator and produces electricity. The vapor is cooled back to a liquid and pumped back to the evaporator to repeat the process.

Figure 37 shows a 3-D CAD drawing of the Clean Cycle. The system layout is shown in Figure 38.

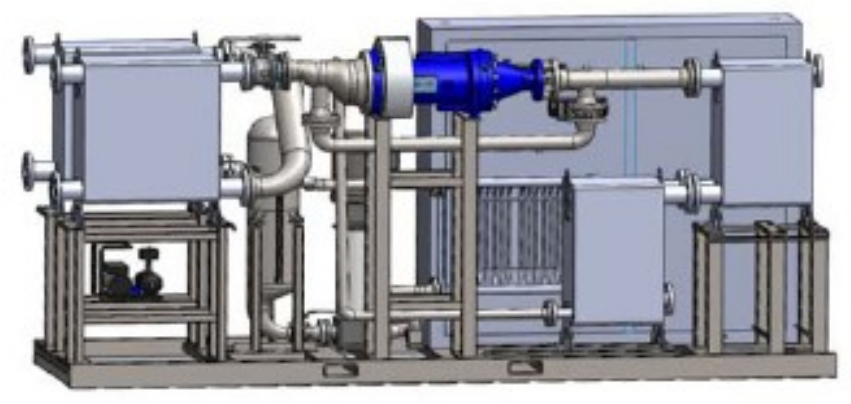

Figure 37. 3D Schematic of the Clean Cycle.

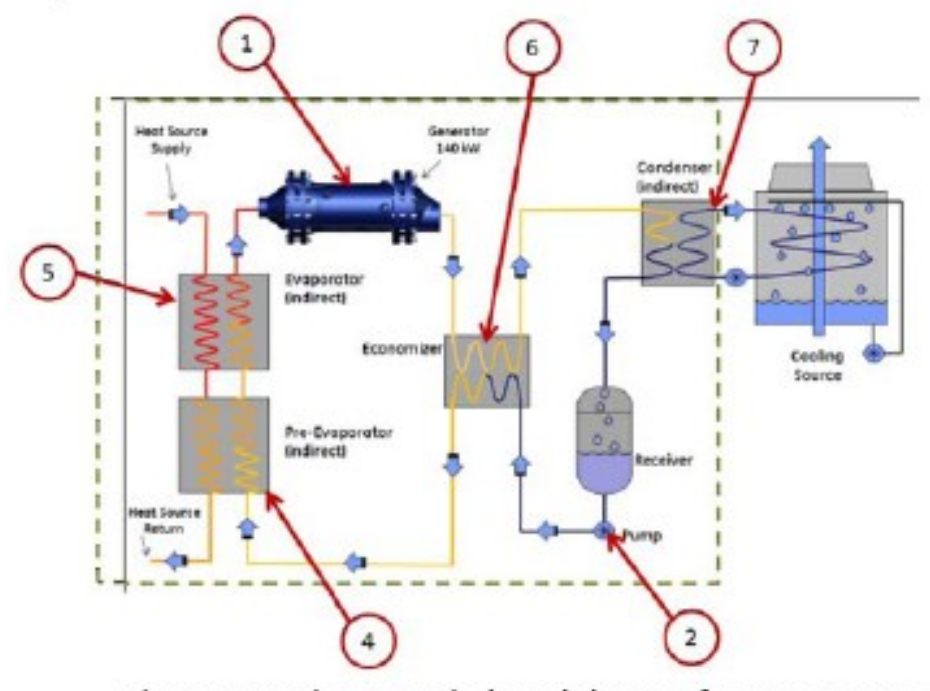

Figure 38. Clean Cycle breakdown of components: (1) generator, (2) circulation pump, (4) pre-evaporator, (5) evaporator, (6) economizer, and (7) condenser.

\subsubsection{Components of the Clean Cycle}

The Clean Cycle test rig is composed of the following seven major parts.[24]

\section{Integrated Power Module}

The Clean Cycle uses a hermetically sealed module containing both the turbine expander and the high speed rare earth permanent magnet generator. This approach eliminates seal systems with no possibility of leaks between rotating parts. There is no gear box or associated lubrication system required. The expander is a fully shrouded radial turbine designed for high-pressure ratio expansion. The expander is designed for minimal maintenance. 


\section{System Pump}

Each system utilizes a working fluid pump controlled by a variable frequency drive to circulate the fluid. This pump is a multiple stage liquid pump designed for low inlet pressure and high flow rates, driven by a 15 horsepower motor.

\section{Cold Plate}

Located in the single electronics box, the cold plate acts as a heat sink for the switching transistors related to the power electronics. The cold plate is cooled by liquid working fluid.

\section{Pre-Evaporator}

The pre-evaporator is a brazed plate heat exchanger where the liquid working fluid is first exposed to the source of waste heat and warmed. No phase changes occur in the pre-evaporator.

\section{Main Evaporator}

The evaporator is a brazed plate heat exchanger where the liquid working fluid has been pre-warmed by the pre-evaporator and is subjected to the waste heat source. This is where the working fluid changes phase from liquid to vapor and the vapor is superheated before entering the integrated power module.

\section{Economizer}

The economizer improves the efficiency of the system by utilizing the heat left in the working fluid after leaving the expander (integrated power module). The working fluid still has an enormous amount of heat, some of which is transferred to the pumped liquid in the economizer. This helps in two ways: 1) this heat would have otherwise been extracted in the condenser and 2) there is less heat required at the evaporator due to the liquid being pre-warmed.

\section{Condenser}

The optional condenser for indirect application is a brazed plate heat exchanger where working fluid leaving the expander is cooled from a vapor to a liquid.

\section{Receiver (Fluid Reservoir)}

The receiver is where the working fluid is stored as a liquid.

\subsubsection{Standard Operation of the Clean Cycle [24]}

The working fluid, R245fa, is in the receiver as a liquid at the condensing pressure and temperature. It enters the pump where the working fluid's pressure is raised to the evaporating pressure. The high pressure fluid passes through the cold plate removing heat from the single electronics box which warms the high pressure working fluid. Now the high pressure working fluid passes through a heat exchanger (economizer) to take heat out of the gas leaving the integrated power module. This improves system efficiency.

The working fluid is now a warmer, high pressure liquid. The working fluid then enters the pre-evaporator, where it removes a portion of the waste heat to increase the high pressure liquid temperature prior to entering the evaporator. When entering the evaporator, the high pressure fluid evaporates to a high-pressure vapor. The working fluid (now a vapor) enters the turbine of the integrated power module. The working fluid's pressure drops across the turbine to the condensing pressure, spinning the turbine (which is connected to the generator) in the process.

The driving force is the pressure difference across the turbine. The working fluid still has an enormous amount of heat, some of which is transferred to the pumped liquid in the economizer. This helps in two ways: 1) the heat would have otherwise been extracted in the condenser and 2) there is less heat required at the evaporator due to the liquid being pre-warmed. 
The working fluid (still a vapor) then flows to the condenser where heat is extracted and the working fluid condenses to a liquid. The low pressure, liquid working fluid drains back to the receiver and is ready to be pumped to high pressure to repeat the cycle.

Although the basic operation of the system remained the same for the new working fluid, the control logic was adjusted to incorporate differences in thermophysical properties. 


\subsection{EXPERIMENTAL PLAN}

Based on the background investigations and the predicted results in Figure 42, the team generated a design-of-experiment test matrix. A design of experiment ensures that a systematic, rigorous technique was used while constraint of a minimal expenditure of engineering runs. The three factors that were examined are outlined in Table 13.

Table 13. R245fa and new fluid test matrix for the subcritical Clean Cycle.

\begin{tabular}{c|c|c|c}
\multicolumn{1}{c}{ Parameter } & Low & $\begin{array}{c}\text { Normal } \\
\text { Operating } \\
\text { Condition }\end{array}$ & High \\
\hline $\begin{array}{c}\text { Generated Power } \\
(\mathrm{kW})\end{array}$ & 75,90 & 105,120 & 130,140 \\
\hline Temperature ( C) & 127 & 131 & 145 \\
\hline Turbine Speed (rpm) & 26,000 & 27,500 & 29,000 \\
\hline
\end{tabular}

Figure 39 shows sections of the Clean Cycle rig and Figure 40 shows the method used to change the working fluid. Figure 40 shows a $1000 \mathrm{lb}$ tank of the new working fluid on a scale, along with a transfer pump. This scale was used to weigh the fluid transfer to the rig.

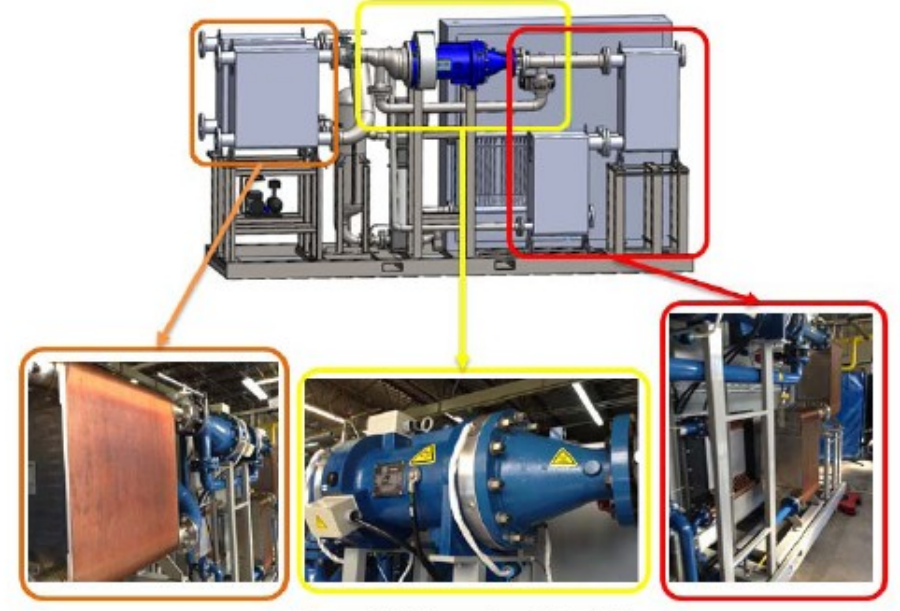

Figure 39. Clean Cycle test rig.

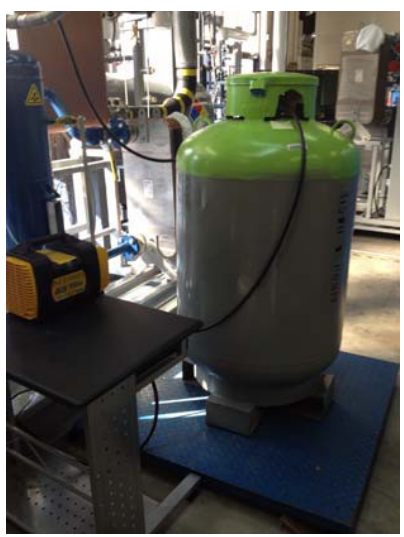

Figure 40. Tank of the new working fluid 


\subsection{EXPERIMENTAL OBSERVATIONS, RESULTS AND COMPARISONS}

During the experiments with R245fa and the new working fluid, the dynamic behavior of the cycle was monitored. Both fluids have similar stability during the start-up, steady-state, and shut-down. In fact, the start-up and shut-down for experiments using the new fluid were observed to be slightly faster.

From a material compatibility standpoint, the O-rings and seals were able to maintain their structural integrity during the experimental runs with both fluids. Further details on the material compatibility are discussed in Chapter 3.

Due to the temperature and pressure properties of the new fluid, for the same inlet temperatures, the test unit operated a slightly lower expander inlet pressure (approximately 1 bar).

Measurements were taken before and after the turbine expander and the experimental data showed an improved expander performance for the new fluid. The overall pressure ratio of the turbine expander was higher (see Figure 41), which implied an overall higher efficiency. Indeed, the data did support the theory and the average improvement was observed to be greater than five percentage points.

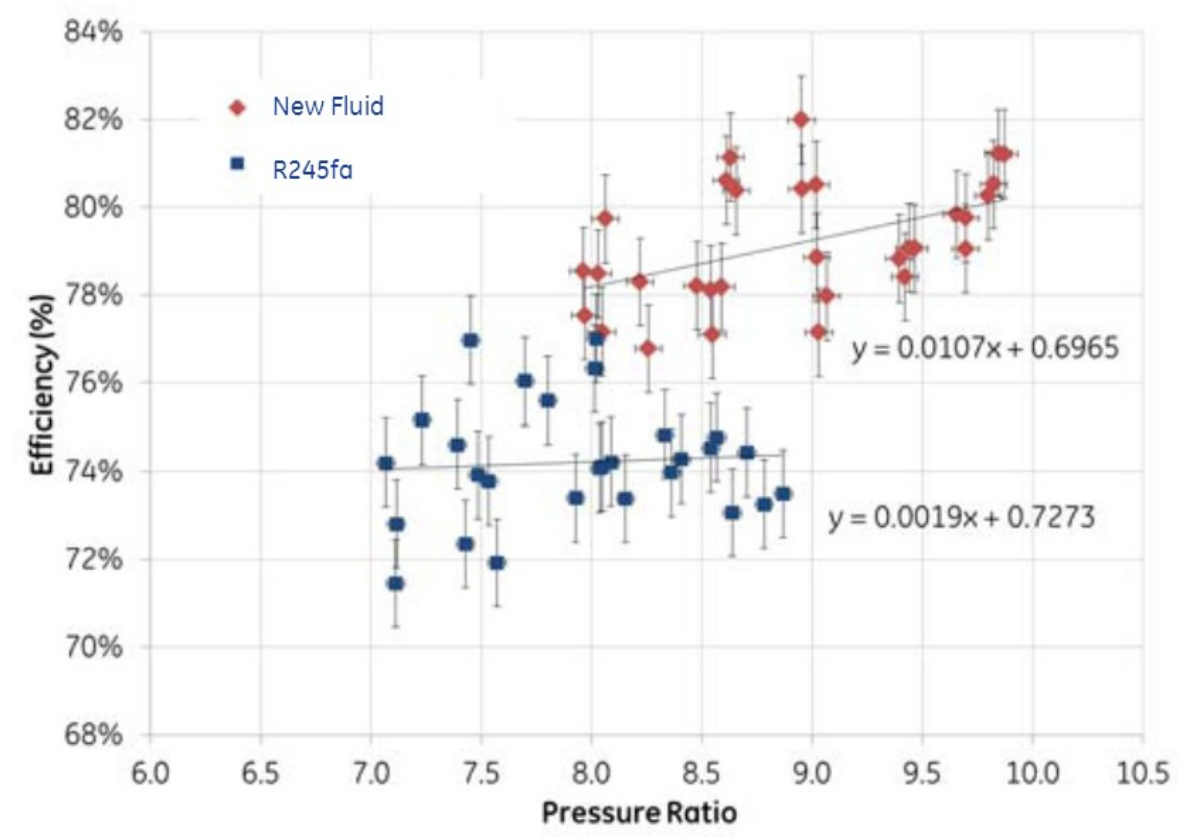

Figure 41. Turbine efficiency versus pressure ratio of R245fa and the new fluid

The data also showed that some existing components were oversized in the test unit. This was particularly evident when using the new working fluid. This was due to a fluid property difference that decreases the excess superheat in the fluid leaving the turbine.

The component that was particularly oversized was the evaporator. Figure 42 shows a side-by-side comparison of the efficiency versus heat in the pre-evaporator and the evaporator.

The pre-evaporator and evaporator GEA (WP-10 series) plate heat exchanger specifications are outlined in Table 14. The heat transfer $(\mathrm{Q})$ was calculated by using the equation:

$Q=U \cdot A \cdot \Delta T$ 
where the overall heat transfer coefficient (U) was a value provided by GE Heat Recovery Solution and was based on $\mathrm{R} 245 \mathrm{fa}$ properties. $\Delta \mathrm{T}$ is the temperature difference between the outlet and inlet of the evaporator and the area was calculated using the equation:

$$
A=(0.386 \cdot 0.875) \cdot n_{\text {plates }}=0.338 \cdot n_{\text {plates }}\left[\mathrm{m}^{2}\right]
$$

where the values of $0.386 \mathrm{~m}$ and $0.875 \mathrm{~m}$ are the width and height of the heat exchanger.[26]

Table 14. Design heat exchanger information.[25,26]

\begin{tabular}{l|c|r|r|r} 
Components & $\begin{array}{c}\text { Transfer Coefficient } \\
\left(\mathrm{W} / \mathrm{m}^{2}-\mathrm{C}\right)\end{array}$ & $\begin{array}{c}\text { \# of } \\
\text { plates }\end{array}$ & $\begin{array}{c}\text { Area } \\
\left(\mathrm{m}^{2}\right)\end{array}$ & $\begin{array}{c}\text { UA } \\
\left(\mathrm{kW} /{ }^{\circ} \mathrm{C}\right)\end{array}$ \\
\hline Pre-evaporator & 1090 & 200 & 66.9 & 72.9 \\
\hline Evaporator & 1100 & 300 & 100.6 & 110.7 \\
\hline
\end{tabular}
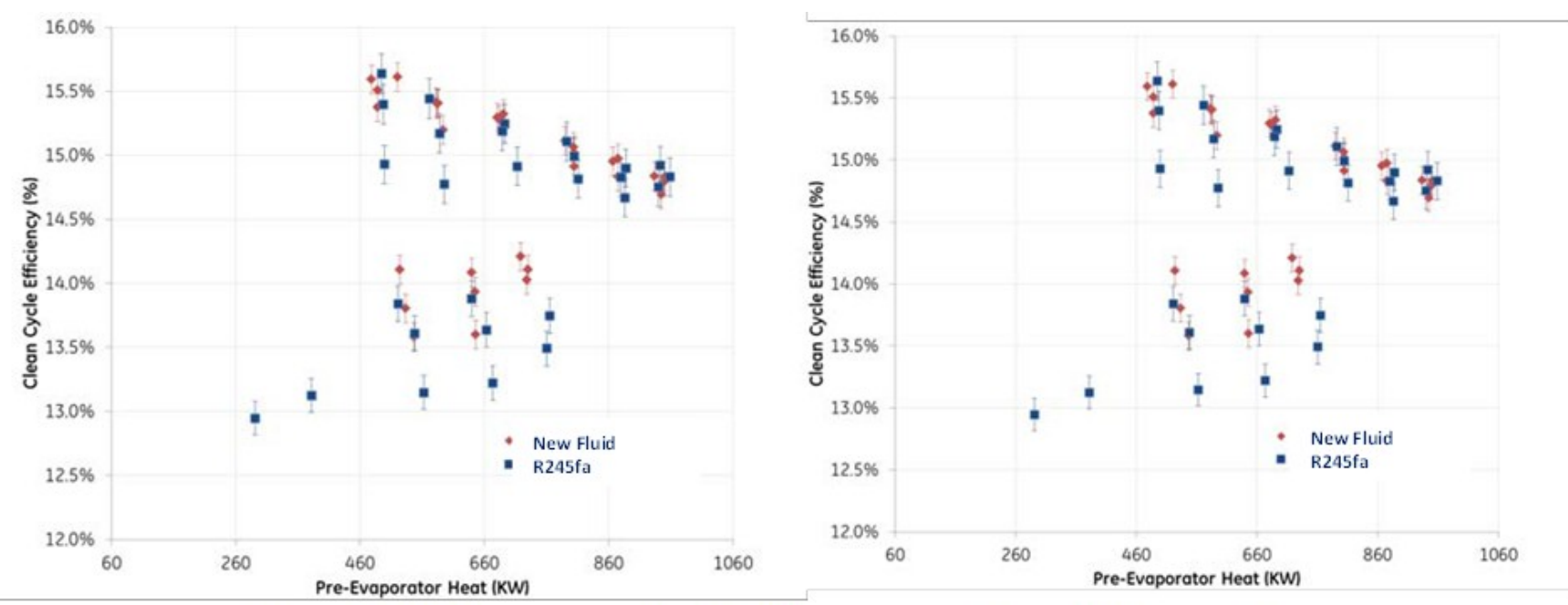

Figure 42. Efficiency versus heat for (A) pre-evaporator and (B) evaporator.
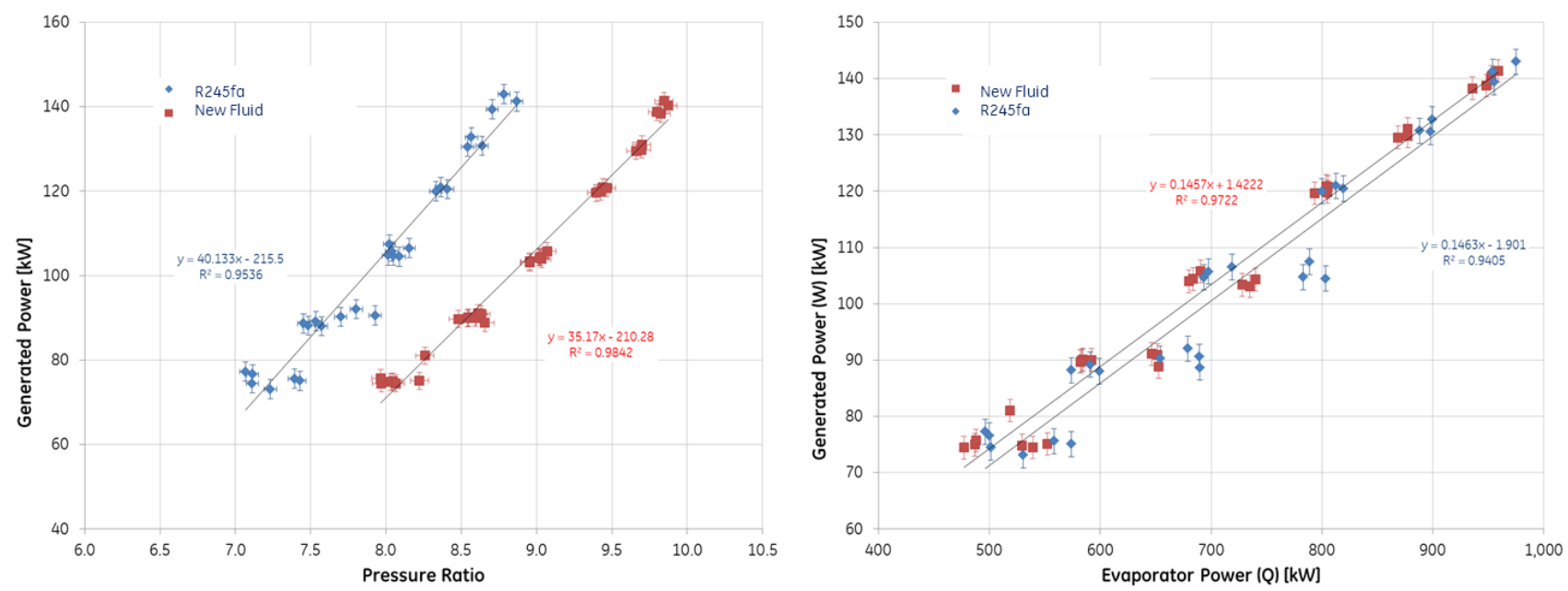

Figure 43. Generated power versus (A) pressure ratio and (B) evaporator inlet power for R245fa and the new fluid. 
The generated power was evaluated against pressure ratio and evaporator power was plotted in Figure 43. In Figure 43A, the pressure ratio measured matched the predicted pressure ratio in Figure 36. Taking into account the variance in the data, the data shows that for the same power the new fluid does result in a higher pressure ratio.

The overall Clean Cycle system efficiency was evaluated between the two fluids in Figure 44. In Figure 44, there is a natural grouping of data as a result of the high and low temperature experimental runs that were performed. Therefore, the lower temperature runs $\left(127^{\circ} \mathrm{C}\right)$ had a lower cycle efficiency compared to the higher temperature $\left(145^{\circ} \mathrm{C}\right)$. The Clean Cycle efficiency range narrowed when using the new fluid to $13.6-15.6 \%$, where the R245fa range was $12.9-15.6 \%$.

In both Figure 43B and Figure 44, the data indicates that the new fluid slightly outperforms R245fa. However, after conducting a statistical exercise "2-sample T-test", the results show that there is not a significant statistical difference. Therefore, using the new fluid as the working fluid matches the performance of R245fa.

Table 15 outlines the data used in the 2-sample T-Test, assessing efficiency of the Clean Cycle, based on working fluid. The objective was to perform a hypothesis test and compute a confidence interval of the difference between two population means (in this exercise, the efficiency of the Clean Cycle using R245fa and the new fluid) when the population standard deviations ( $\sigma s)$ are unknown.

A confidence interval of $95 \%$ was found using the difference in means $(\mu)$ of the efficiency of $\mathrm{R} 245 \mathrm{fa}$ and the new fluid. The hypothesis $\left(\mathrm{H}_{\mathrm{o}}\right)$ was that the efficiency was equal between the two populations, and the null hypothesis $\left(\mathrm{H}_{1}\right)$ was that they were different:

$$
\mathrm{H}_{0}: \mu \mathrm{R} 245 \mathrm{fa}=\mu \mathrm{NewFluid} \text { versus } \mathrm{H}_{1}: \mu \mathrm{R} 245 \mathrm{fa} \neq \mu \text { NewFluid }
$$

The results of test determined that R245fa and the new fluid had statistically the same Clean Cycle efficiency.

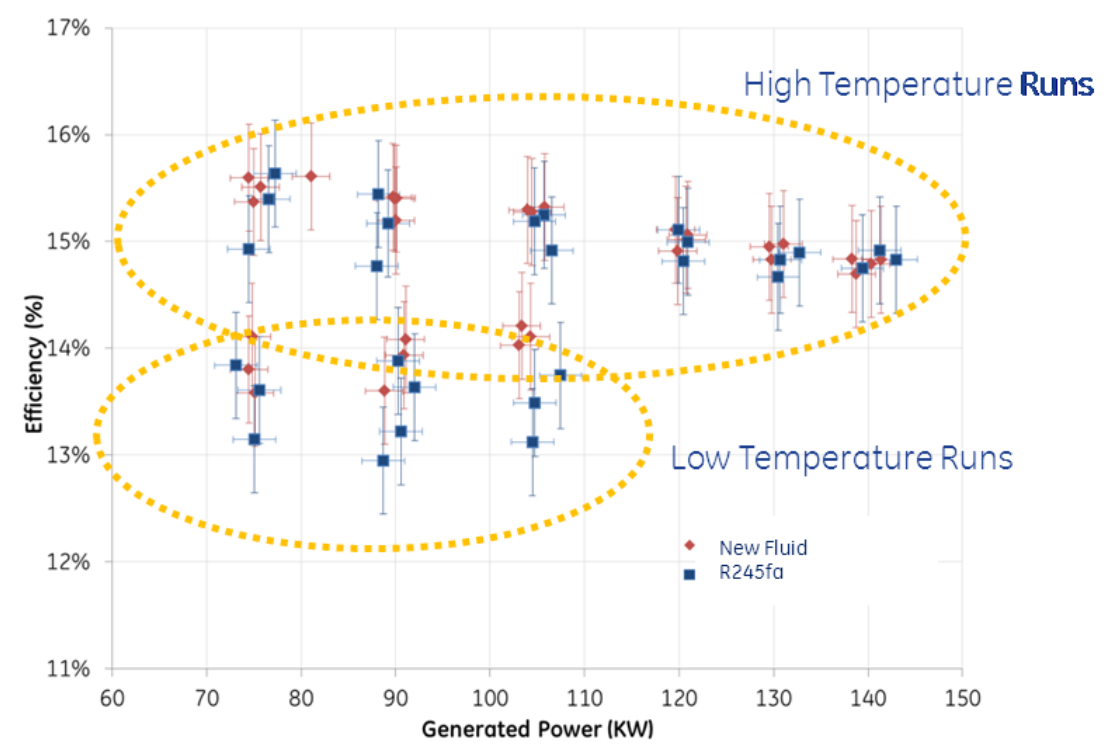

Figure 44. Efficiency versus generated Power for R245fa and the new fluid.

Table 15. Data used in the 2-sample T-test

\begin{tabular}{|c|c|c|c|c|}
\hline & $\begin{array}{c}\text { Sample Size } \\
\text { (n) }\end{array}$ & Mean & $\begin{array}{c}\text { Standard } \\
\text { Deviatio } \\
n\end{array}$ & $\begin{array}{l}\text { Standard } \\
\text { Error Mean }\end{array}$ \\
\hline Efficiency_R245fa & 18 & 0.14933 & 0.00297 & 0.00070 \\
\hline Efficiency_newfluid & 22 & 0.15127 & 0.00310 & 0.00066 \\
\hline
\end{tabular}




\subsubsection{Statistical Data Variance}

The data was collected when the unit stabilized and reached steady state. Steady state was determined to be the generated power that varied less than $\pm 5 \mathrm{KW}$ for a 5 minute period.

The data was analyzed using multiple parameters.

Table 16. Error analysis for the new fluid and R245fa.

\begin{tabular}{|c|c|c|c|c|}
\hline \multicolumn{5}{|c|}{ New Fluid } \\
\hline & & $\begin{array}{l}\text { Power Output } \\
\text { (HP) }\end{array}$ & Turbine Efficiency & Pressure Ratio \\
\hline \multirow[t]{2}{*}{ High power generation } & Standard deviation & 2.02 & 0.00 & 0.02 \\
\hline & Average & -194.8 & 0.79 & 10.02 \\
\hline \multirow[t]{2}{*}{ Normal power generation } & Standard deviation & 1.28 & 0.00 & 0.05 \\
\hline & Average & -123.45 & 0.78 & 8.49 \\
\hline \multirow[t]{2}{*}{ Low power generation } & Standard deviation & 1.55 & 0.01 & 0.06 \\
\hline & Average & -97.03 & 0.74 & 7.93 \\
\hline \multicolumn{5}{|c|}{ R245fa } \\
\hline & & $\begin{array}{l}\text { Power Output } \\
\text { (HP) }\end{array}$ & Turbine Efficiency & Pressure Ratio \\
\hline \multirow[t]{2}{*}{ High power generation } & Standard deviation & 2.25 & 0.01 & 0.03 \\
\hline & Average & -174.63 & 0.72 & 8.85 \\
\hline \multirow[t]{2}{*}{ Normal power generation } & Standard deviation & 1.49 & 0.00 & 0.03 \\
\hline & Average & -134.55 & 0.74 & 8.04 \\
\hline \multirow[t]{2}{*}{ Low power generation } & Standard deviation & 1.36 & 0.00 & 0.04 \\
\hline & Average & -102.1 & 0.74 & 7.03 \\
\hline
\end{tabular}

Table 16 outlines an example of the average value and standard deviations for three cases (low, medium, and high data set). This was done for both the new fluid and R245fa.

\subsection{ANALYSIS AND COMPARISON}

The modeling effort downselected the new fluid as the working fluid that best matched the performance of R245fa for the ORC conditions in the Clean Cycle. The experimental results validated the Aspen HYSYS modeling work that was conducted and as predicted, the new fluid performed at least as well as R245fa. 
To compare the state points between the working fluids, Figure 45 and Figure 46 show the states points on a Temperature-Pressure and Pressure-Enthalpy plot, respectively. Figure 45 and Figure 46 show that the new fluid is operated at 1 bar lower than R245fa, which was also predicted in the Aspen HSYSY model.

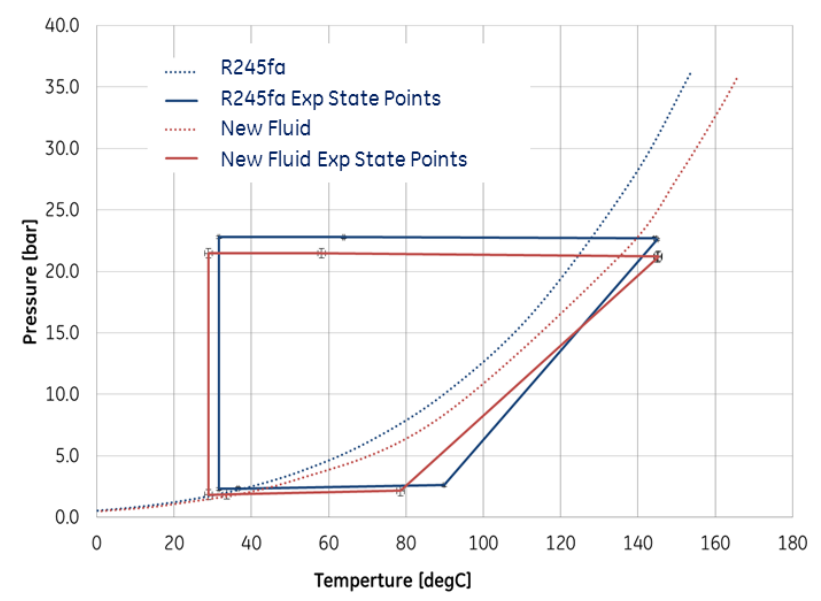

Figure 45. Pressure-temperature plot. Experimental state points of the new fluid and R245fa

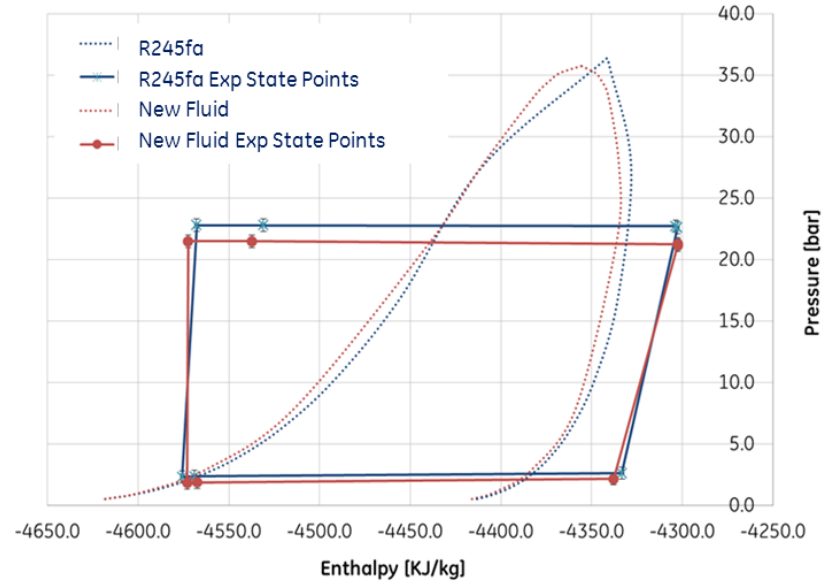

Figure 45. Pressure-Enthalpy plot.

Experimental state points of the new fluid and R245fa

In conclusion, the new fluid has low global warming properties and is a non-flammable working fluid with similar performance as R245fa. As a drop-in replacement fluid for R245fa, it is at least as good as R245fa in terms of performance and stability.

The results of the experiments also revealed opportunities for system optimization for both R245fa and the new fluid. In particular, downsizing the evaporator could lead to system efficiency improvements. This would have the most impact on performance with the new fluid. 


\section{Supercritical Experiment}

\subsection{RIG CYCLE DESIGN}

A demonstration test rig was designed and built to validate that the thermodynamic state points prescribed by the optimized model matched predicted output power.

Results of the comparative modeling study showed that a supercritical cycle operating with R245fa as the working fluid was the most efficient and cost effective means of converting a $200^{\circ} \mathrm{C}$ thermal resource to electrical power. Because of its global warming potential, we anticipate that R245fa will be either phased out or heavily taxed in the next 10 years. A relatively new fluid that has recently been introduced by a vendor for ORC application, has similar thermodynamic properties to R245fa without the negative environmental impacts. We therefore decided to build a supercritical cycle designed for this new working fluid and $200^{\circ} \mathrm{C}$ as the thermal resource.

An additional objective of the demonstration phase of the program was to show that this new fluid is a functional equivalent to R245fa and can replace R245fa without any hardware changes. This additional objective was demonstrated in a subcritical cycle using commercial hardware. A 140kW Clean Cycle II unit was purchased from GE Heat Recovery Solutions. The Clean Cycle nominally operates with R245fa as the working fluid in a commercial environment. We tested the commercial unit with R245fa under a variety of operating conditions to establish baseline performance. We then removed the R245fa and replaced it with the new fluid. The same operating conditions were rerun to show that the new fluid performs at least as well as R245fa in a subcritical cycle.

The thermodynamic state points in the subcritical Clean Cycle were not chosen by the model developed in this program. Moreover, the Clean Cycle could not operate as a supercritical cycle, which our model determined to be the best use of a $200^{\circ} \mathrm{C}$ resource. We therefore still needed to build a separate supercritical demonstration to validate the model.

The size of the test rig was chosen to be $5 \mathrm{~kW}$ of equivalent turbine output power. In an analysis of expected heat losses, this size was determined to be large enough to attain high confidence measurements in spite of the losses.

Figure 47 shows the temperature-entropy diagram for the chosen supercritical cycle with the new working fluid. A circulation pump pressurizes the fluid to a supercritical pressure, 48 bar, at State 1 . The fluid then warms in an evaporator to a supercritical temperature, $182.5^{\circ} \mathrm{C}$, at State 2 . The temperature at State 2 is approximately $10 \%$ higher than the critical temperature of the new fluid. In a power generating cycle, an expander would extract thermal energy from the fluid between States 2

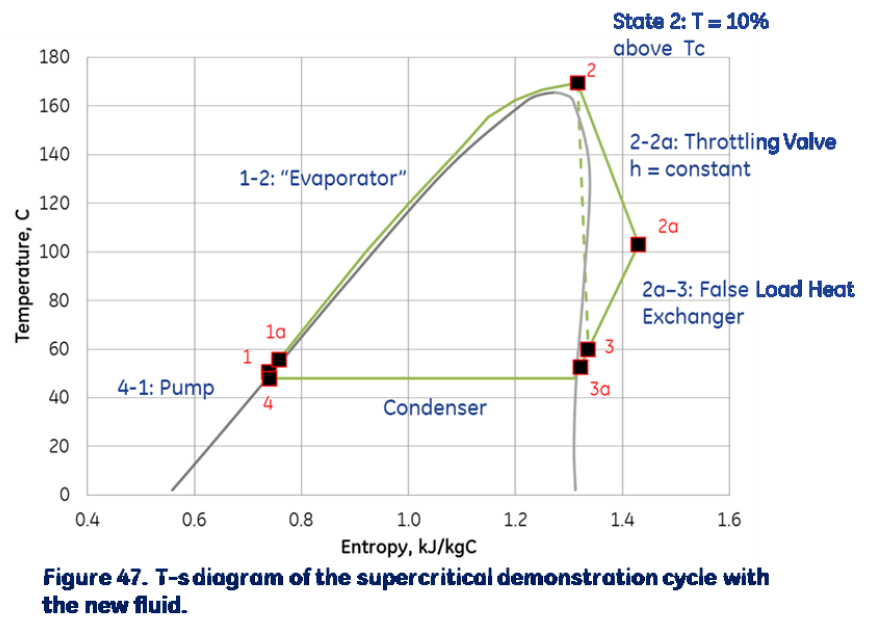
and 3 and convert it to mechanical energy. A supercritical expander does not yet exist for this fluid, and we therefore had to devise a thermodynamically functional equivalent. An isenthalpic valve followed by a heat exchanger with no pressure drop would be the ideal functional equivalent of a turbine for a demonstration rig. In the realistic case of a valve that is not perfectly isenthalpic and a proceeding heat exchanger that 
has a measurable pressure drop, the same State 3 can be reached as would be expected with an $85 \%$ efficient expander. The heat removed in the false load heat exchanger between States $2 \mathrm{a}$ and 3 is slightly less than the enthalpy change between States 2 and 3 . Heat losses account for the difference. State 3 is a slightly superheated vapor state at approximately 3 bara and $63^{\circ} \mathrm{C}$. A condenser between States 3 and 4 brings the fluid back to a subcooled liquid state upstream of the circulation pump. States $3 \mathrm{a}$ and 1a are shown in Figure 47 to indicate where a recuperator might be used. Recuperation was not a cost effective addition to the cycle design and was omitted.

Table 17 indicates the state points predicted by the model to be verified. In the design of an ORC for geothermal application, it is important to note the temperature and pressure at State 4 . On a hot day in many places where geothermal power can be harvested, the air temperature can be as high as $30^{\circ} \mathrm{C}$. In order for air-cooled condensing to be practical, the fluid chosen for the thermodynamic cycle needs to condense near $50^{\circ} \mathrm{C}$ in order to make the air-cooled condenser manageably sized. At this temperature, the saturation pressure needs to be above one atmosphere to prevent air infiltration. Condensation pressures above 5 bara are generally unattractive from performance and economic standpoints. At $52^{\circ} \mathrm{C}$, the new fluid condenses at approximately 3 bara. At State 4 , the fluid has $5^{\circ} \mathrm{C}$ of subcooling.

Table 17. Supercritical state points for the new fluid.

\begin{tabular}{|llccccc|}
\hline & & 1 & 2 & $2 a$ & 3 & 4 \\
Vapor Fraction & & 0 & 1 & 1 & 1 & 0 \\
Temp & $\mathrm{C}$ & 51.28 & 182.50 & 108.46 & 62.86 & 47.83 \\
Pressure & $\mathrm{bar}$ & 47.80 & 46.68 & 3.61 & 3.05 & 2.73 \\
Mass Flow & $\mathrm{kg} / \mathrm{s}$ & 0.14 & 0.14 & 0.14 & 0.14 & 0.14 \\
Volume flow & $\mathrm{m} 3 / \mathrm{h}$ & 0.42 & 1.26 & 31.67 & 32.48 & 0.42 \\
Mass Density & $\mathrm{kg} / \mathrm{m3}$ & 1188 & 397 & 16 & 15 & 1180 \\
Mass Enthalpy & $\mathrm{kJ} / \mathrm{kg}$ & -4772 & -4540 & -4540 & -4579 & -4777 \\
Mass Entropy & $\mathrm{kJ} / \mathrm{kg}-\mathrm{C}$ & 0.74 & 1.32 & 1.44 & 1.34 & 0.74 \\
Conductivity & $\mathrm{W} / \mathrm{mC}$ & 0.06 & 0.03 & 0.02 & 0.01 & 0.06 \\
Heat Capacity & $\mathrm{kJ} / \mathrm{kgC}$ & 1.21 & 3.27 & 0.92 & 0.84 & 1.23 \\
CV & $\mathrm{kJ} / \mathrm{kgC}$ & 0.81 & 0.99 & 0.83 & 0.76 & 1.16 \\
Cp/CV & & 1.49 & 3.30 & 1.10 & 1.11 & 1.05 \\
Viscosity & $\mathrm{CP}$ & 0.1860 & 0.0309 & 0.0132 & 0.0114 & 0.1885 \\
\hline
\end{tabular}




\subsection{SUPERCRITICAL TEST RIG DESCRIPTION AND OPERATION}

Figure 48 is a sketch of the major components in the refrigerant loop. This sketch allowed us to begin specifying parts and develop a series of process and instrumentation diagrams from which the test rig was built.

A process and instrumentation diagram was drawn for each of the three fluid loops in the test rig:

1. The refrigerant or working fluid loop

2. The heating oil loop, which interfaced with the evaporator heat exchanger

3. The cooling water loop, which interfaced with the false load and

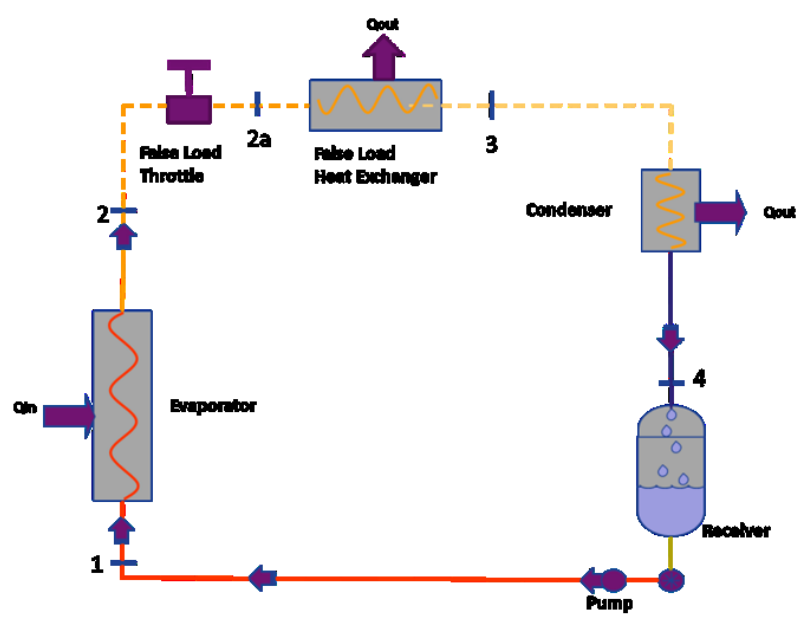

Figure 48. Sketch of the major components in the refrigerant loop. condenser heat exchangers

A Labview code was written to communicate with the pump, heater, control valves, and all instruments. Feedback control over the pump, heater, and valves was included in the Labview code, but the automation was optional; controlling these components in Labview without feedback control was often preferable during the testing phase.

Figure 49 shows the process and instrumentation diagram for the refrigerant loop. The names of the major components in the refrigerant loop are:

1. $\quad$ Feed Pump 100

2. Evaporator 200

3. Expansion Valve 300

4. False Load Heat Exchanger 400

5. Condenser 500

6. Receiver Tank 600

The fluid moved clockwise around the loop. Starting with Feed Pump 100, the components and instruments shown will be described in order.

The Feed Pump 100 was a diaphragm pump driven by a 5 horsepower motor. Teflon diaphragms and elastomers were ultimately chosen for material compatibility reasons. The Feed Pump 100 was typically controlled by the operator in Labview, but feedback control based on the fluid mass flow rate was optional. The downstream Feed Pump 100 was an isolation hand valve, which was installed to isolate and service the pump as needed. A bypass line going directly back to the Receiver Tank 600 was available but not used during normal operation of the test rig. Downstream of the bypass was a coriolis flow meter, FT 100, whose primary purpose was to accurately measure mass flow. A high accuracy pressure transducer and RTD preceded the Evaporator 200. These temperature and pressure measurements were used to validate State 1 as predicted by the thermodynamic model.

Following the Evaporator 200 was another coriolis meter, FT-State 2. The primary purpose of this meter was to accurately measure the density of the fluid at State 2, which had been designed to be very near the critical point. Following FT-State 2 were another high accuracy pressure transducer and RTD. Density, temperature, and pressure were used to verify State 2 as predicted by the model. 


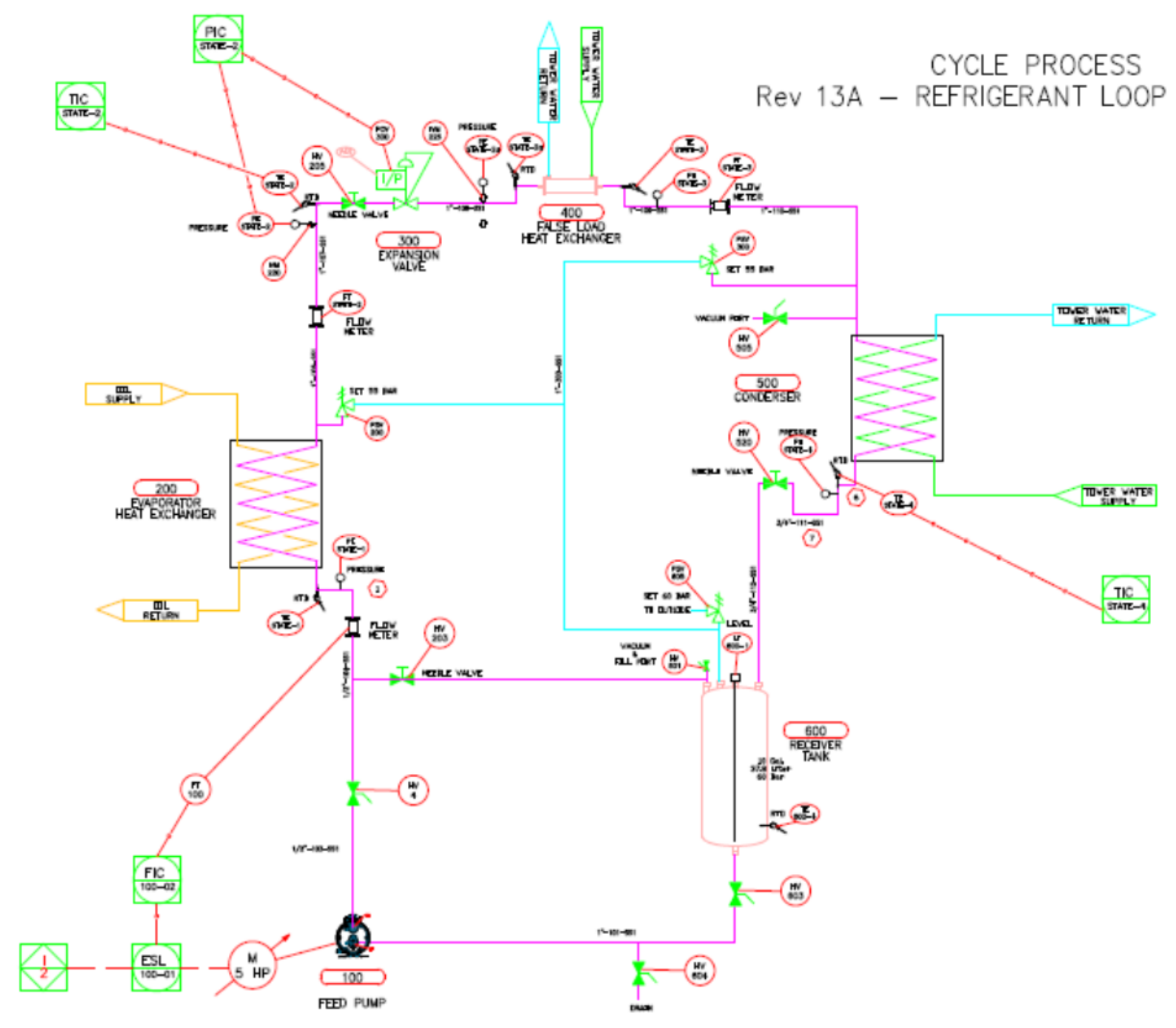

Figure 49. Process and instrumentation diagram for the refrigerant loop.

The Expansion Valve 300 was a pressure control valve designed to drop fluid pressure from 48 bar to 3 bar. The Expansion Valve 300 had been controlled in Labview without feedback control. However, feedback control based on the pressure at State 2 was an option that the operator could exercise. Immediately upstream of the Expansion Valve 300 was a needle valve that had been left completely open during operation of the test unit. It had been installed to potentially serve as a manually controlled equivalent of the Expansion Valve 300. State 2a is an intermediate superheated vapor state that had been verified by a high accuracy pressure transducer and RTD.

State 3 was a superheated vapor state near saturation conditions that was verified by measurements of pressure, temperature, and density. The density measurement was made with another coriolis meter, FT-State 3. Between States 2a and 3 was the False Load Heat Exchanger 400. The majority of the enthalpy change of the fluid between States 2 and 3 was expected to occur between States 2a and 3, with the balance being heat losses through insulation.

The Condenser 500 brought the working fluid back to a subcooled liquid state. State 4, downstream of the condenser and upstream of the Feed Pump 100, was verified using another high accuracy pressure transducer and RTD. A network of pressure relief lines are indicated but were 
never used. The pressure relief valves on these lines were set to open if pressures in the refrigerant loop ever exceeded 55 bar.

All three heat exchangers were constructed out of stainless steel welded plates. The evaporator was $10 \mathrm{ft}^{2}$, the false load was $6 \mathrm{ft}^{2}$, and the condenser was $24 \mathrm{ft}^{2}$.

The thermophysical properties of the new fluid are not as well-known as they are for water and heating oil. For this reason, calorimetry calculations were performed on the heating and cooling loops. Temperature, pressure, and density measurements were made on the refrigerant loop to verify state points only. Heat input was calculated using the measured mass flow rate and temperature change of oil as it passed through the Evaporator 200 and transferred heat to the the new fluid. Turbine output power was estimated using the measured mass flow rate and temperature change of cooling water as it passed through the False Load Heat Exchanger 400. The low pressure in the system was controlled by the cooling load of the condenser.

Figure 50 shows the process and instrumentation diagram for the heating oil loop. As indicated in Figure 50, the oil loop interfaced with the refrigerant loop via the Evaporator 200. The oil circulated clockwise. The oil heater was an off-the-shelf $48 \mathrm{~kW}$ oil heater with a temperature controller. The temperature of the oil upstream of the temperature control valve, TCV 210, was therefore controlled by the separate temperature controller on the oil heater. During the supercritical test runs, the oil temperature was set to approximately $191^{\circ} \mathrm{C}$ in order to attain the desired refrigerant temperature of $\sim 182.5^{\circ} \mathrm{C}$ at State 2 . The TCV 210 was optionally controlled by a feedback loop with the refrigerant temperature at State 2 as the input. In practice, the feedback control loop was typically disabled; the operator could set the position of the TCV 210 via Labview. Downstream of the TCV 210 was flow meter FT 200, whose primary purpose was to accurately measure the mass flow rate of oil flowing through the Evaporator 200. A high accuracy pressure transducer and RTD were located at the inlet and exit ports of the Evaporator 200. The temperature and mass flow rate measurements were used to estimate the heat absorbed by the working fluid. Pressure relief lines are indicated but were never used. In the case of pressures in the oil lines above 5 bar, the pressure relief valves shown would open and oil would flow into a 
catch drum.

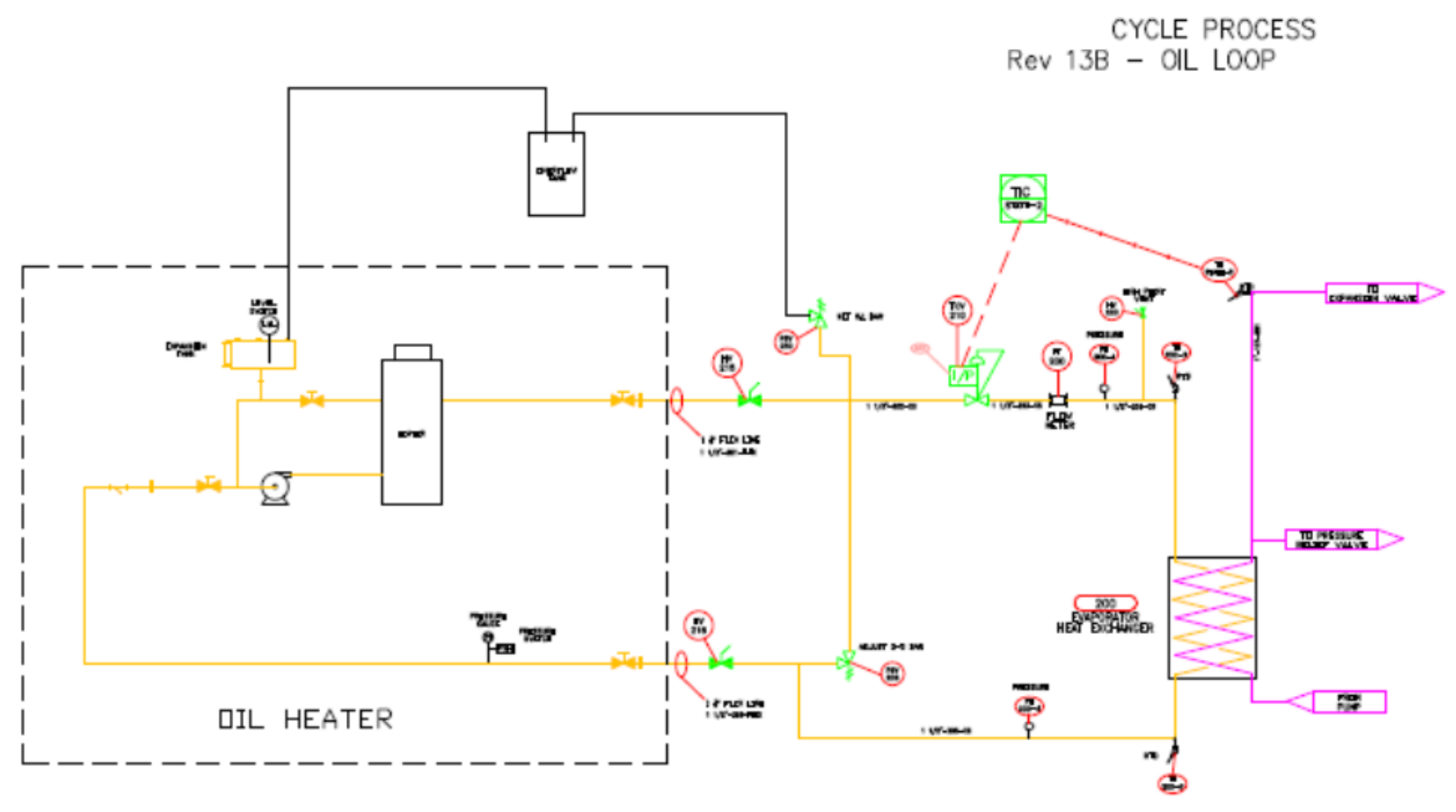

Figure 50. Process and instrumentationdiagram for the heating oil loop. 
Figure 51 shows the process and instrumentation diagram for the heating oil loop. As shown, the cooling water loop interfaced with the refrigerant loop via the False Load Heat Exchanger 400 and Condenser 500. Instrumentation on the two sets of cooling water lines mirrored each other. The inlet lines are shown in green and the exit lines are shown in blue. Flow meters FT 400 and FT 500 served to accurately measure the mass flows of cooling water into the False Load Heat Exchanger 400 and Condenser 500 respectively. RTDs located at the inlet and exit ports made accurate temperature measurements so that we could estimate the cooling load of each heat exchanger. This test rig was designed such that the cooling load of the False Load Heat Exchanger 400 was similar to the power output of a turbine between States 2 and 3. The cooling load of the Condenser 500 was desired to demonstrate the energy balance of the refrigerant loop and thus the confidence of the calorimetry estimates. A temperature control valve was located on each exit line. The TCV 400 was optionally feedback controlled by the refrigerant temperature at State 3 .

Similarly, the TCV 500 was optionally feedback controlled by the temperature of the refrigerant at State 4. Because the fluid was near saturation conditions at State 4, the temperature and pressure were coupled and the condenser duty set the low pressure of the refrigerant loop. In practice, the position of each valve was controlled by the operator in Labview.

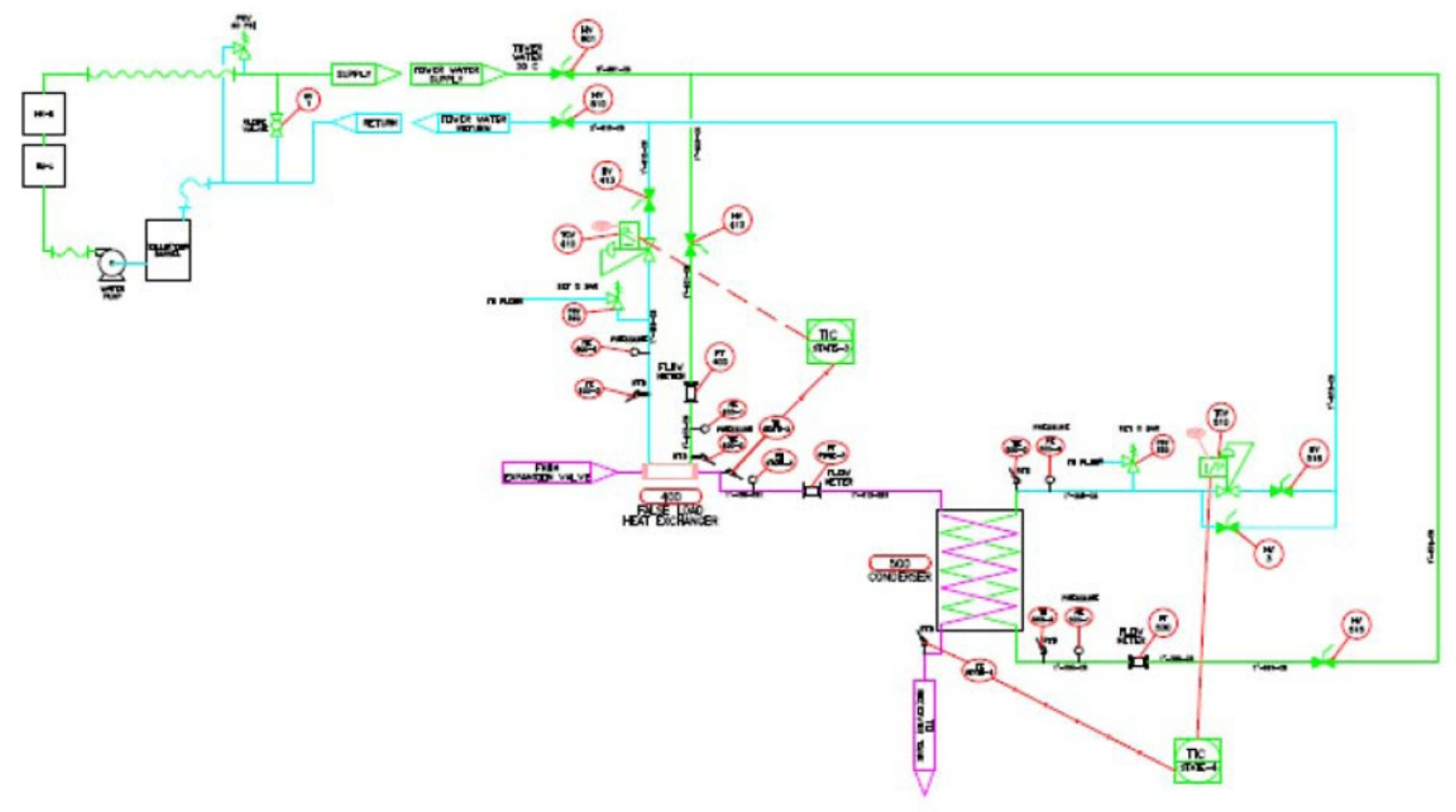

Figure 51. Process and instrumentation diagram for the cooling water loop. 
Figure 52 is a process and instrumentation diagram showing how the refrigerant loop was charged. The vacuum port of the refrigerant loop was located at a high spot on the test rig. Vapor was pulled from this port by a transfer pump which concurrently pressurized a refrigerant source tank. Liquid refrigerant flowed from the refrigerant source tank into the refrigerant lines of the test rig via the drain port. The refrigerant source tank was placed on a pallet scale (not shown) so that a calculated mass of refrigerant could be transferred. Figure 53 shows how the refrigerant was purged from the system.

In order to purge the system of the refrigerant, a cylinder of pressurized nitrogen was connected to the vacuum port on the test rig and the refrigerant source tank was connected to the drain port. The nitrogen pushed the refrigerant out of the refrigerant lines of the test rig and back into the source tank.

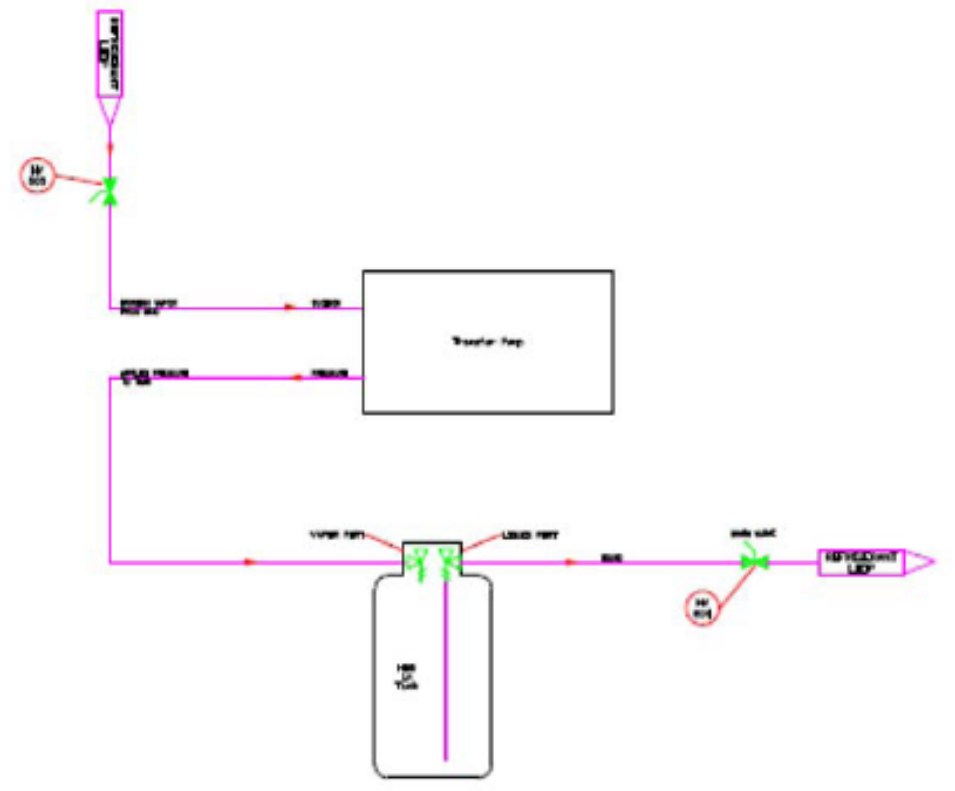

Figure 52. Process and instrumentation diagram indicating how the refrigerant lines were charged.
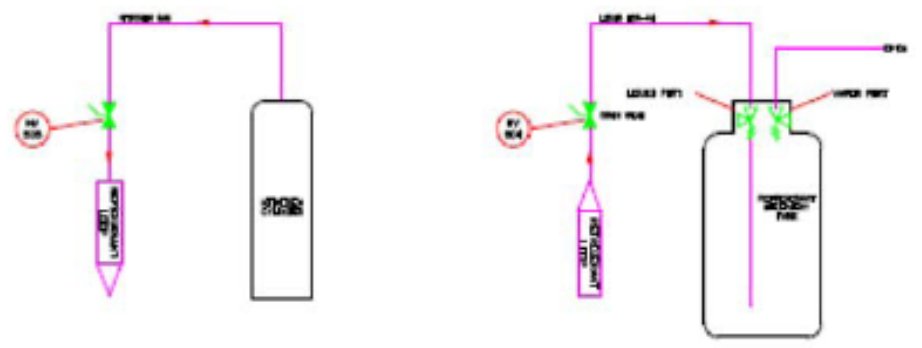

Figure 53. process and instrumentation diagram indicating how the refrigerant was removed from the system. 


\subsection{HEAT EXCHANGER SIZING FOR THE SUPERCRITICAL ORC TEST RIG}

There are three heat exchangers in the supercritical ORC test rig: the heater, the false load heat exchanger, and the condenser. The heater was used to heat the fluid with a thermal oil loop. The heat sink of the false load heat exchanger and the condenser was city tap water. Figure 54 and Figure 55 show the heater (HX1), false load heat exchanger (HX4), and condenser (HX5). Due to the fact that a new fluid is being used, no heat exchanger has been designed around it by any heat exchanger vendor. R245fa is a common fluid among heat exchanger vendors and was used as a reference for the three heat exchangers with the new fluid. In order to estimate the heat transfer coefficients of the new fluid in the three heat

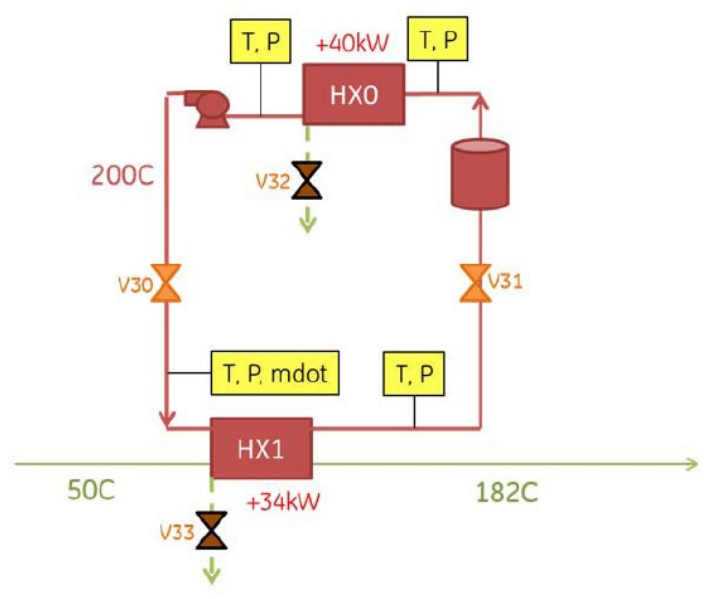

Figure 54. Heater of the supercritical ORC rig and the thermal oil heating loop. exchangers, an Aspen Exchanger Design and Rating tool was used. The heater, false load heat exchanger, and the condenser were all designed as shell and tube heat exchangers in the Exchanger Design and Rating tool and simulated with both R245fa and the new fluid. The heat transfer coefficient ratio between the two fluids with the same heat exchanger was considered as the "sizing factor" for the new fluid.

Table 18 shows the heat transfer coefficient comparison between R245fa and the new fluid in the heater, false load heat exchanger, and the condenser. For each heat exchanger, the simulation was done with two fluids having the same flow rate and heat source condition. The results show that for the heater and condenser, R245fa and the new fluid have about the same heat transfer coefficients. Note that in both heat exchangers, the log mean temperature difference (LMTD) with the new fluid is a lot bigger than that of R245fa. The reason is that the new fluid has a smaller specific heat than R245fa with the same pressure and temperature conditions. For the case of false load heat exchanger, they have about the same LMTD, and the heat transfer coefficient of the new fluid was $83.8 \%$ of R245fa. Note that this comparison is served mainly as a reference for the heat exchanger selection for the supercritical ORC test rig with the new fluid. The heat exchangers bought were compact plate exchangers, not the shell and tube heat exchangers simulated here.

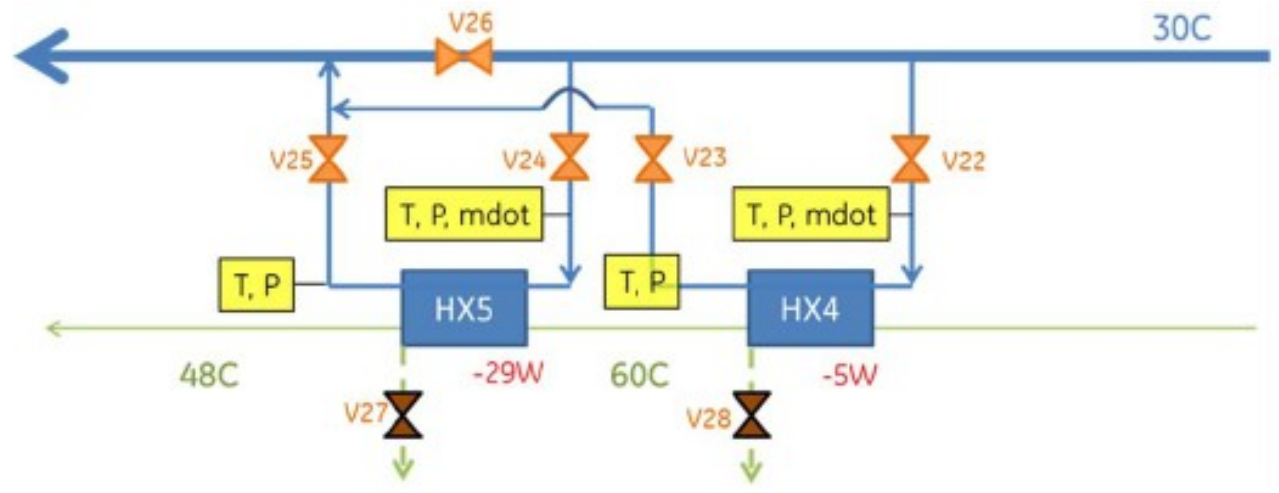

Figure 55. False load heat exchanger and condenser of the supercritical ORC rig and the cooling water supply. 
Table 18. Heat transfer coefficient comparison between R245fa and the new fluid.

\begin{tabular}{|c|c|c|c|c|c|c|}
\hline & ORC fluid process & $\begin{array}{l}\text { Hot } \\
\text { fluid }\end{array}$ & Cold Fluid & $\begin{array}{l}\text { LMTD } \\
\left({ }^{\circ} \mathrm{C}\right)\end{array}$ & $\begin{array}{l}\text { U_clean } \\
\text { (W/Sq.m.K) }\end{array}$ & $\begin{array}{l}\text { U value ratio } \\
\text { (New Fluid } \\
\text { versus } \\
\text { R245fa) }\end{array}$ \\
\hline Heater with R245fa & Liquid to supercritical & Hot oil & R245fa & 11.17 & 113.2 & \multirow{2}{*}{$99.6 \%$} \\
\hline Heater with new fluid & Liquid to supercritical & Hot oil & New Fluid & 33.33 & 112.8 & \\
\hline False load HX with R245fa & Desuperheating & R245fa & Tap water & 59.08 & 201.8 & \multirow{2}{*}{$83.8 \%$} \\
\hline $\begin{array}{l}\text { False load HX with new } \\
\text { fluid }\end{array}$ & Desuperheating & $\begin{array}{l}\text { New } \\
\text { Fluid }\end{array}$ & Tap water & 59.66 & 169.2 & \\
\hline Condenser with R245fa & Condensing & R245fa & Tap water & 13.47 & 805.7 & \multirow{2}{*}{$98.5 \%$} \\
\hline Condenser with new fluid & Condensing & $\begin{array}{l}\text { New } \\
\text { Fluid }\end{array}$ & Tap water & 18.88 & 793.8 & \\
\hline
\end{tabular}




\subsection{CONTROLS}

Data acquisition and control of the experiment was handled with LabView software running on a PC connected to the DAQ as shown in Figure 56. Process variable inputs came from the sensors shown in the process and instrumentation diagram (Figure 57) and control output from the DAQ was via either 4-20mA analog output or Modbus. There were two modes of operation for control in LabView: manual control and PID control. In manual mode, the operator could use the LabView GUI to directly control the signal to a given device. In PID mode, the user could set the desired process variable and the PID algorithm would determine and send the control signals or commands. The LabView GUI allowed the operator to select for each individual controllable device whether to run in manual or PID mode.

In conjunction with the controls system there were three levels of process safety limits which would either prompt user action or automatically shut down and cool down the rig if it went out of spec. The specified temperature and pressure ranges got progressively wider with each level. The first level was the software alarm specifications. If any of the measurements went outside of these specifications, an alarm would sound prompting the user to take action. The second level was software shutdown of the system. If any of the measurements went outside of these specifications the software would automatically shut off the heat source, turn up the cooling water flow, open the expansion control valve, and reduce the speed of the VFD. These measures would remove heat and depressurize the system. The final level of process limits were the hardware temperature limits and pressure relief valves. If the loop temperature exceeded what was specified by the limit controller the oil heater would be shut off. If the loop pressure exceeded the pressure set by the relief valves then the valves would open and depressurize the loop.

The overall strategy was to control both the pump speed and throttle valve manually, and the temperatures automatically using a PID algorithm. The flow rate of refrigerant in the loop was set

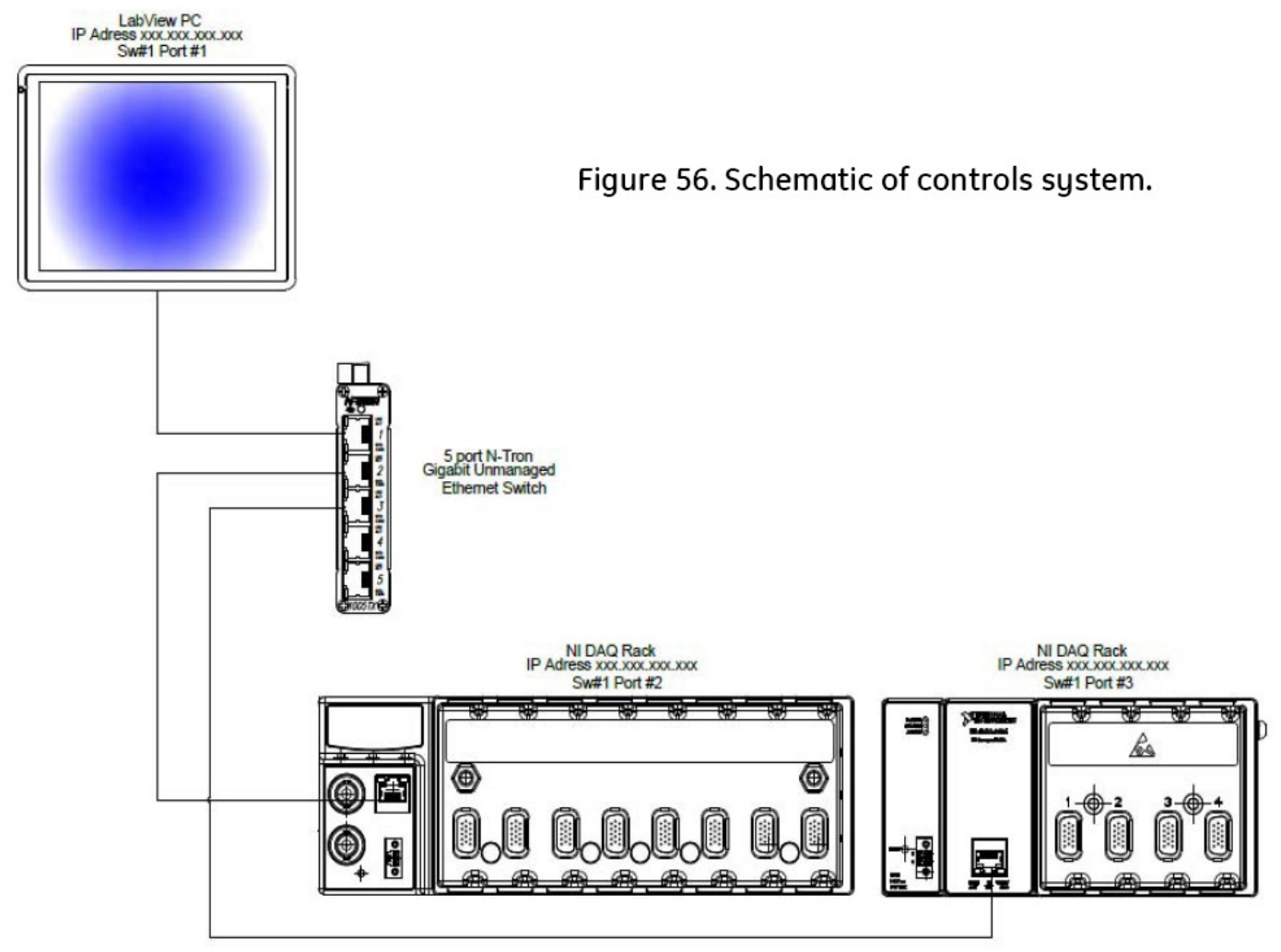




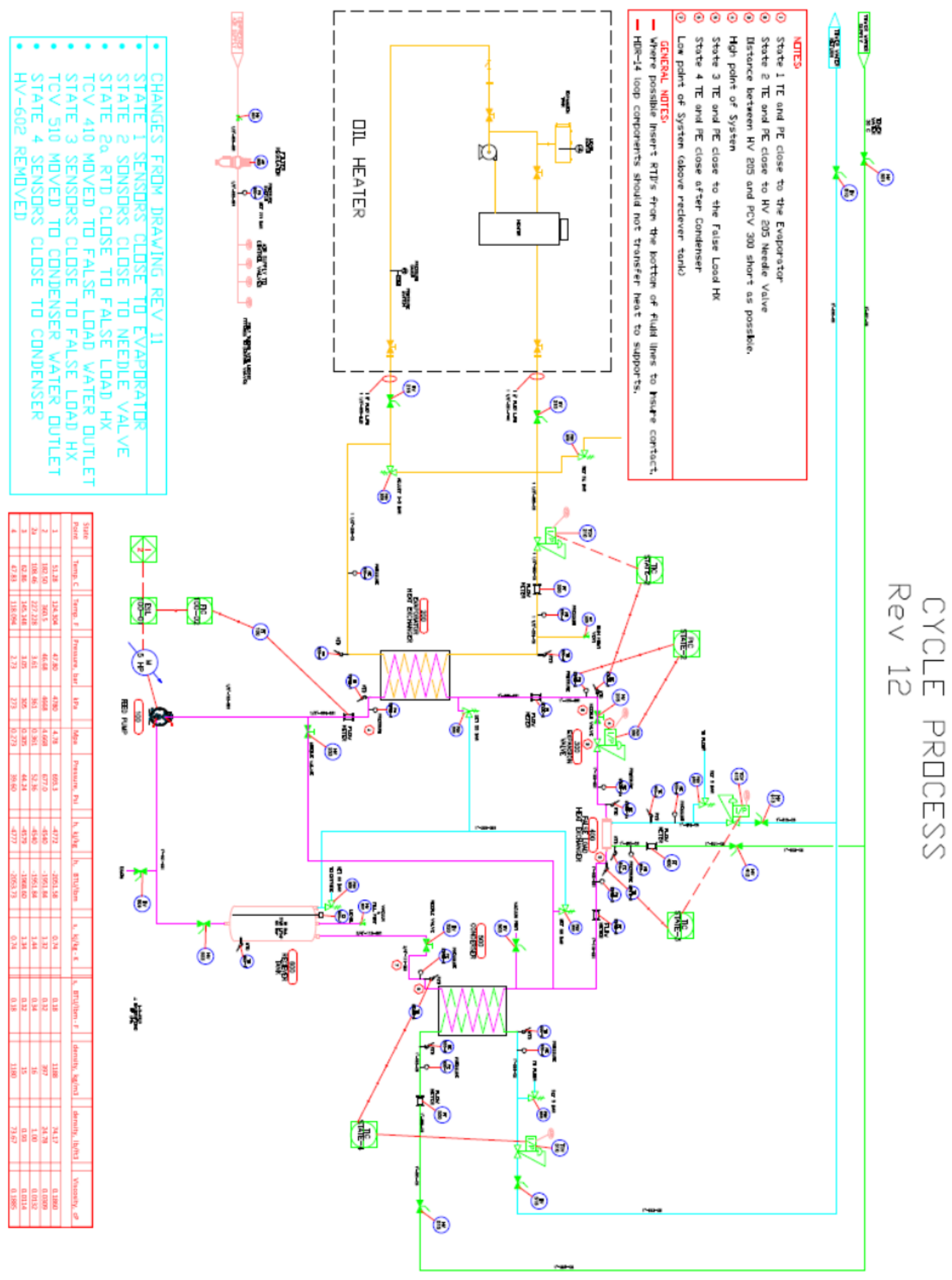

Figure 57. Piping and instrumentation diagram for the $5 \mathrm{~kW}$ supercritical test rig. 
using the feed pump motor VFD. The pressure downstream of the pump and upstream of the false load (States 1 and 2) is a function of the flow rate and the false load expansion valve setting. The pressure drop through the false load expansion valve is also a function of both the flow rate and the valve position. Thus, to set both the loop pressure and false load pressure drop, both the valve position and flow rate needed to be adjusted together. Because these parameters are so closely coupled, it did not make sense to control them with independent PID controllers since this could have led to an unstable system. These devices were therefore controlled in manual mode. Fluid temperature at States 2, 3, and 4 were controlled by adjusting the flow rate of heating oil or cooling water to their respective heat exchangers. Fluid temperature could be controlled in PID mode since control could be implemented independent of the other parameters. PID mode was only used to bring the loop through predefined state points to steady state. Once steady state was reached, the operator had the option to switch all controls over to manual control to minimize oscillations. 


\subsection{RESULTS AND ANALYSIS}

\section{Overview}

The primary goal of the $5 \mathrm{~kW}$ experimental test rig work was to validate the state points of the new refrigerant (aka new fluid) at transcritical conditions as predicted by an Aspen Hysys thermophysical model. The Hysys model was built to simulate the $5 \mathrm{~kW}$ test rig and incorporated properties of the new fluid provided by the vendor. As a result, most of the experimental runs were aimed at gathering data for the supercritical case with the new fluid. In addition, experiments were also run with at subcritical conditions in the new fluid and for R245fa both supercritical and subcritical. To summarize, data were gathered for the following four cases:

1. New Fluid, supercritical

2. New Fluid, subcritical

3. R245fa, supercritical

4. R245fa, subcritical

\section{State Point Predictions}

Table 19 summarizes the state point prediction results for all four cases. The measured experimental data at all of the state points are compared against data generated from the Hysys model of the experimental rig. To simplify this comparison, the percent difference between each of the measured values and their corresponding Hysys values were computed for each state point and are included in Table 19. Note that the percent differences computed for temperature and pressure are based on absolute values. Also included in Table 19 is the measurement uncertainty estimates as an absolute value and also as a percent of the measurement.

The methodology for running the Hysys model was as follows. The measured temperatures at States 1, 2, 3, and 4 were directly input into the model, as well as pressures at States 1, 2, 2a, 3, and 4. The mass flow rate measurement at State 1 was arbitrarily chosen as the mass flow input. Additionally, the cooling water temperatures and resource (oil) temperature were input into the Hysys model along with the measured flow rates for the oil and cooling water. Finally, engineering estimates were made for the performance for all components (heat exchangers, pump, etc.). The Hysys model predicts the rest of the state points and performs the appropriate energy balances. All of the model inputs have a percent difference of zero by definition and are thus colored yellow in Table 19 to distinguish them from the state points actually calculated by Hysys.

Table 19.Comparison of measured and Hysys predicted state points.

\begin{tabular}{|c|c|c|c|c|c|c|c|c|c|c|c|c|c|c|c|c|c|}
\hline & & \multicolumn{16}{|c|}{ State Point Properties } \\
\hline & & $\mathrm{T}_{1}$ & $P_{1}$ & $\mathrm{~m}_{1}$ & $\rho_{1}$ & $\mathrm{~T}_{2}$ & $P_{2}$ & $\mathrm{~m}_{2}$ & $\rho_{2}$ & $T_{2 a}$ & $P_{2 a}$ & $\mathrm{~T}_{3}$ & $P_{3}$ & $\mathrm{~m}_{3}$ & $\rho_{3}$ & $\mathrm{~T}_{4}$ & $P_{4}$ \\
\hline & & ${ }^{\circ} \mathrm{C}$ & BARG & $\mathrm{kg} / \mathrm{min}$ & $\mathrm{kg} / \mathrm{L}$ & ${ }^{\circ} \mathrm{C}$ & BARG & $\mathrm{kg} / \mathrm{min}$ & $\mathrm{kg} / \mathrm{L}$ & ${ }^{\circ} \mathrm{C}$ & BARG & ${ }^{\circ} \mathrm{C}$ & BARG & $\mathrm{kg} / \mathrm{min}$ & $\mathrm{kg} / \mathrm{L}$ & ${ }^{\circ} \mathrm{C}$ & BARG \\
\hline \multirow{5}{*}{ 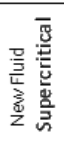 } & Measured & 36.13 & 47.85 & 11.012 & 1.25 & 179.82 & 47.085 & 11.069 & 0.545 & 91.05 & 4.18 & 63.30 & 2.10 & 11.012 & 0.015 & 34.29 & 1.839 \\
\hline & Hysys & 36.132 & 47.85 & 11.012 & 1.251 & 179.825 & 47.085 & 11.012 & 0.5256 & 89.662 & 4.176 & 63.30 & 2.096 & 11.012 & 0.0154 & 34.258 & 1.839 \\
\hline & \% Difference & $0.00 \%$ & $0.00 \%$ & $0.00 \%$ & $0.08 \%$ & $0.00 \%$ & $0.00 \%$ & $0.52 \%$ & $3.69 \%$ & $0.38 \%$ & $0.00 \%$ & $0.00 \%$ & $0.00 \%$ & $0.00 \%$ & $2.60 \%$ & $0.01 \%$ & $0.00 \%$ \\
\hline & Uncertainty & 0.48 & 0.22 & 0.01 & 0.00 & 1.20 & 0.44 & 0.04 & 0.00 & 0.76 & 0.42 & 0.62 & 0.04 & 0.04 & 0.00 & 0.47 & 0.04 \\
\hline & \% Uncerta inty & $0.16 \%$ & $0.45 \%$ & $0.10 \%$ & $0.05 \%$ & $0.26 \%$ & $0.92 \%$ & $0.35 \%$ & $0.05 \%$ & $0.21 \%$ & $8.11 \%$ & $0.18 \%$ & $1.36 \%$ & $0.36 \%$ & $0.05 \%$ & $0.15 \%$ & $1.48 \%$ \\
\hline \multirow{5}{*}{ 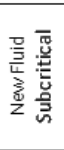 } & Measured & 36.7 & 23.2 & 5.68 & 1.239 & 145.10 & 22.69 & 5.71 & 0.144 & 110.7 & 2.896 & 65.21 & 2.074 & 5.668 & 0.015 & 37.11 & 2.005 \\
\hline & Hysys & 36.7 & 23.2 & 5.68 & 1.249 & 145.1 & 22.69 & 5.68 & 0.1451 & 112 & 2.896 & 65.21 & 2.074 & 5.68 & 0.01522 & 37.11 & 2.005 \\
\hline & \% Difference & $0.00 \%$ & $0.00 \%$ & $0.00 \%$ & $0.80 \%$ & $0.00 \%$ & $0.00 \%$ & $0.53 \%$ & $0.76 \%$ & $0.34 \%$ & $0.00 \%$ & $0.00 \%$ & $0.00 \%$ & $0.21 \%$ & $1.45 \%$ & $0.00 \%$ & $0.00 \%$ \\
\hline & Uncertainty & 0.48 & 0.22 & 0.01 & 0.00 & 1.03 & 0.44 & 0.02 & 0.00 & 0.85 & 0.42 & 0.63 & 0.04 & 0.02 & 0.00 & 0.49 & 0.04 \\
\hline & \% Uncertainty & $0.16 \%$ & $0.91 \%$ & $0.23 \%$ & $0.05 \%$ & $0.25 \%$ & $1.86 \%$ & $0.37 \%$ & $0.16 \%$ & $0.22 \%$ & $10.78 \%$ & $0.19 \%$ & $1.37 \%$ & $0.37 \%$ & $0.12 \%$ & $0.16 \%$ & $1.40 \%$ \\
\hline \multirow{5}{*}{ 焉 } & Measured & 33.07 & 48.19 & 9.046 & 1.331 & 180.6 & 47.41 & 9.142 & 0.3697 & 125.1 & 3.639 & 62.26 & 2.029 & 9.062 & 0.0148 & 31.62 & 1.862 \\
\hline & Hysys & 33.07 & 48.19 & 9.046 & 1.317 & 180.6 & 47.41 & 9.046 & 0.3632 & 125.5 & 3.639 & 62.26 & 2.029 & 9.046 & 0.01529 & 31.62 & 1.862 \\
\hline & \% Difference & $0.00 \%$ & $0.00 \%$ & $0.00 \%$ & $1.06 \%$ & $0.00 \%$ & $0.00 \%$ & $1.06 \%$ & $1.79 \%$ & $0.10 \%$ & $0.00 \%$ & $0.00 \%$ & $0.00 \%$ & $0.18 \%$ & $3.20 \%$ & $0.00 \%$ & $0.00 \%$ \\
\hline & Uncertainty & 0.47 & 0.22 & 0.02 & 0.00067 & 1.20 & 0.44 & 0.032 & 0.00019 & 0.93 & 0.42 & 0.61 & 0.04 & 0.032 & $8.4 \mathrm{E}-06$ & 0.46 & 0.04 \\
\hline & \% Uncerta inty & $0.15 \%$ & $0.45 \%$ & $0.18 \%$ & $0.05 \%$ & $0.27 \%$ & $0.91 \%$ & $0.35 \%$ & $0.05 \%$ & $0.23 \%$ & $9.05 \%$ & $0.18 \%$ & $1.39 \%$ & $0.35 \%$ & $0.06 \%$ & $0.15 \%$ & $1.47 \%$ \\
\hline \multirow{5}{*}{ 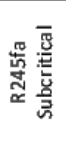 } & Measured & 27.11 & 22.46 & 5.169 & 1.338 & 145.3 & 21.95 & 5.209 & 0.127 & 120.5 & 2.605 & 64.64 & 1.911 & 5.158 & 0.01474 & 26.92 & 1.898 \\
\hline & Hysys & 27.11 & 22.46 & 5.169 & 1.334 & 145.3 & 21.95 & 5.169 & 0.1285 & 120.5 & 2.605 & 64.64 & 1.911 & 5.169 & 0.01495 & 26.92 & 1.898 \\
\hline & \% Difference & $0.00 \%$ & $0.00 \%$ & $0.00 \%$ & $0.30 \%$ & $0.00 \%$ & $0.00 \%$ & $0.77 \%$ & $1.17 \%$ & $0.00 \%$ & $0.00 \%$ & $0.00 \%$ & $0.00 \%$ & $0.21 \%$ & $1.40 \%$ & $0.00 \%$ & $0.00 \%$ \\
\hline & Uncertainty & 0.44 & 0.22 & 0.01 & 0.00067 & 1.03 & 0.44 & 0.02 & 0.00017 & 0.90 & 0.42 & 0.62 & 0.04 & 0.019 & $1.4 \mathrm{E}-05$ & 0.43 & 0.04 \\
\hline & \% Uncerta inty & $0.15 \%$ & $0.94 \%$ & $0.21 \%$ & $0.05 \%$ & $0.25 \%$ & $1.92 \%$ & $0.38 \%$ & $0.13 \%$ & $0.23 \%$ & $11.65 \%$ & $0.18 \%$ & $1.44 \%$ & $0.37 \%$ & $0.09 \%$ & $0.14 \%$ & $1.45 \%$ \\
\hline
\end{tabular}


A summary of the property prediction results is presented graphically in Figure 58. This is a bar chart that shows the percent difference for all of the calculated property values for all four cases along with error bars for each. In Figure 58, several things are readily apparent. In general, there is good agreement between the measured values and the modeled values from Hysys. All of the properties agree to within $4 \%$, and most are much better than that. T2a and the mass flow measurement differences are for the most part within measurement uncertainty. The largest differences are with the density predictions and the greatest of these occurs at the State 2 density measurement for the new fluid at supercritical conditions. This is not surprising given that this state point is very close to the critical point. In this region all intensive thermodynamic properties are highly sensitive to changes in the others.

It is likely that the measured values for density are very accurate. This assumes steady state conditions exist (i.e., no large oscillations) and there is good reason to believe that this is so. The data show no evidence of significant oscillation in the flow rate or any of the measured properties. High frequency oscillations not picked up by the instrumentation due to aliasing is very unlikely. Any large fluctuations would be expected to take place on the order of seconds or longer because of fluid inertia, volume, and thermal mass. The coriolis meter damping parameters were set to low values: 1.6 seconds for density measurement and 0.8 seconds for mass flow rate measurement, and all of the pressure and temperature measurements were acquired at $1 \mathrm{~Hz}$. Coriolis meters calculate fluid density by measuring the mass of fluid inside their oscillating tubes and dividing by the tube volume. The mass of the fluid in the tubes is a function of the tube resonant frequency. This method of density measurement is highly accurate as long as the fluid is in a single phase. The single phase assumption was checked by monitoring the drive gain of the coriolis meters. The two phase flow results in spikes in the drive gain.

A plausible reason for the density percent differences is propagation of measurement error through the model in the calculation of the state parameters. The error bars in Figure 58 show

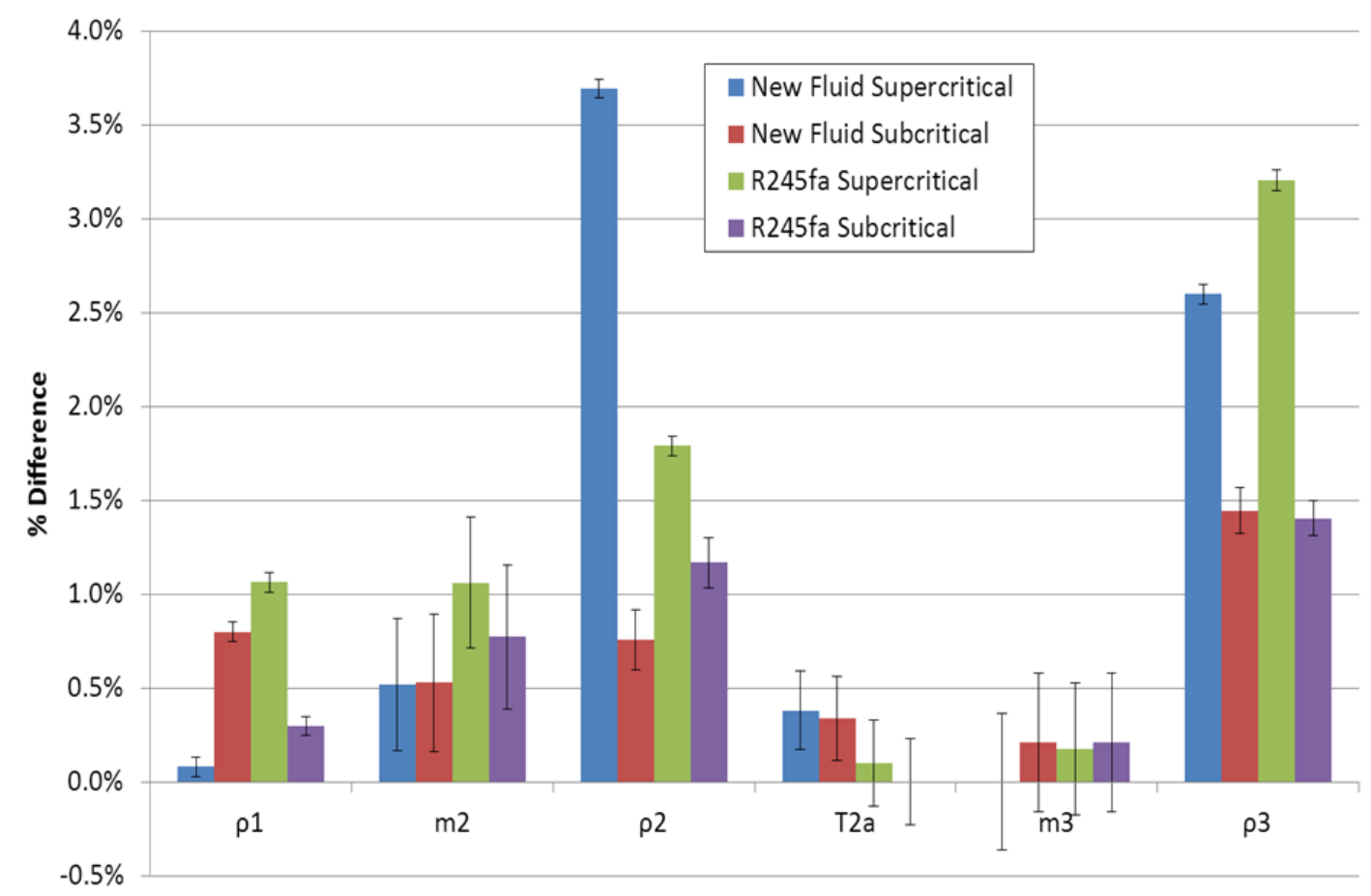

Figure 58. Graphical summary of percent difference between measured and predicted stute points. 
measurement uncertainty, not the resulting uncertainty of the model due to measurement uncertainty. For example, the uncertainty of the density measurement near the critical point at State 2 was estimated at $0.05 \%$ of the measured value. At this same location, the RTD uncertainty was estimated at $1.21^{\circ} \mathrm{C}$, which corresponds to a $3.5 \%$ change in density when propagated through the model. Other reasons for the differences would include the effect of pressure drop through the coriolis meter and heat loss.

The overall conclusion from the above analysis is that the property data match for all four cases is very good. Differences are within acceptable tolerances given the measurement uncertainties and relative location of the state points compared to the critical point.

\section{Energy Balance}

An energy balance was performed on the experimental data in order to compare the results against those obtained with Hysys. The calculations were performed using Engineering Equation Solver software. The measurement uncertainty was propagated through the calculations to obtain uncertainty estimates for all of the calculated parameters. The resulting energy balance comparisons are made in Table 20, which takes the same form as Table 19.

Table 20.Comparison of cakukted and Hysys predicted energy balance parameters.

\begin{tabular}{|c|c|c|c|c|c|c|}
\hline & & \multicolumn{5}{|c|}{ Energy Balance } \\
\hline & & Evaporator & False Load & Condenser & $\eta_{\text {cycle }}$ & $\eta_{\text {isen, turb }}$ \\
\hline & & kW & kW & kW & & \\
\hline \multirow{5}{*}{ 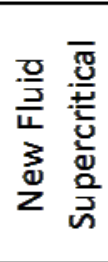 } & Measured & 44.93 & -3.89 & -38.82 & $8.66 \%$ & \multirow{5}{*}{$85 \%$} \\
\hline & Hysys & 41.85 & -3.85 & -38.67 & $9.20 \%$ & \\
\hline & \% Difference & $7.36 \%$ & $1.09 \%$ & $0.39 \%$ & $5.84 \%$ & \\
\hline & Uncertainty & 1.12 & 0.02 & 0.65 & $0.22 \%$ & \\
\hline & $\%$ Uncertainty & $2.50 \%$ & $0.46 \%$ & $1.67 \%$ & $2.54 \%$ & \\
\hline \multirow{5}{*}{ 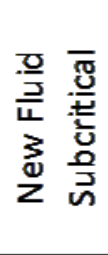 } & Measured & 24.77 & -3.663 & -19.52 & $14.79 \%$ & \multirow{5}{*}{$103 \%$} \\
\hline & Hysys & 23.69 & -3.702 & -19.63 & $15.63 \%$ & \\
\hline & \% Difference & $4.56 \%$ & $1.05 \%$ & $0.56 \%$ & $5.37 \%$ & \\
\hline & Uncertainty & 1.05 & 0.02 & 0.21 & $0.63 \%$ & \\
\hline & $\%$ Uncertainty & $4.22 \%$ & $0.44 \%$ & $1.07 \%$ & $4.25 \%$ & \\
\hline \multirow{5}{*}{ 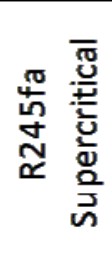 } & Measured & 44.59 & -9.479 & -32.85 & $21.26 \%$ & \multirow{5}{*}{$123 \%$} \\
\hline & Hysys & 41.33 & -9.42 & -32.07 & $22.79 \%$ & \\
\hline & \% Difference & $7.89 \%$ & $0.63 \%$ & $2.43 \%$ & $6.73 \%$ & \\
\hline & Uncertainty & 1.12 & 0.04 & 0.68 & $0.54 \%$ & \\
\hline & $\%$ Uncertainty & $2.51 \%$ & $0.42 \%$ & $2.0 \% \%$ & $2.54 \%$ & \\
\hline \multirow{5}{*}{ 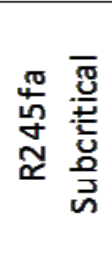 } & Measured & 25.72 & -4.846 & -19.46 & $18.84 \%$ & \multirow{5}{*}{$136 \%$} \\
\hline & Hysys & 24.22 & -4.869 & -19.04 & $20.10 \%$ & \\
\hline & \% Difference & $6.19 \%$ & $0.47 \%$ & $2.21 \%$ & $6.28 \%$ & \\
\hline & Uncertainty & 1.06 & 0.02 & 0.49 & $0.78 \%$ & \\
\hline & $\%$ Uncertainty & $4.12 \%$ & $0.35 \%$ & $2.52 \%$ & $4.14 \%$ & \\
\hline
\end{tabular}


States 1 through 4 were chosen to match the supercritical and subcritical state points used in the Clean Cycle 140kW experiment previously described for the new fluid. This corresponds to a turbine with $85 \%$ isentropic efficiency for the new fluid supercritical case. Out of convenience many of the same state points were also used for the other three cases, and they all correspond to a turbine with more than 100\% isentropic efficiency. The nature of the experimental rig is such that any state point can be generated, regardless of whether it is actually achievable with an expander between States 2 and 3. Thus, the results from the energy balance for the four different cases should not be compared against each other. If one were to do that they might, for example, falsely conclude that the cycle efficiency for subcritical new fluid is better than supercritical. The results of the energy balance are only to be compared against the corresponding values predicted from the Hysys model. In hindsight, we realize it would have been better to choose state points corresponding to an $85 \%$ efficient turbine for cases 2 through 4 as well. However, the primary goal of comparing measured properties of the state points versus the Hysys model was achieved, and the model can subsequently be used to predict thermodynamic performance for any conditions.

The results of Table 20 are summarized in Figure 59. Overall, the energy balances from the experiment and model compare reasonably well. The false load and condenser duties are all less than $2.5 \%$ different, and most are much better than that. The differences largely fall within the uncertainty of the duty calculations. The largest discrepancy is with the evaporator duties. Although the error bars are relatively large here, there still appears to be a clear bias indicating that the real value is larger than the modeled one by about 5-7\%. Plausible reasons for this offset include heat loss and bias error with the Paratherm oil specific heat. Since this is the hottest region on the rig, one would expect the largest heat loss to take place here. The largest percent difference is just under $8 \%$ which is still acceptable.

\section{Uncertainty}

The estimated experimental uncertainty of the measured values at all state points is shown in both Table 19 and Table 20. The uncertainty is a function of both the stated accuracy of the instruments and the measurement variation (standard error) at steady state.

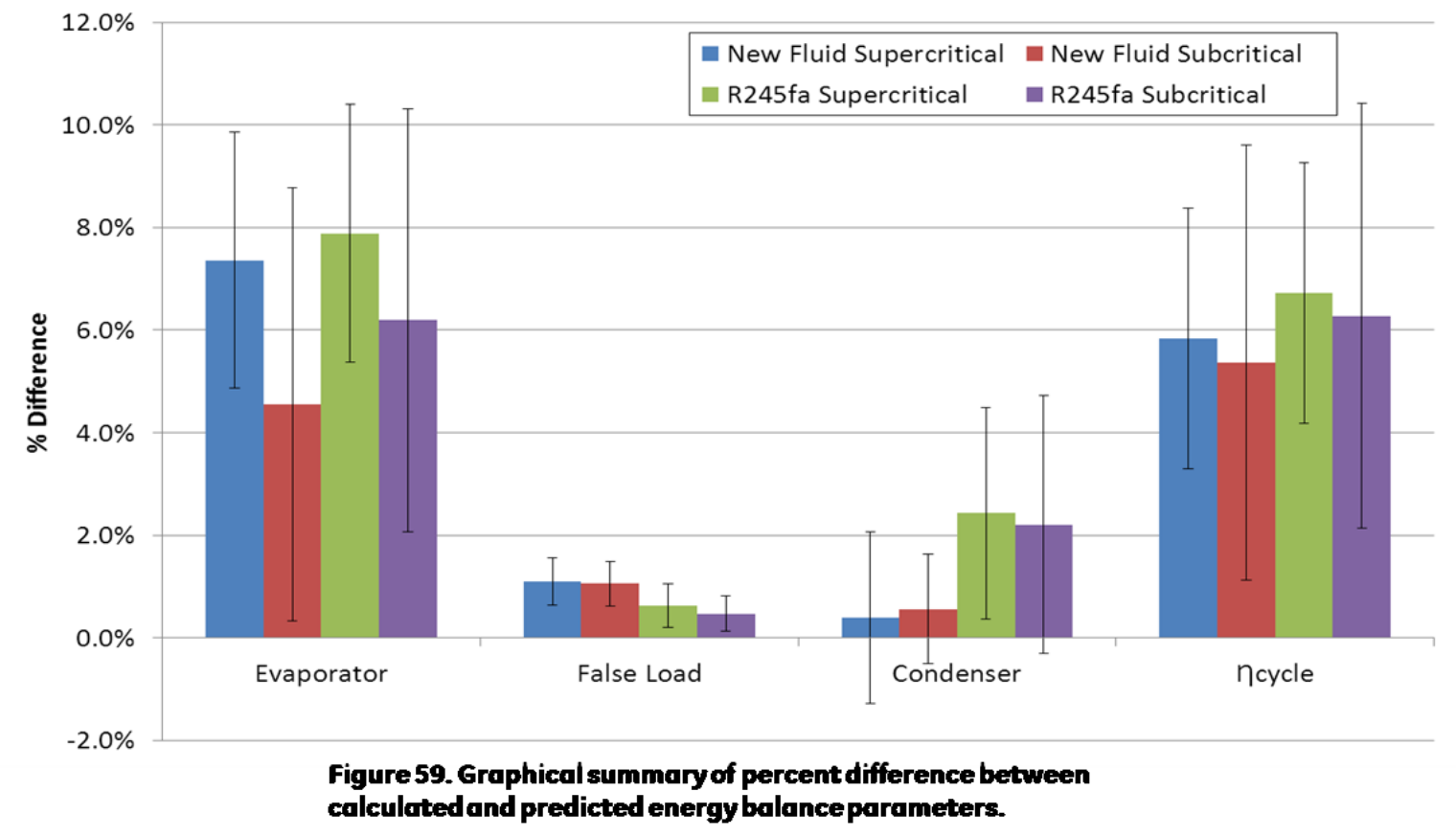


Details on the calculation of experimental uncertainty can be found in the next section of this report. The uncertainty was also calculated as a percentage and these values are colored green so that they may be easily compared with the percent difference values. As with the percent difference calculations, the percent uncertainty values are based on the absolute values for temperature and pressure.

For the most part, experimental uncertainty for measurements at all of the state points was very low. The biggest exception is the pressure measured at State 2a, which has an uncertainty of about $10 \%$ for all cases. This is because the pressure transducer supplied for this state point was not of the appropriate pressure range. The team decided that it made more sense to live with the higher uncertainty and proceed with testing rather than remove the over-ranged transducer, send it back, wait for a new one to arrive, and have it installed in the rig. State point 2a is an intermediate state point and we were more concerned with accuracy at States 2 and 3 than at State 2a. Also, the percent difference in the temperature T2a was based on the measured pressure P2a and found to be in good agreement indicating that this transducer was probably accurate.

It is worth repeating here that the percent differences in density are probably not explained by the uncertainty of the density measurement (which was a fraction of a percent) but rather by: 1) the uncertainty of the state point measurements propagating through the Hysys model, and 2) the sensitivity of all properties near the critical point. Uncertainty in the measurements was propagated through the energy balance calculations and the resulting values for calculated duties was fairly low for the false load and condenser (usually less than $2 \%$ ) and slightly higher for the evaporator (up to about 4\%). These numbers are reduced slightly from the original values because we post calibrated some of the RTDs after the experiment ended.

\section{Repeatability}

Repeatability of the experiments was very good. Case 1 (supercritical new fluid) was run four times on four different days with very little variation. The other cases were less important and were thus only run once each. Table 20 compares the results from case 1 on two different days. The repeatability was extremely good considering the sensitivity of State 2 near the critical point.

\section{Summary}

Four different cases were run with the two refrigerants, the new fluid and R $245 \mathrm{fa}$ for subcritical and supercritical cycles. The new fluid supercritical case was the most important and was run four times on four different days. Repeatability was very good between runs. There was a good match between the measured and Hysys predicted state point property data and duties from the energy balance. The largest percent differences occurred with densities and evaporator duty. The density difference can be explained by considering the measurement uncertainty of the temperatures and pressures and propagating them through the Hysys model. This is especially true near the critical point where all of the properties are sensitive to small changes in the others. The evaporator duty differences are explained by heat loss to ambient at the evaporator. Measurement and calculation uncertainty were relatively low and are documented in detail. The most important point is that the new fluid supercritical case 1 matched just as well as the other cases in terms of state points and heat duties for all states except for density near the critical point. This was a couple percent higher in percent difference compared to the other cases which isn't bad considering how close it is to the critical point. It is therefore reasonable to conclude that the state point model has been validated with a real system. 
Table 21.Repeatability of supercritical runs with the new firid

\begin{tabular}{|c|c|c|c|c|}
\hline \multicolumn{5}{|c|}{ State Point Summary } \\
\hline & 27-Mar & 5-Apr & Units & \% Difference \\
\hline $\mathrm{T} 1=$ & 36.132 & 36.53 & C & $0.13 \%$ \\
\hline$P 1=$ & 47.85 & 47.87 & BARG & $0.04 \%$ \\
\hline $\mathrm{m} 1=$ & 11.012 & 11.03 & $\mathrm{~kg} / \mathrm{min}$ & $0.16 \%$ \\
\hline$\rho 1=$ & 1.25 & 1.249 & $\mathrm{~kg} / \mathrm{L}$ & $0.08 \%$ \\
\hline$T 2=$ & 182.494 & 182.6 & C & $0.02 \%$ \\
\hline$P 2=$ & 47.085 & 47.12 & BARG & $0.07 \%$ \\
\hline $\mathrm{m} 2=$ & 11.069 & 11.08 & $\mathrm{~kg} / \mathrm{min}$ & $0.10 \%$ \\
\hline$\rho 2=$ & 0.545 & 0.5473 & $\mathrm{~kg} / \mathrm{L}$ & $0.42 \%$ \\
\hline $\mathrm{T} 2 \mathrm{a}=$ & 91.047 & 91.52 & C & $0.13 \%$ \\
\hline $\mathrm{P} 2 \mathrm{a}=$ & 4.176 & 4.207 & BARG & $0.60 \%$ \\
\hline$T 3=$ & 63.299 & 63.18 & C & $0.04 \%$ \\
\hline $\mathrm{P} 3=$ & 2.096 & 2.157 & BARG & $1.97 \%$ \\
\hline $\mathrm{m} 3=$ & 11.012 & 11.04 & $\mathrm{~kg} / \mathrm{min}$ & $0.25 \%$ \\
\hline$\rho 3=$ & 0.015 & 0.01514 & $\mathrm{~kg} / \mathrm{L}$ & $0.93 \%$ \\
\hline $\mathrm{T} 4=$ & 34.286 & 35.11 & C & $0.27 \%$ \\
\hline $\mathrm{P} 4=$ & 1.839 & 1.901 & BARG & $2.18 \%$ \\
\hline \multicolumn{5}{|c|}{ HX Energy Balance } \\
\hline & 27-Mar & 5-Ap & Units & \% Difference \\
\hline Evaporator & 44.93 & 44.94 & kW & $0.02 \%$ \\
\hline False Load & -3.892 & -3.94 & kW & $-1.31 \%$ \\
\hline Condenser & -38.82 & -38.45 & $\mathrm{~kW}$ & $-0.95 \%$ \\
\hline
\end{tabular}




\subsection{METHOD FOR ESTIMATION OF MEASUREMENT UNCERTAINTY}

An overall uncertainty interval $\left(U_{i}\right)$ was estimated for each measured value $\left(M_{i}\right)$ and each calculated value $\left(C V_{i}\right)$ following the procedures in sources 1 and 2 below. The results are expressed in the current report as follows:

$$
M_{i} \pm U_{i} \text { or } C V_{i} \pm U_{i}
$$

where $U$ is the estimated uncertainty interval based on a $95 \%$ confidence interval, $M$ is a measured value, $C V$ is a calculated value, and $i$ is the index specifying a measurement from a particular sensor or a specific calculation. For example $M_{1}$ could be the measured temperature at State $1, M_{2}$ the measured temperature at State 2, and $C V_{l}$ the calculated duty from the false load heat exchanger. All uncertainty intervals and all error bars shown for the $5 \mathrm{~kW}$ test rig are reported this way.

The equation for the overall uncertainty estimate is as follows:

$$
U_{i}=\left(B_{i}^{2}+P_{i}^{2}\right)^{1 / 2}
$$

The overall uncertainty $(U)$ is a function of two types of measurement uncertainty:

1. The bias limit $\left(B_{i}\right)$ which comes from the manufacturer's specifications on the accuracy of a single measurement for a given instrument based on a $95 \%$ confidence interval. These

specifications come from performance statistics gathered by the manufacturer when calibrating their instruments against a known standard.

2. The precision limit $\left(P_{i}\right)$ which comes from the standard deviation of a measurement at steady state.

The standard deviation is defined in the usual way:

$$
S_{i}=\left\{\sum_{k=1}^{N_{i}} \frac{\left[\left(X_{i}\right)_{k}-\bar{X}_{l}\right]^{2}}{N_{i}-1}\right\}^{1 / 2}
$$

where $S_{i}$ is the standard deviation for $N_{i}$ measurements of the measured variable $X_{i}$. Thus the precision limit is:

$$
P_{i}=K S_{i}
$$

where the coverage factor $K=2$ for a $95 \%$ confidence interval according to National Institute of Standards and Technology practice.

Every measured or calculated value reported in the current study is a 5 minute average taken at steady state conditions during which the values drifted around slightly due to controller oscillations and natural resonance in the system. Data was logged every second so each reported value is an average of 300 measured values. It is assumed that the values take on a Gaussian distribution and are uncorrelated with each other. This results in a very conservative estimate of the precision error since, in reality, there will actually be some correlation between measured variables. Take as an example the scenario where the steady state pressure drifts slightly upwards and then downwards due to controller variability. The temperature will follow the pressure with a certain time lag in the measurement. This has the effect of increasing the standard deviation of the measurements above what it would be if the process were perfectly steady and the only variability in the measurement was due to random error. 
Because a mean value of each measured $X_{i}$ is used, the appropriate precision limit becomes the standard error instead of the standard deviation:

$$
P_{\overline{X_{L}}}=\frac{P_{i}}{\sqrt{N_{i}}}
$$

It was found that for all of the measurements, except for the mass flow rate and density, the standard error resulted in a precision estimate which was more than an order of magnitude smaller than the bias error estimate and thus could be neglected. For example, the accuracy of the RTDs used to measure the inlet and outlet temperatures were $\pm 0.2^{\circ} \mathrm{C}$ and the measured standard deviations of the temperature measurements over 5 minutes are $0.0185^{\circ} \mathrm{C}$ and $0.0075^{\circ} \mathrm{C}$ respectively. Thus the standard errors would be $0.0011^{\circ} \mathrm{C}$ and $0.0004^{\circ} \mathrm{C}$. This is 2 to 3 orders of magnitude lower than the RTD accuracy and can clearly be neglected. For density and mass flow, both the manufacturer's accuracy specs and standard error had to be used to estimate the total uncertainty. 


\section{Supercritical Turboexpander Design Study}

\subsection{RATIONALE}

Phase 1 of this program was solely focused on the technical aspects of geothermal power generation with special attention paid to fluid selection, fluid validation, different cycles (subcritical, supercritical, trilateral flash), and different cycle configurations (dual pressure). A lot of assumptions in the models, like pinch points or efficiencies, were taken as constants across all models.

In Phase 2 of this program, a detailed analysis of the thermo-economic performance of the EGS power plant was completed. There was special emphasis on the economics of EGS wherein the component cost functions were developed for the power block and the overall LCOE calculations and optimization were performed. This analysis done in Phase 2 highlighted the effectiveness of new working fluids and novel power cycle architectures in reducing the LCOE. In the current phase of the program being reported here, the impact of newly chosen working fluids and cycle configurations on the technology and cost is evaluated on the component level and system level through experimentation, theoretical studies, and component tests. This chapter particularly focuses on the development, feasibility, and costing of the turboexpander for the downselected fluid-cycle combination.

The EGS power block product is expected to be in the size range of 5-15 MWe, to be large enough to achieve economies of scale while being modular to provide flexibility in terms of operation and implementation. Detailed design and testing of such an expander is out of the scope of this program. However, using the current design practice for expanders and theoretical predictions, it is possible to go through the preliminary design exercise to establish product specifications, performance, and cost with reasonable accuracy. The primary challenge with the proposed turbomachinery is the operation at supercritical pressures at the turbine inlet and high pressure ratio across the expansion process. In the size range of interest, traditionally radial in-flow turbine architecture is most competitive for commercial applications but such high pressure ratios are easier to achieve across a multi-stage axial turbine. Considering the technical and commercial benefits of both designs, preliminary design analysis was completed for both architectures and optimal design is proposed in this chapter.

\subsection{DESIGN PROCESS}

For the multi-stage axial turbine design, GE Energy gas turbine design expertise was leveraged and a GE Aviation tool (TP3) was modified to incorporate real gas properties to complete the preliminary aero design of the machine. Following the aero design, mechanical design of the rotor, bearings, casing, axial thrust balance, and auxiliaries including the sealing system were accomplished to determine the machine cost and performance at different power ratings.

The radial turbine aero profiles were computed using the GE Oil \& Gas design practice and standardized casing sizing and pressure ratings were used to obtain the mechanical design and performance. GE Oil \& Gas commercial tools were further leveraged to obtain the cost estimates for these machines. The details of this process are explained in greater detail in the section below.

\subsubsection{Axial Expander Design Process}

\section{Flowpath Design Process}

The primary goal of turbine aerodynamic conceptual design is to define the cross-section of the turbine's primary flowpath. During this phase of design, 1D calculations are performed to relate non-dimensional aerodynamic parameters to meanline flow vectors and basic airfoil geometry. 
From these calculations, the number of turbine stages, airfoil corner points (defining the projection of the airfoils in the radial-axial plane), and airfoil counts are determined. Additional correlation-based calculations are used to estimate the turbine performance from the flowpath geometry and meanline velocity vectors.

Turbine flowpath design is generally iterative, as shown generically in Figure 60. There are several means of defining inputs and calculating the resulting flowpath geometry. For general open Brayton cycle applications (aircraft turbines and land-based gas turbines), GE has a well established, calibrated design tool to perform the 1D design function. Due to the highly non-ideal properties of the geothermal cycle's working fluid, a separate process was developed for evaluating design options. The following sections describe the process that was used specifically for designing the flowpath of the geothermal turbine.

\section{Velocity Triangle Calculation}

A turbine stage, shown in Figure 61, is comprised of a stationary row of airfoils (referred to as vanes) followed by a rotating row of airfoils (referred to as rotors). The vanes accelerate the gas stream, adding tangential momentum as depicted in Figure 62's velocity vectors. The rotors extract power from the gas stream by removing tangential momentum, also shown in Figure 62 .

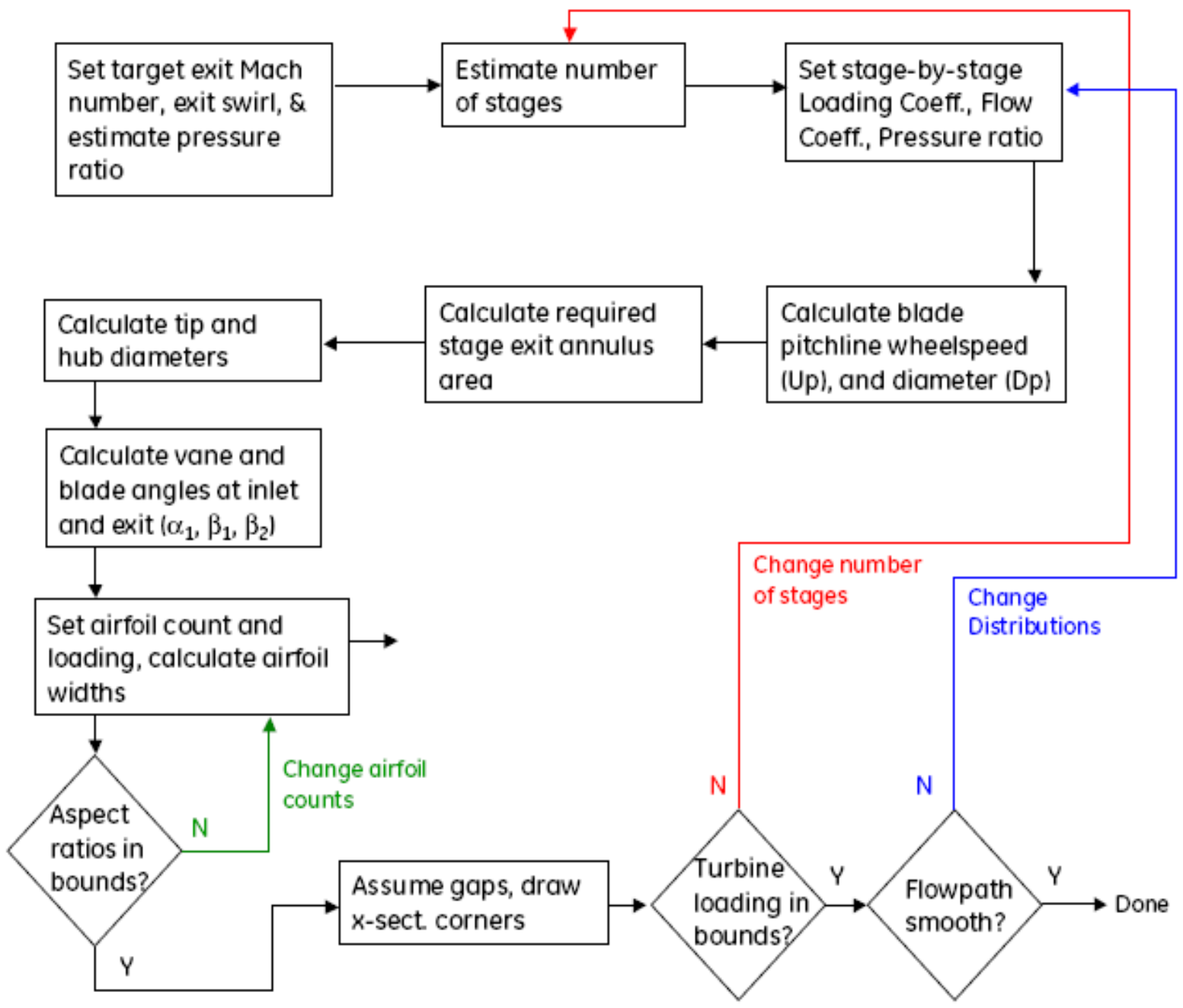

Figure 60. Generic flowpath aerodynamic design process. 


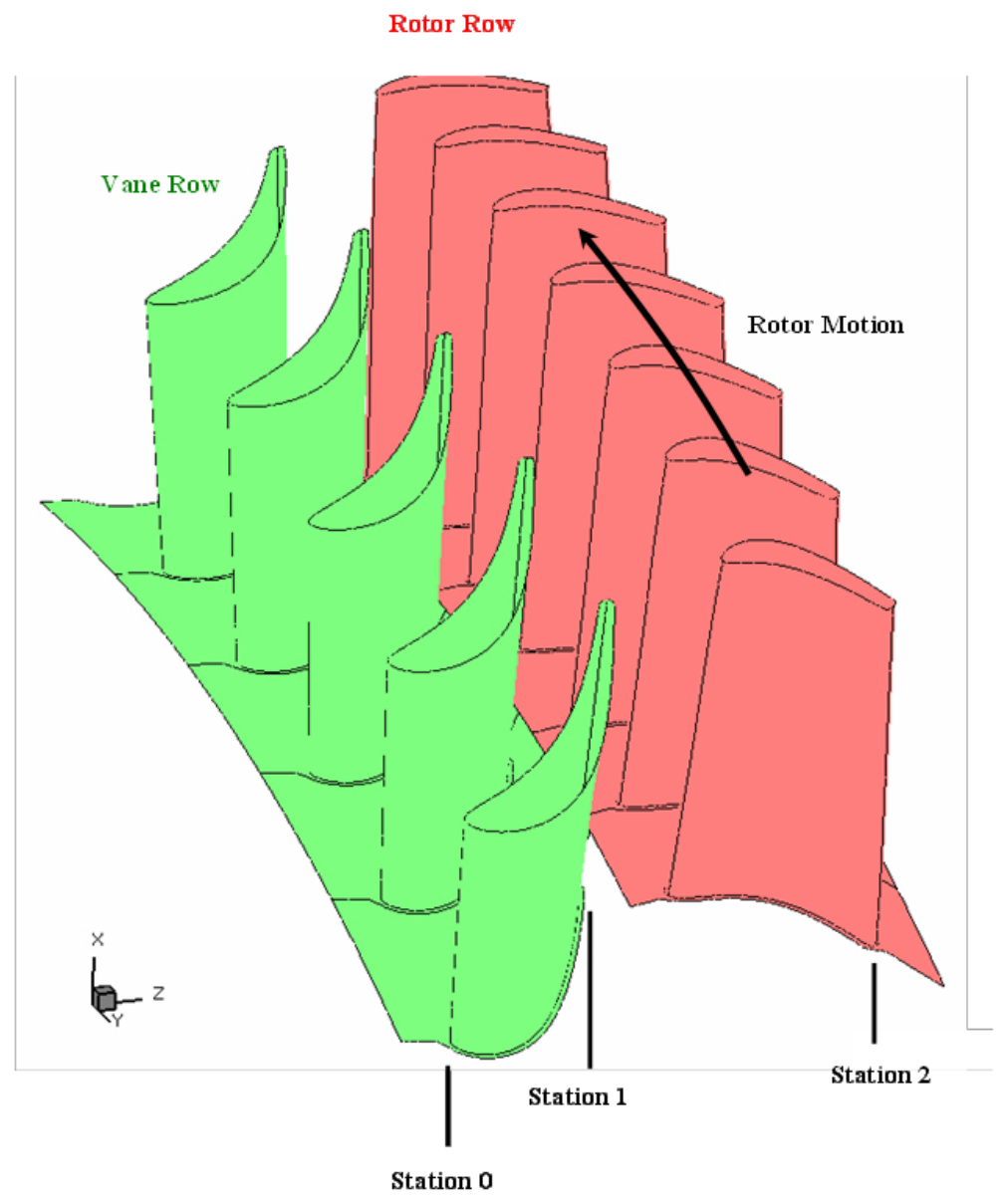

Figure 61. Turbine Stage and Stution Definition

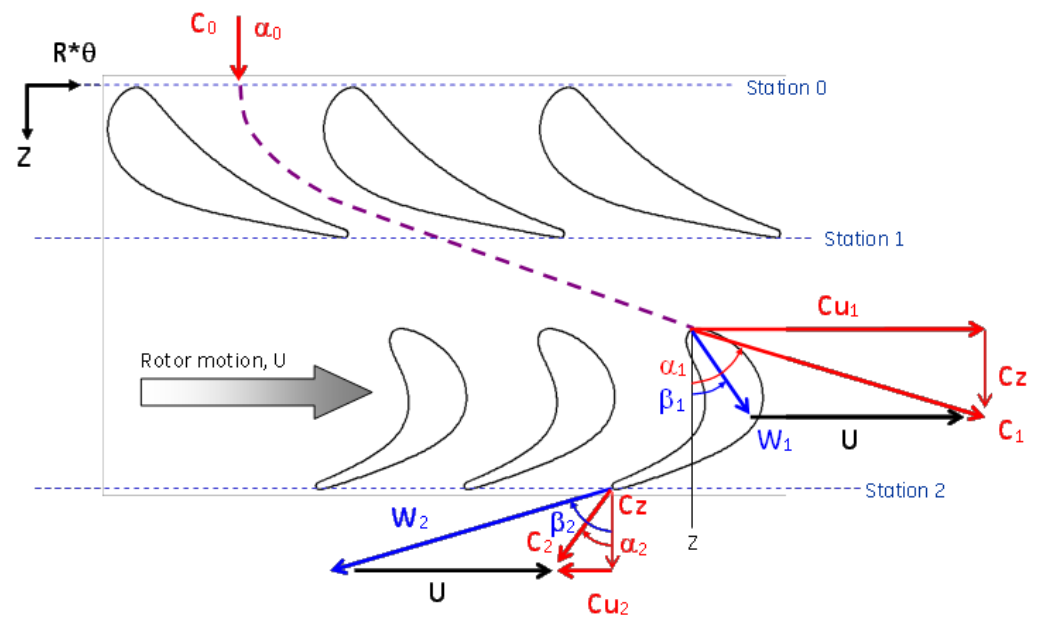

Figure 62. Turbine stage velocity triangles and flow angle definition. 
The shaft power generated by a turbine stage is related to this change in tangential momentum, and thus the airfoil velocity vectors, by the Euler work equation:

$$
-P_{\text {shaft }}=\dot{m}\left(U_{2} C_{u 2}-U_{1} C_{u 1}\right)
$$

Equation 1. Euler work equation

Several one-dimensional parameters are defined to characterize the velocity vectors of a turbine stage. They include the work coefficient, flow coefficient, and stage reaction, each of which are briefly described in the following sections. The process for relating the $1 \mathrm{D}$ design parameters to the required flowpath coordinates then follows.

\section{Work Coefficient}

The work coefficient, designated by the Greek letter $\Psi$, relates the stage work to the square of the pitchline wheelspeed, as defined in Equation 2:

$$
\psi=\frac{\Delta H t}{2 \cdot U^{2}}
$$

Equation 2. Work coefficient definition

Work coefficient is a parameter that is commonly used to balance the pitchline diameter of a turbine stage against the total amount of work to be extracted from that stage. High work coefficient is indicative of high flow turning (steep flow angles at stations 1 and 2 in Figure 61). For a fixed wheelspeed (fixed pitchline diameter), increasing work coefficient will produce higher pressure and temperature drops within the turbine stage.

\section{Flow Coefficient}

The flow coefficient, designated by the Greek letter $\Psi$, relates the axial flow velocity at the rotor trailing edge to the pitchline wheelspeed, as defined in Equation 3:

$$
\phi=\frac{C_{z}}{U}
$$

\section{Equation 3. Flow coefficient definition}

Flow coefficient is a parameter that is commonly used to set the flowpath height. For a fixed mass flow, increasing flow coefficient will reduce the required height of the turbine flowpath. It will also result in higher Mach numbers, and lower turning requirements for the airfoils.

\section{Stage Reaction}

The stage reaction, designated by $\mathrm{Rx}$, relates the enthalpy drop across the rotor to the enthalpy drop across the stage, as defined in Equation 4:

$$
R x=\frac{H s_{1}-H s_{2}}{H t_{1}-H s_{2}}
$$

\section{Equation 4. Stage Reaction}

Stage reaction has a smaller impact on the definition of the turbine cross-section, though it does have a substantial effect on the velocity triangles. 50\% reaction designs have symmetrical velocity triangles, while low reaction designs have highly skewed velocity triangles. In the limit of $0 \%$ 
reaction (an impulse stage), the flow angle at the inlet and exit of the rotor are equal, but with opposite signs.

Stage reaction is particularly important for adjusting the swirl angle leaving a turbine stage, which then becomes the inlet condition to downstream components (either another turbine stage, or the turbine exhaust structure). In order to simplify flowpath design calculations, the stage exit swirl may be directly set as a proxy for stage reaction.

\section{Flowpath Calculation}

The turbine flowpath design process starts with setting boundary conditions defined by the engine cycle. These include:

- Turbine inlet total pressure, PT

- Turbine inlet total temperature, TT

- Turbine inlet mass flow, $m$

- Turbine exit static pressure, PS

- Shaft RPM

An initial assumption is made for the number of turbine stages. A target exit Mach number for the turbine is also set. For each stage, selections are made for the following flowpath quantities:

- Work coefficient, $\Psi$

- Flow coefficient, $\phi$

- Rotor exit pitchline diameter, Dp

- Stage exit swirl, $\alpha_{2}$

The amount of work produced by each turbine stage is directly calculated from the selected $\Psi$ and Dp through the definition of $\Psi$. The values of $\Psi$ and Dp must be iterated so that the overall turbine pressure ratio (and expected shaft output) is consistent with the cycle.

The blade root and tip trailing edge radii are calculated using the selected $\phi$, mass flow, pitchline diameter, and RPM through conservation of mass. The values of $\phi$ need to be carefully tailored between turbine stages so that the turbine flowpath is relatively smooth and free of large wall angle discontinuities.

The axial projection of the turbine airfoils (axial chord, designated by AW) and the radial coordinates for the remaining stations of the turbine stage require additional assumptions and the introduction of a non-dimensional parameter for airfoil loading. For the geothermal study, the following airfoil quantities were set as design inputs:

- Vane and rotor incompressible Zwiefel coefficient, Zwi

- Vane and rotor airfoil count, $\mathrm{N}$

- Vane and rotor exit to inlet height ratio, $h_{1} / h_{0}$ and $h_{2} / h_{1}$

- Stage axial velocity ratio, $\mathrm{Cz}_{1} / \mathrm{Cz}_{2}$

- Vane and rotor axial gap, $\Delta \mathrm{Z} /($ upstream $\mathrm{AW})$

- Vane and rotor taper ratio, $\mathrm{AW}_{\text {tip }} / \mathrm{AW}_{\text {hub }}$ 
The Zwiefel coefficient, also referred to as the blade force coefficient, relates the actual lift on an airfoil to a reference lift, as illustrated in Figure 63. For incompressible flow, and allowing for height change through the bladerow, the following relations may be derived:

$$
Z w i_{\text {vane }}=\left[4 \cdot \cos \left(\alpha_{1}\right) \cdot\left[\left(\frac{h_{1}}{h_{0}}\right) \cdot \tan \left(-\alpha_{0}\right) \cdot \cos \left(\alpha_{1}\right)+\sin \left(\alpha_{1}\right)\right] \cdot \frac{\pi \cdot D p}{N \cdot A W}\right] /\left[1+1 /\left(\frac{h_{1}}{h_{0}}\right)\right]
$$

Equation 5. Vane Zwiefel coefficient

$$
Z w i_{\text {rotor }}=\left[4 \cdot \cos \left(-\beta_{2}\right) \cdot\left[\left(\frac{h_{2}}{h_{1}}\right) \cdot \tan \left(\beta_{1}\right) \cdot \cos \left(-\beta_{2}\right)+\sin \left(-\beta_{2}\right)\right] \cdot \frac{\pi \cdot D p}{N \cdot A W}\right] /\left[1+1 /\left(\frac{h_{2}}{h_{1}}\right)\right]
$$

Equation 6. Rotor Zwiefel coefficient
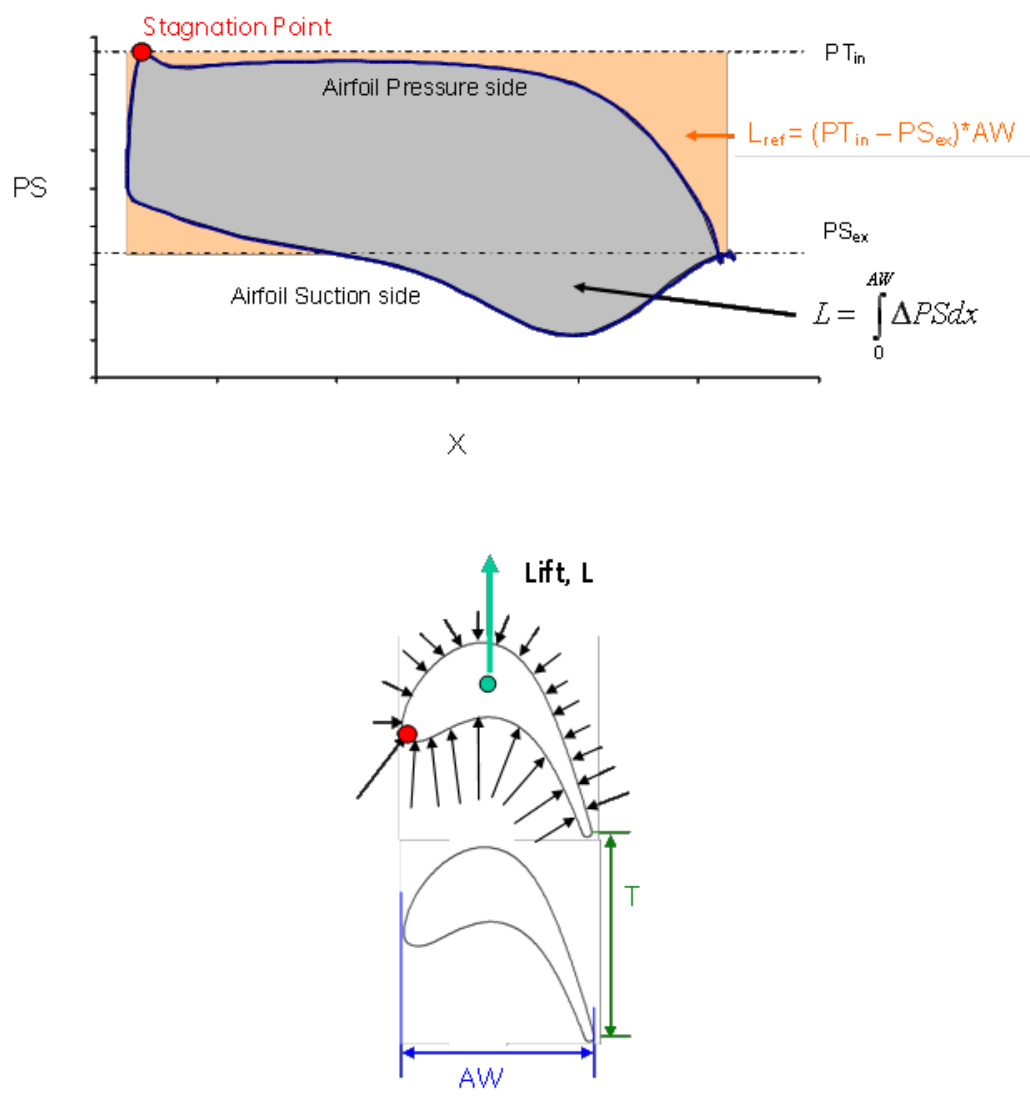

Figure 63. Zwiefel coeficient definition. 
Apparent from the Zwiefel equation is a direct relationship between airfoil count (which has been assumed) and airfoil axial chord (which still needs to be determined). Also apparent is the strong reliance of Zwiefel coefficient on the airfoil flow angles. The flow angles are calculated by combining the 1D design parameter definitions (particularly Equations 2 and 3), the Euler work equation (Equation 1), and the flow vector definitions from Figure 62. From these, the following relations are derived:

$$
\alpha_{1}=\tan ^{-1}\left(\frac{C z_{2}}{C z_{1}} \cdot\left(2 \cdot \frac{\Psi}{\phi}+\tan \left(\alpha_{2}\right)\right)\right.
$$

Equation 7. Vane exit flow angle

$$
\beta_{1}=\tan ^{-1}\left(\tan \left(\alpha_{1}\right)-\frac{1}{\phi} \cdot \frac{C z_{2}}{C z_{1}}\right)
$$

Equation 8. Rotor inlet relative flow angle

$$
\beta_{2}=\tan ^{-1}\left(\tan \left(\alpha_{2}\right)-\frac{1}{\phi}\right)
$$

Equation 9. Rotor exit relative flow angle

Equations 5 through 9, in combination with the selected airfoil design quantities, are used to calculated the axial chord for each airfoil, the radial coordinates for the vane leading and trailing edges, and the radial coordinate for the rotor leading edge.

Of note is that several key aerodynamic parameters are not set by the process detailed here, but are instead implied. Particularly, the stage reaction and airfoil aspect ratio (airfoil height to axial chord ratio) are calculated as outputs, and they must be monitored during the design process. Reaction is adjusted by changing the stage exit swirl assumption (more negative for higher reaction). Airfoil aspect ratio is adjusted by changing either count or Zwiefel. To reduce aspect ratio, count may be reduced at fixed Zwiefel, or Zwiefel may be reduced at fixed count.

\section{Stage Property Calculation}

The flowpath calculation process described in Section 7.2.1 requires knowledge of fluid properties at several stations within the turbine. The new working fluid for the geothermal turbine is highly non-ideal over this cycle's range of temperature and pressure. Gas properties were determined through table interpolation. The property tables used for this turbine design included the following:

- Temperature $=f$ (pressure, enthalpy)

- Entropy $=f$ (pressure, enthalpy)

- Density $=f$ (pressure, enthalpy)

Contours of these functions are included in Figure 64. Additionally, the density and entropy maps were combined to produce a map of $(\partial \mathrm{P} / \partial \mathrm{p})$, which was used to calculate airfoil inlet and exit Mach numbers.

The changes in fluid properties were calculated within each stage according to the thermodynamic process illustrated in Figure 64's H-S diagram. The calculation begins at the inlet of the first vane using the cycle-prescribed boundary conditions. All subsequent stages use the outlet conditions from the preceding stage for inlet conditions. 


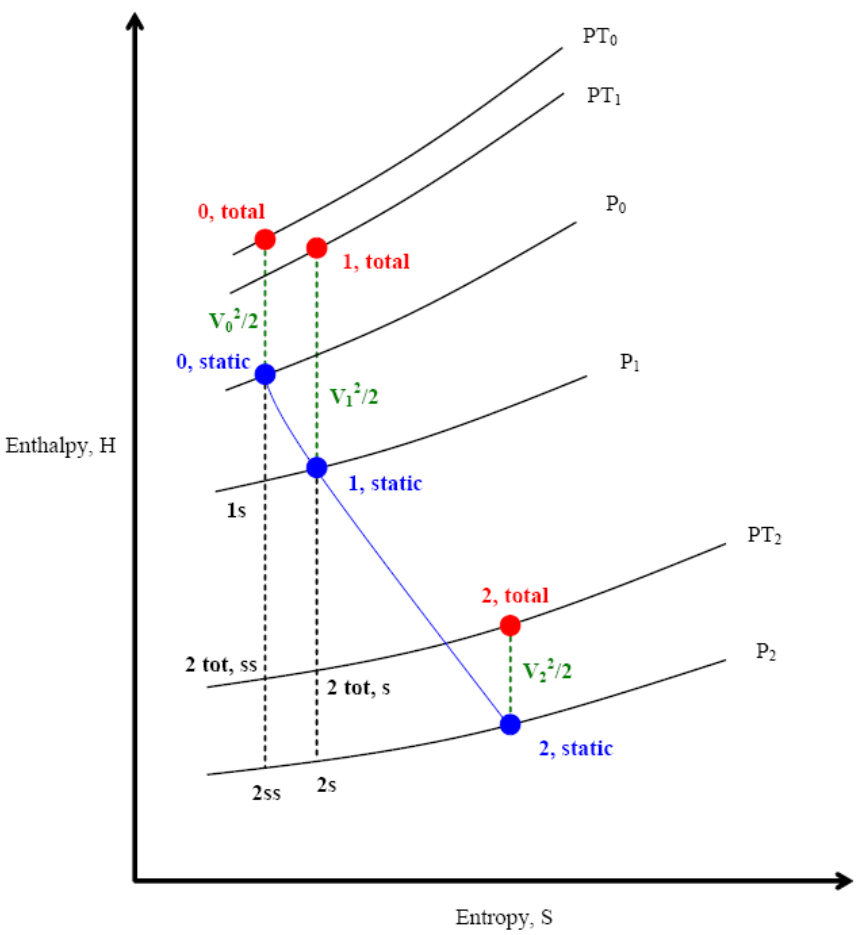

\section{Efficiency Calculation}

Figure 64. $\mathrm{H}-\mathrm{S}$ diagram for a turbine stage.

The fluid property calculation process requires an estimate for each airfoil's efficiency. For the geothermal design process, this quantity is explicitly set as an input quantity. An initial guess is required, and an actual efficiency is produced at the end of the velocity triangle calculation. The guessed efficiency is continually updated with the calculated efficiency until the velocity triangle and efficiency calculations converge. The airfoil efficiency for the geothermal design is calculated using empirical loss correlations. Several components of loss are considered, including profile loss, secondary loss, sonic flow shock loss, and clearance loss. The applied loss model was benchmarked against GE proprietary design tools. The airfoil efficiency prediction error was estimated to be $+/-0.3$ points.

This level of accuracy was deemed sufficient for the high-level configuration studies performed in this design exercise.

\section{Geothermal Axial Turbine Flowpath Design}

The section above described the iterative process that was used to design the flowpath of the geothermal turbine. This section discusses the conceptual turbine design produced by this process. The boundary condition inputs are documented, and the design criteria used for bounding the turbine design are also discussed.

\section{Boundary Conditions}

All of the geothermal turbine design iterations were performed with a consistent set of boundary conditions, as listed below:

- Inlet total pressure, $\mathrm{PT}=47 \mathrm{bar}$

- Inlet total temperature, $\mathrm{TT}=182^{\circ} \mathrm{C}$

- Inlet mass flow $=140 \mathrm{~kg} / \mathrm{s}$

- $\mathrm{RPM}=3600$ 
- Exit static pressure $=2.9$ bar

- Turbine exit swirl (last stage 2) $=0^{\circ}$

- Turbine exit Mach number $=0.565$

In the above list, RPM, all inlet properties, and turbine exit swirl are directly set in the design process. The exit static pressure and exit Mach number, however, must be arrived at iteratively.

The exit static pressure depends on both the turbine work and the turbine efficiency. Starting from initial assumptions for stage $\Psi$, the stage pitchline diameters were adjusted to produce a smooth flowpath with roughly the correct exit pressure and turbine output. The final match for exit static pressure was then set by iteratively tuning the turbine work with small adjustments to $\Psi$ at a fixed pitchline diameter. For all design candidates, the turbine total-to-static pressure ratio was matched to within $0.1 \%$ of the cycle target.

The exit Mach number is strongly influenced and effectively changed by the flow coefficient, $\phi$, of the last turbine stage. When changing $\phi$ to match the exit Mach number, adjustments to work coefficient and pitch diameter may also be required to maintain smooth flowpath angles and to maintain the target exit static pressure. For all design candidates, the turbine exit Mach number was matched to within $0.1 \%$ of the aero target.

\section{Stage Count Selection}

Three axial turbines, each with a different stage count, were produced for the initial flowpath screening: 2 stages, 3 stages, and 4 stages. For each turbine, the stage and airfoil inputs were adjusted so that the individual aerodynamic parameters fit within the GE Power and Water product history as best as possible. The resulting stage properties are shown in Figure 67, airfoil properties are shown in Figure 68, and wall slopes are shown in Figure 69. The resulting performance trends are shown in Figure 70. An overlay of the flowpaths is shown in Figure 71.

While most parameters could be held within GE Power and Water history for all of the stage counts, it becomes apparent that the two-stage turbine is quite aggressive and produces some far outlying aerodynamic properties that are highly undesirable. In particular, the stage pressure ratios (and resulting airfoil Mach numbers) are very high, and the wall slopes in the second stage are substantially beyond current design experience. That, combined with the low predicted performance, eliminated the two-stage turbine from further consideration in this study.

The three stage turbine more closely fits the product history - it has fewer outlier quantities, and the outliers do not move nearly as far beyond current experience as observed in the two-stage design. The four stage turbine also has few outlier quantities, and some parameters that fall outside of the product history range are not aerodynamically detrimental (such as low turning and high convergence in blade 1). As seen in Figure 70, the four stage turbine also has a sizeable efficiency advantage relative to the three stage turbine-more than 1 point in overall efficiency. The four stage turbine was therefore selected for further development as the candidate configuration for the geothermal turbine. 
Work Coefficient

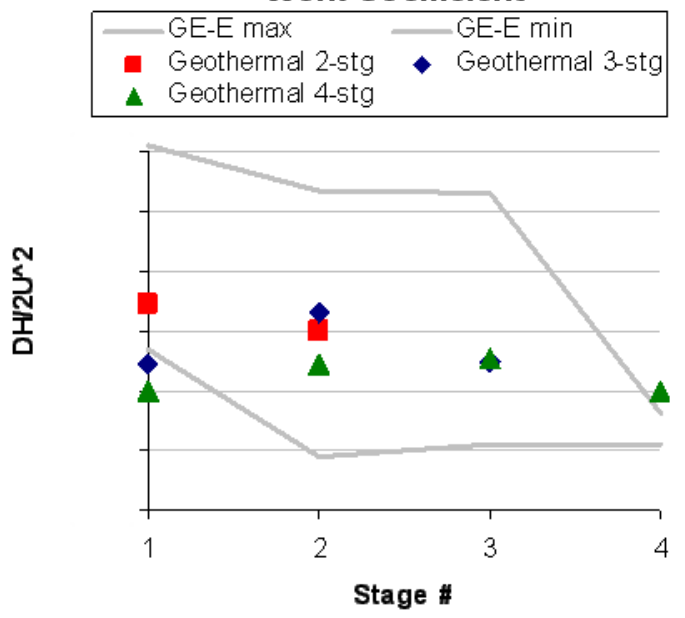

Stage Pressure Ratio

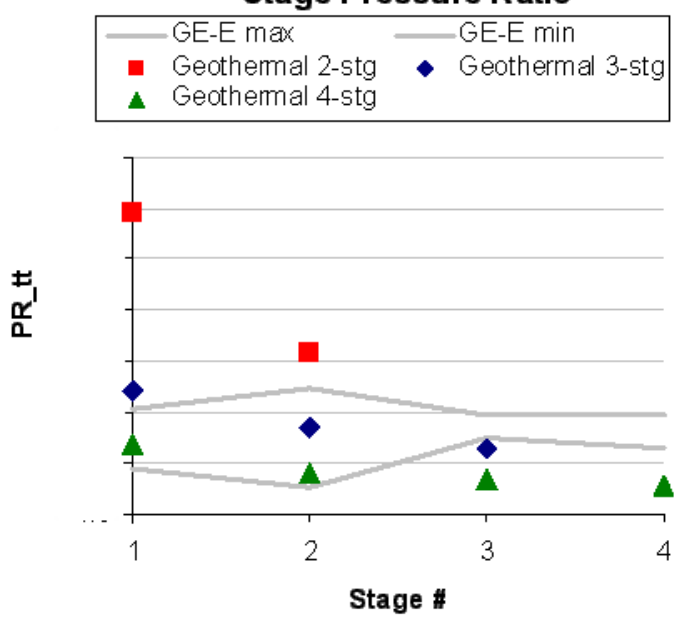

Stage Work Split

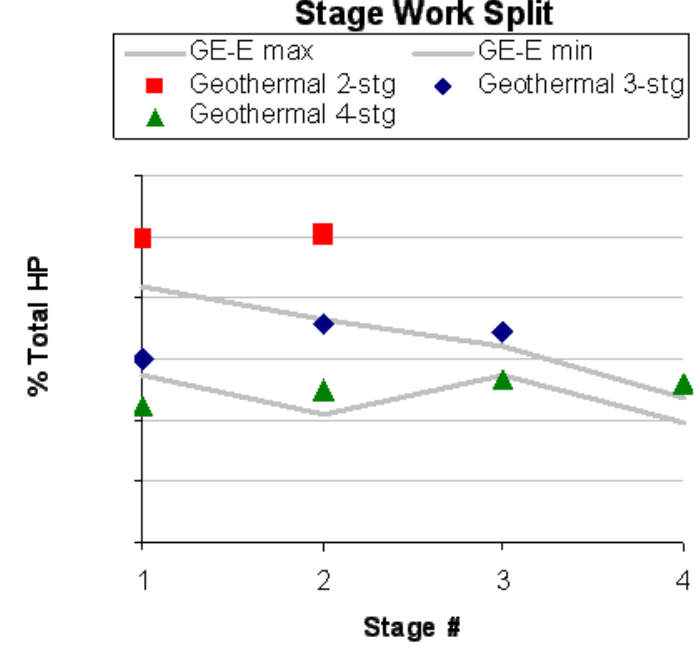

Flow Coefficient

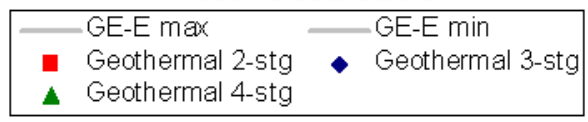

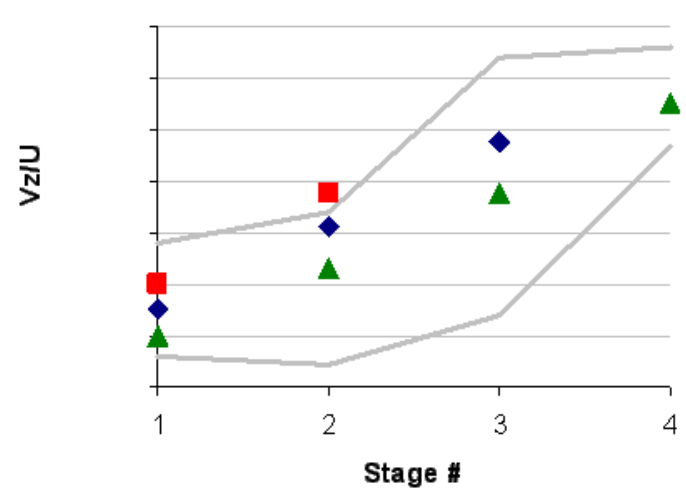

Stage Reaction

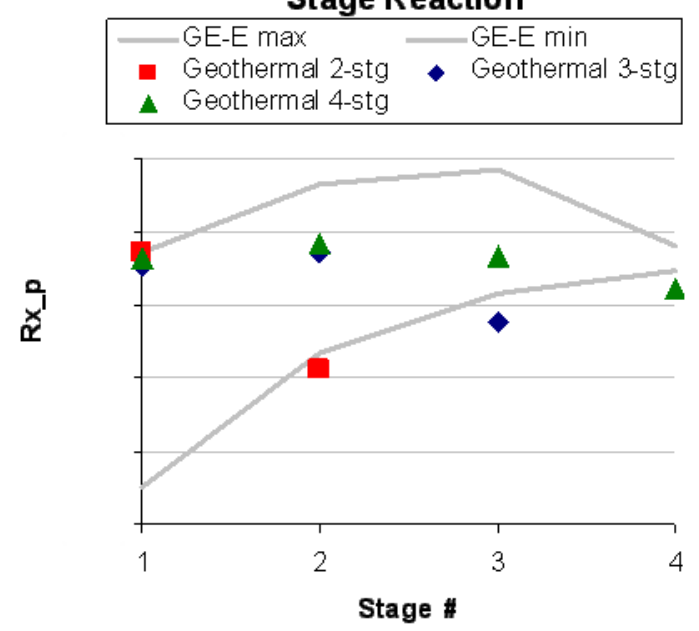

Stage Exit Swir

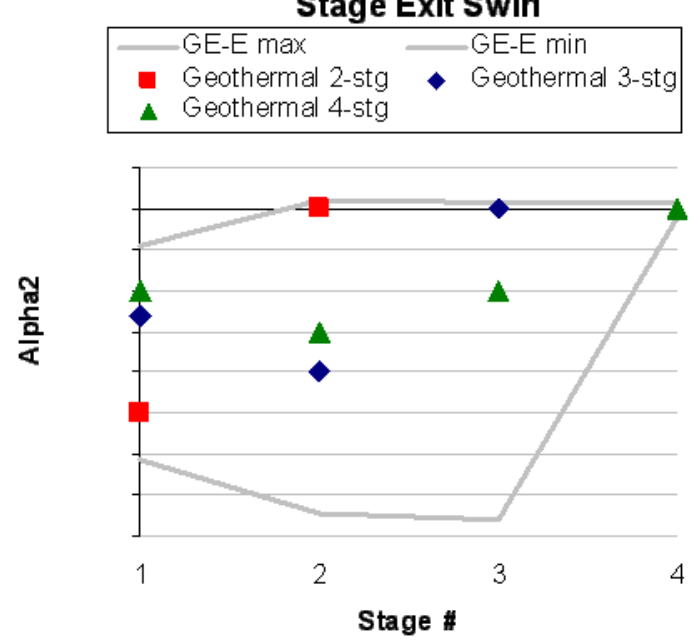

Figure 67 . Count screening study-stage properties 


\section{Blade Turning}

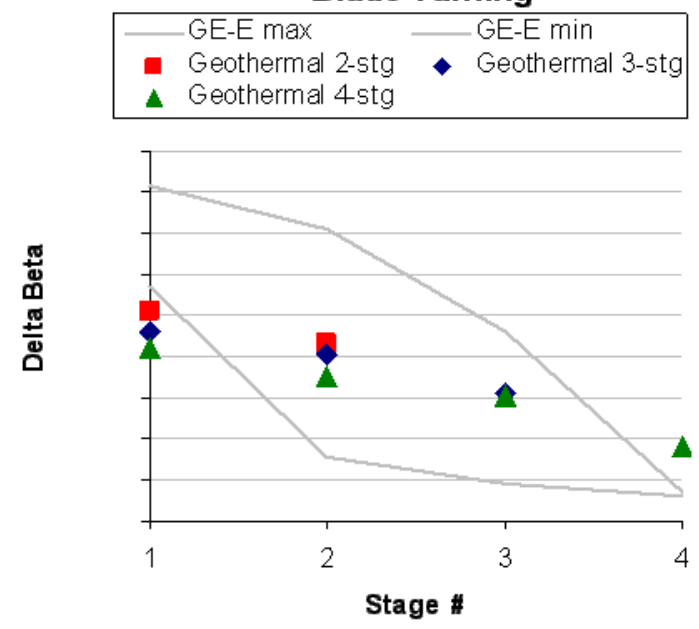

Airfoil Aspect Ratio

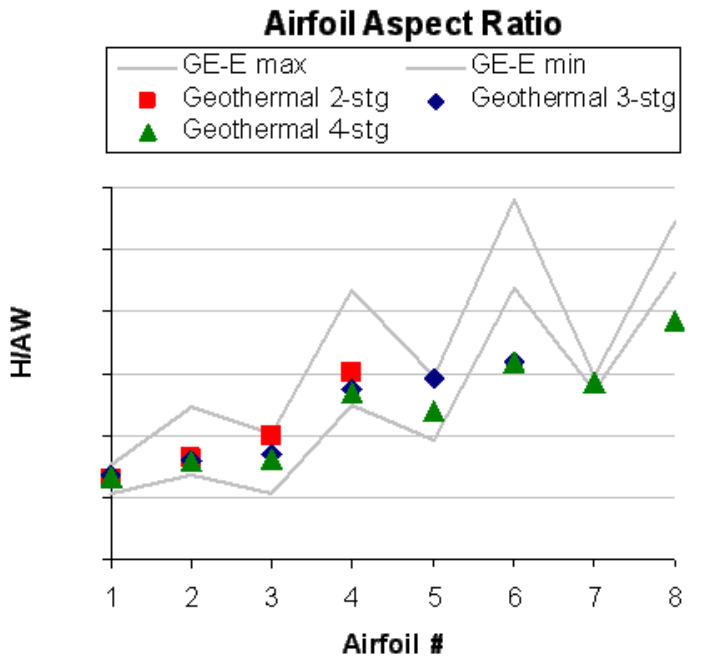

\section{Airfoil Loading}

\begin{tabular}{|ll|}
\hline - GE-E max & Geothermal 2-stg \\
- Geothermal 4stg &
\end{tabular}

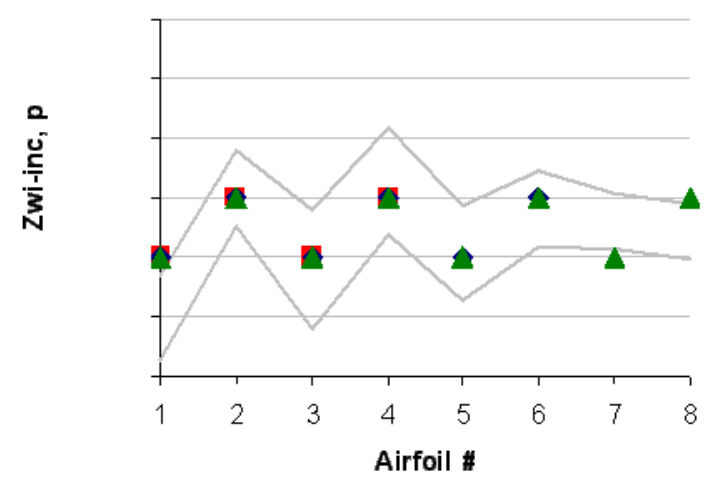

Blade Convergence

\begin{tabular}{|l}
\hline GE-E max \\
\hline Geothermal 2-stg \\
A Geothermal 4stg
\end{tabular}

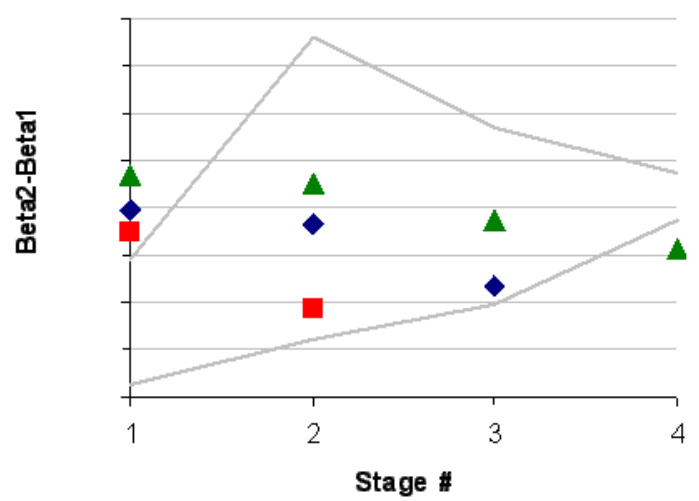

Airfoil Solidity
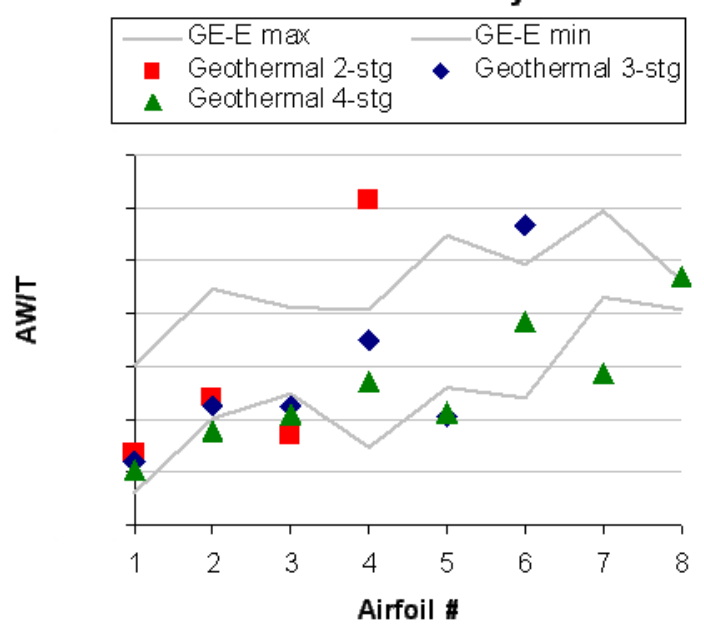

Figure 68. Count screening study-airfoil properties. 

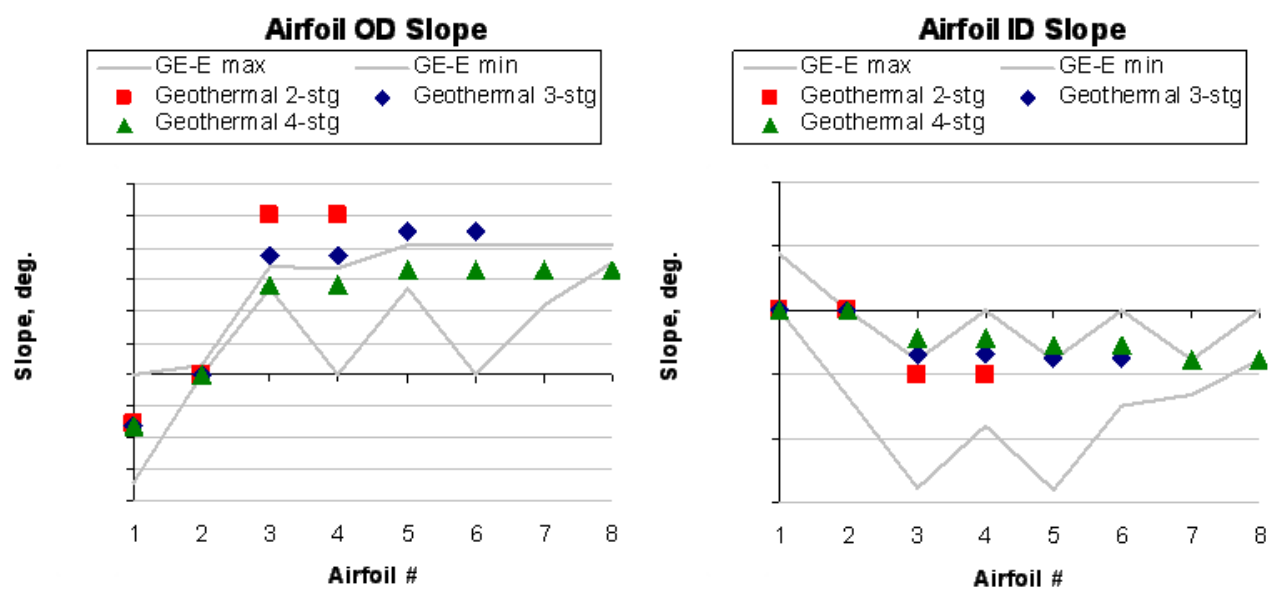

Figure 69. Count screening study-wall slopes.
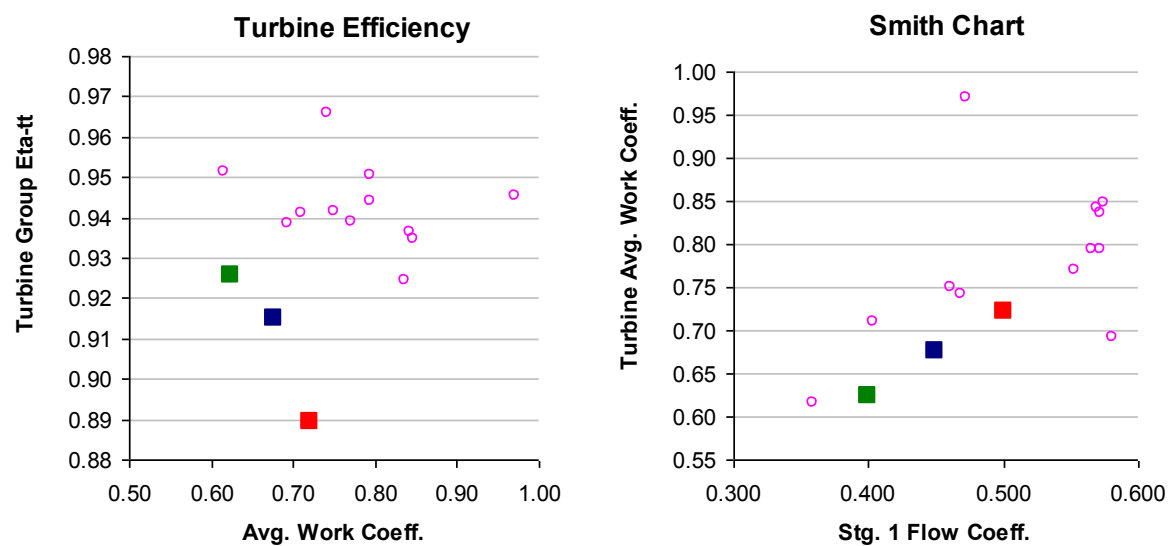

Figure 70. Count screening study-efficiency and Smith chart.

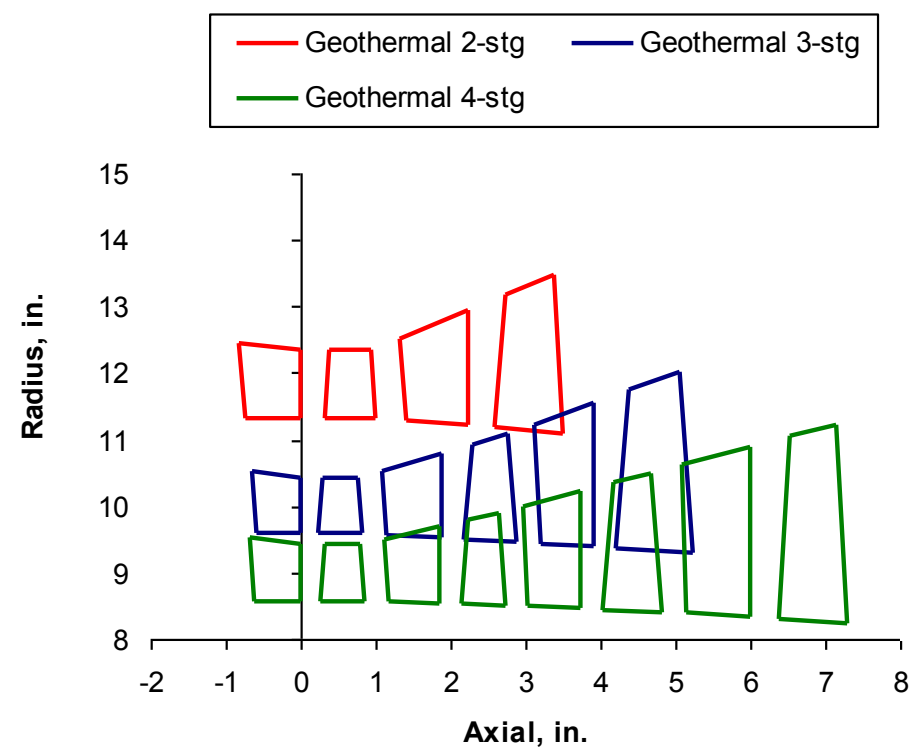

Figure 71. Count screening study-flowpath overlay. 


\section{Final Conceptual Flowpath}

Several adjustments were made to the final conceptual four stage turbine design in order to simplify the mechanical design and improve the efficiency estimate. These changes included:

- The aerodynamic flowpath design was constrained to produce a constant hub diameter through the entire turbine. This was implemented to simplify the mechanical design and to minimize turbine cost.

- An exhaust diffuser was added to the flowpath calculation process to better reflect the actual mechanical configuration. Because the diffusing section is assumed to be rather short (much like a hot-end drive gas turbine or a low pressure steam turbine), a relatively low compressible recovery factor of 0.3 was assumed for the diffuser. The addition of the diffuser required some small modifications to turbine work, as the exit static pressure boundary condition is now applied at the diffuser exit. This yields a slightly higher turbine pressure ratio than what had been used to originally bound the design.

- The efficiency calculation process used with the geothermal design accounts for the bypass flow around the rotor tips. It does not, however, account for bypass flows around the vane hubs. An additional loss was added to each vane to account for this leakage path. The magnitude of this loss was estimated based on the tip clearance loss model. The overall vane leakage loss was then compared to derivatives produced from an existing design system model for a GE Power and Water four stage turbine to ensure that it was sufficiently conservative. For the four stage geothermal design, the applied vane leakage penalty was 0.5 points in overall turbine efficiency.

Table 22 shows key geometric and aerodynamic parameters for the four stage geothermal turbine design. Figure 72, and Figure 73 show the turbine flowpath cross-section and conceptual airfoil sections at hub, pitch, and tip. 
Table 22. Final conceptual flowpath-geometric properties.

\section{Geometric Properties}

Turbine flowpath maximum length 7.791 inches

\begin{tabular}{|c|c|c|c|c|c|}
\hline & Stage 1 & Stage 2 & Stage 3 & Stage 4 & \\
\hline Vane count & 54 & 66 & 74 & 74 & - \\
\hline Vane axial chord (mid) & 0.637 & 0.706 & 0.702 & 0.845 & inches \\
\hline Vane height (trailing edge) & 0.851 & 1.137 & 1.692 & 2.476 & inches \\
\hline Vane aspect ratio & 1.34 & 1.61 & 2.41 & 2.93 & - \\
\hline Rotor count & 80 & 110 & 110 & 110 & - \\
\hline Rotor axial chord (mid) & 0.535 & 0.520 & 0.634 & 0.746 & inches \\
\hline Rotor height (trailing edge) & 0.851 & 1.353 & 1.989 & 2.892 & inches \\
\hline Rotor tip diameter & 18.851 & 19.853 & 21.124 & 22.932 & - \\
\hline Rotor aspect ratio & 1.59 & 2.60 & 3.14 & 3.88 & - \\
\hline
\end{tabular}

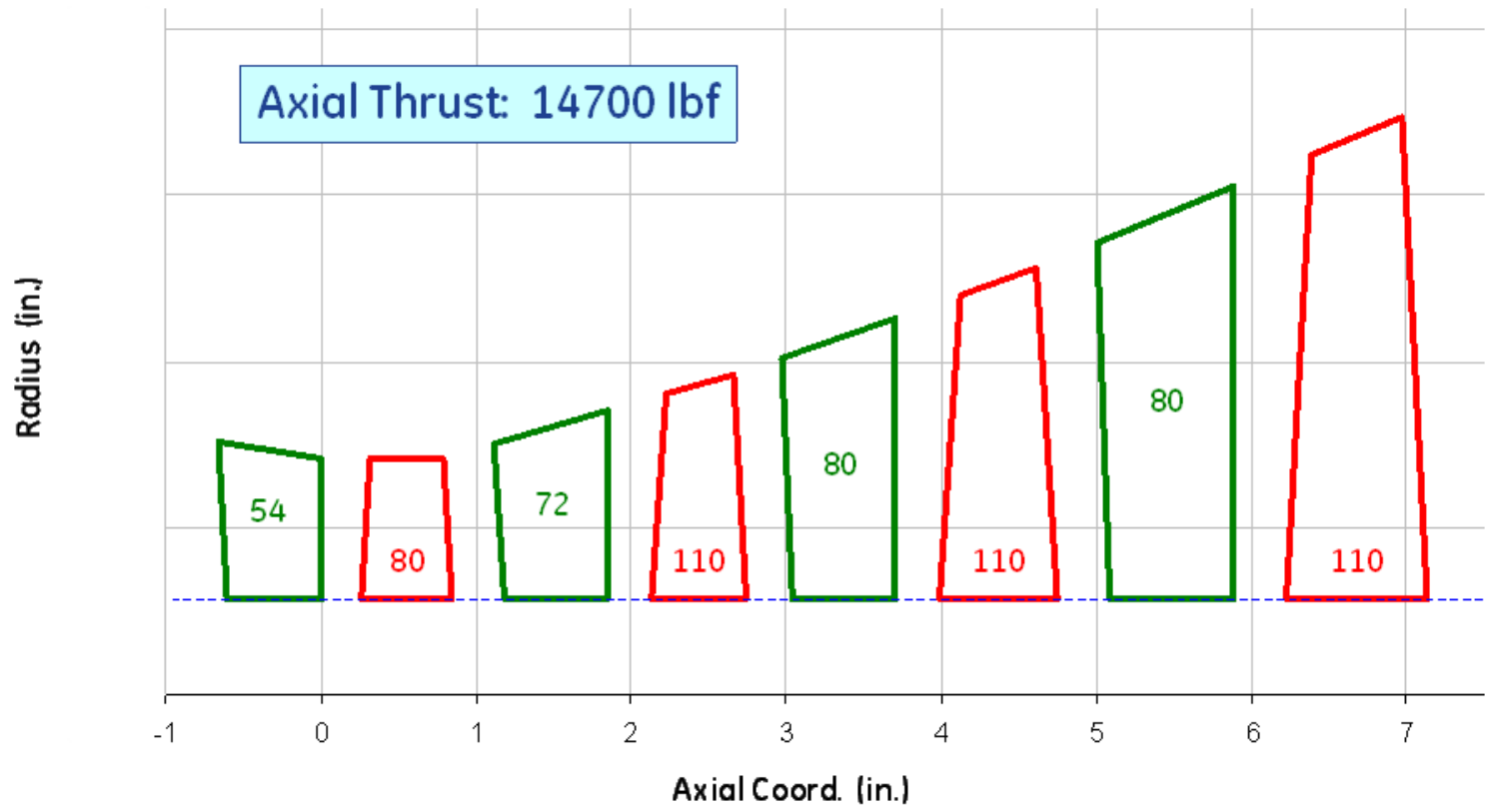

Figure 72. Final conceptual flowpath cross section. 
$\begin{array}{llllllll}\mathrm{N} 1 & \mathrm{~B} 1 & \mathrm{~N} 2 & \mathrm{~B} 2 & \mathrm{~N} 3 & \mathrm{~B} 3 & \mathrm{~N} 4 & \mathrm{~B} 4\end{array}$
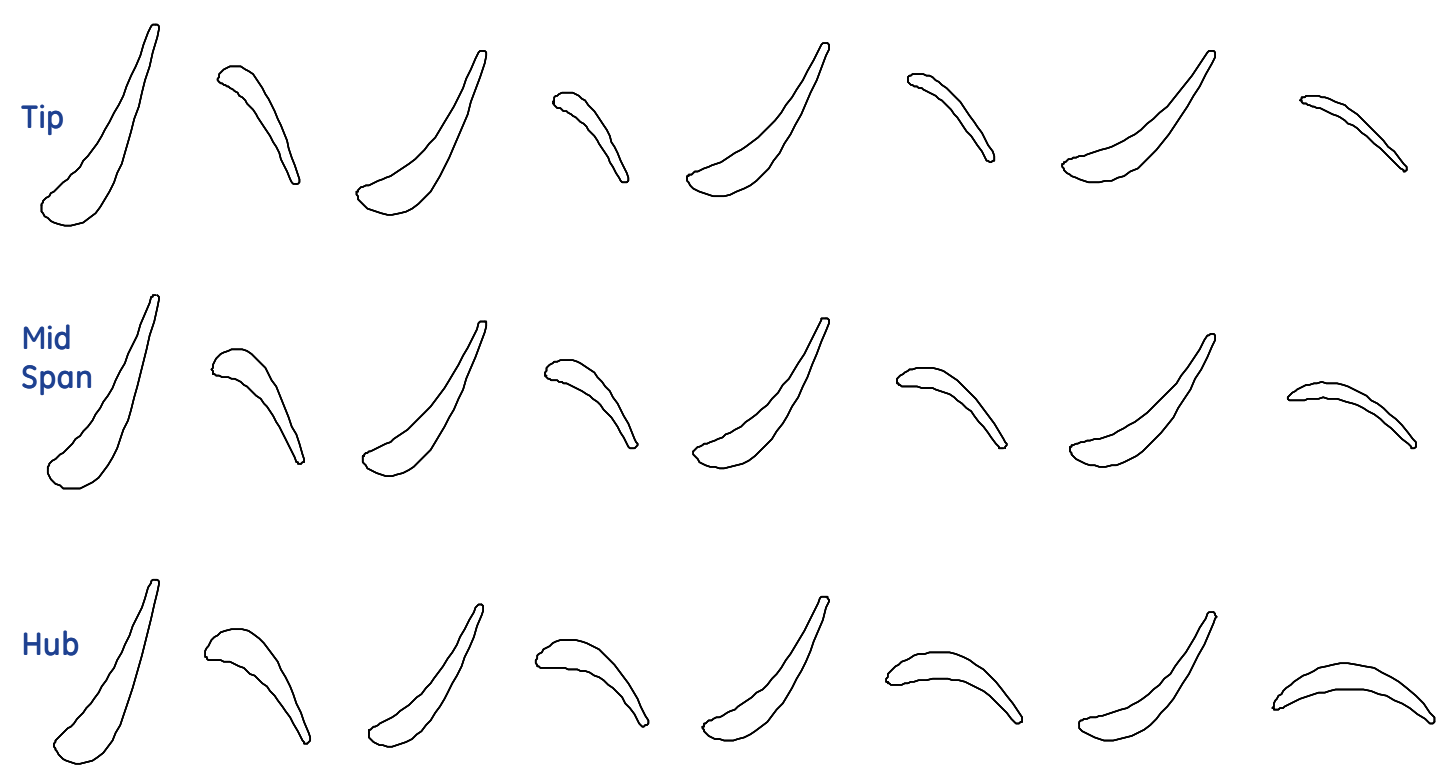

Figure 73. Conceptual airfoil hub, pitch, and tip sections. 


\subsubsection{Radial Expander Design Process}

The turboexpander is a reaction type radial turbine originally developed to replace the Joules Thompson valve in air separation plants. The French Engineer, George Claude, utilized the first radial turbine for air liquefaction in the early 1900s. German engineers, including Dr. Carl von Linde, further developed and improved the turbines for many other applications, such as refrigeration and jet propulsion engines. After World War II, Dr. Judson Swearingen began to develop the turboexpander for natural gas processing applications. He realized the overall cooling capacity of the plant and, therefore, the cost and performance, is greatly improved by replacing the Joules Thompson valve with a simple and reliable machine that expands a single-phase stream in a nearly isentropic method. The fact that the radial inflow turbine could handle two-phase flow at the discharge made the machine perfect for heavy hydrocarbon removal.

The turboexpander expands process fluid from a high pressure to a lower pressure through an isentropic process. The change of enthalpy produces mechanical energy (Figure 74). The GE Oil \& Gas turboexpanders product line is standardized so that most of the components are pre-designed. Parts that normally need to be customized for each project are the wheels (both expander and compressor), shaft, nozzle assembly, diffuser cone, compressor follower, gear, auxiliaries, and controls. The naming convention for machine standardization is called the "frame" size. The frame size is directly linked to the casing and, therefore, the overall dimension of the machine. Each standard frame can accommodate a specific diameter range of expander wheels.

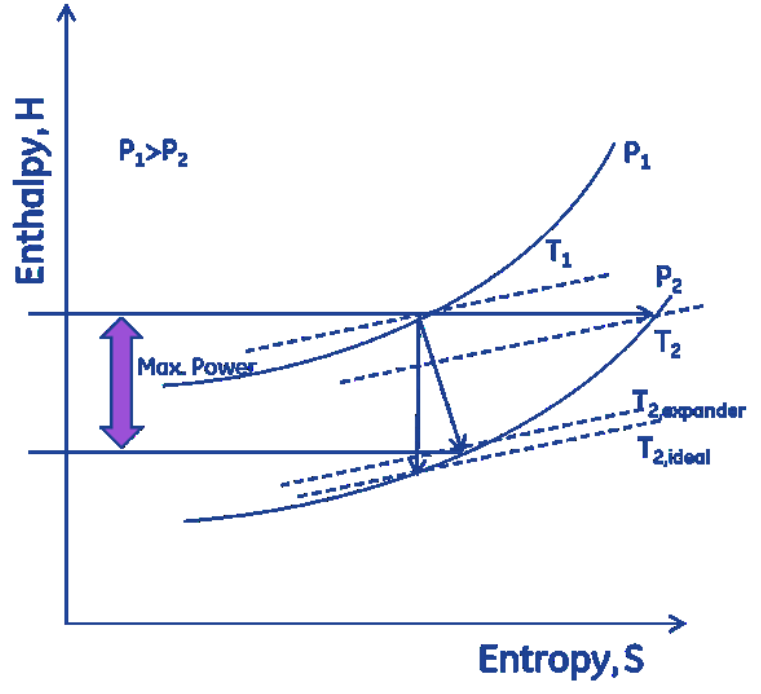

Figure 74. Entropy-enthalpy curves illustrating constant enthalpy, isentropic (ideal), and actual expander cases.

\section{Radial Turboexpander Design}

Typical design limitations for GE Oil \& Gas expanders are as follows:

- Power up to $35 \mathrm{MW}$ with synchronous generator

- Power up to $10 \mathrm{MW}$ with induction generator

- Wheel diameter up to $1800 \mathrm{~mm}$

- Design temperature from $-270^{\circ} \mathrm{C}$ to $+315^{\circ} \mathrm{C}$

- Mechanical design in accordance to API 617

- The active magnetic bearing units need to be checked versus the standard bearing size from suppliers 
Figure 75 shows the impeller wheel for the radial turboexpander.

Once the expander size is down selected, various options towards design integration are available:

- Lube oil integral to baseplate

- External lube oil console

- Induction generator preferred for process gas applications

- Hydraulic actuators for synchronous machines

- Pneumatic, electric or hydraulic actuators for induction generators

- Dry gas seals

- Oil seals (floating ring type)

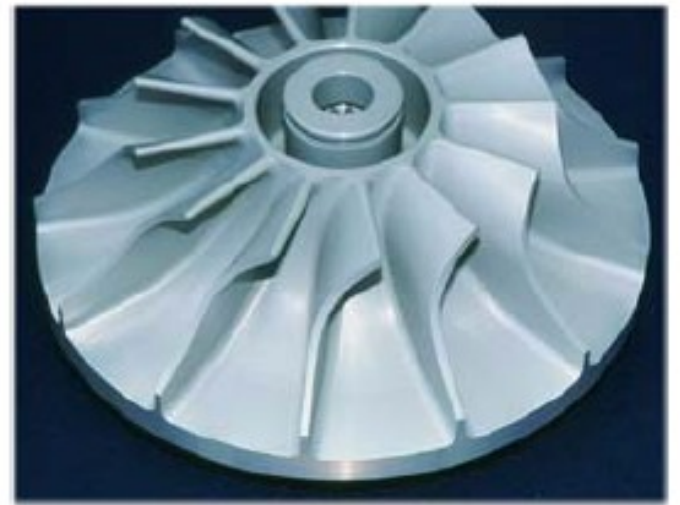

Figure 75. Photo image of the impeller wheel for the radial turboexpander.

\section{Experimental Turboexpander Efficiency and Model}

Based on the experimental and design data for the GE Oil \& Gas turboexpanders, an empirical model for calculating the expander efficiency and size was developed and integrated into the HYSYS model for subcritical and supercritical cycles. This empirical code closely follows the GE Oil \& Gas design practice and incorporates actual experimental data to calculate the parameters including expander efficiency, machine frame size, RPM, specific speed, tip speed, spouting velocity, and the wheel diameter. A typical calculation for the expander design using this empirical model requires input parameters including, stream composition, inlet pressure and temperature of the gas, and the mass flow rate. The radial expanders only accommodate a single phase in the inlet stream. The stream can be $100 \%$ vapor or liquid at the inlet. The outlet stream from the expander can be a maximum of 50-50\% mix of vapor and liquid. The liquid and vapor inlet streams are treated differently in this model. In this calculation, we begin by calculating a RPM factor for the machine based on the mass flow rate, enthalpy drop, and an optimal value of specific speed. Based on the RPM factor, the actual RPM and specific speed can be determined. The specific speed and RPM is then used to calculate the spouting velocity and tip speed of the wheel from digitized curves (Figure 76).

The diameter of the expander follows directly from the RPM and the tip speed. The efficiency is now predicted based on the wheel diameter and the RPM based on the digitized curves shown in Figure 77, while the horse power of the machine is derived from the enthalpy drop, flow rate, and efficiency. In the current model, the wheel diameter is limited to 15 inches based on the previous machines developed by GE Oil \& Gas. When the first iteration of calculations show that to meet the required performance a larger machine is required, the model raises a flag to indicate need for several machines or a higher number of stages.

\section{Radial Expander Designs Boundary Conditions}

All of the geothermal turbine design iterations were performed with a consistent set of boundary conditions, as listed below:

- Inlet total pressure, PT $=47$ bar

- Inlet total temperature, $\mathrm{TT}=182^{\circ} \mathrm{C}$

- Inlet mass flow $=140 \mathrm{~kg} / \mathrm{s}$

- RPM = Optimal for geared designs

- Exit static pressure $=2.9$ bar 


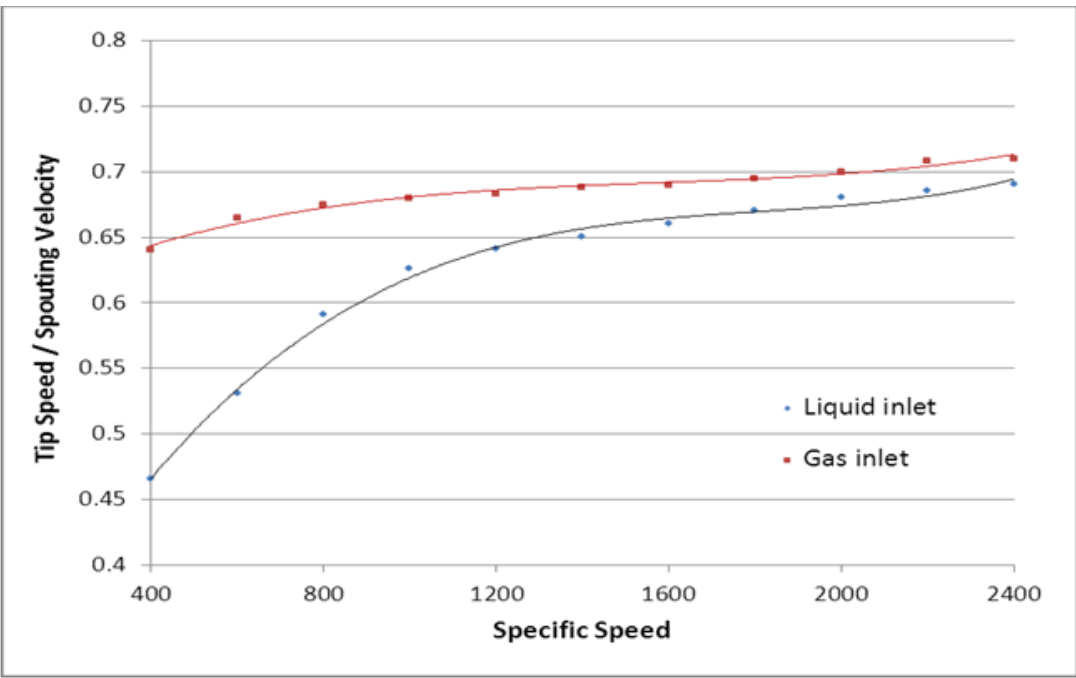

Figure 76. Digitized graphs for the calculation of tip speed based on specific speed and the composition of inlet fluid in the expander design process.

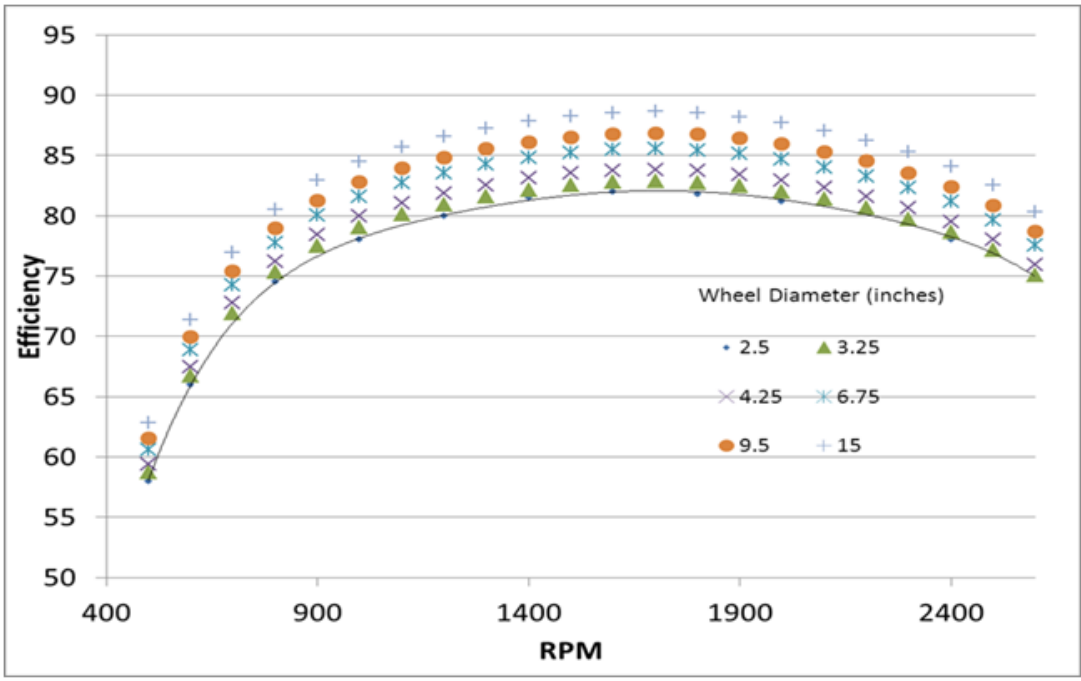

Figure 77. Predicted efficiency as a function of RPM and the wheel diameter. 
Using the set of boundary conditions above a two-stage and a single-stage radial expander designs were accomplished using the GE Oil \& Gas design practice. The details of these designs are presented in Table 24.

\subsection{ANALYSIS AND DISCUSSION}

The radial design specifications were within those of current design practice from GE Oil \& Gas. The cost of these machines was available directly from the GE Oil \& Gas commercial tools meant for cost estimations and budgetary quotes through Damiano Menichetti. The axial machine design costing however was trickier and this was accomplished by leveraging the cost of barrel compressors for the casing including the sealing system for the rated diameter, length, pressure, and temperature without the rotor. The rotor cost was included separately based on the number of stages, blade counts, length, and diameter using axial steam turbine products. Table 25 shows the normalized comparative cost analysis at $5 \mathrm{MWe}$. Table 26 shows the same comparison at 15 MWe.

Table 24. Two-stage and single-stage design details.

\begin{tabular}{|c|c|c|c|c|c|c|}
\hline & \multicolumn{3}{|c|}{ Two-stage } & \multicolumn{3}{|c|}{ Single-stage } \\
\hline & & HP & LP & & & \\
\hline Molecular weight & MW & 130.50 & 130.50 & $\mathrm{~kg} / \mathrm{kmol}$ & 130.50 & $\mathrm{~kg} / \mathrm{kmol}$ \\
\hline Inlet total pressure & $\mathrm{p}_{00}$ & 47.00 & 8.50 & barA & 47.00 & barA \\
\hline Inlet total temperature & $\mathrm{T}_{00}$ & 182.00 & 89.78 & ${ }^{\circ} \mathrm{C}$ & 182.00 & ${ }^{\circ} \mathrm{C}$ \\
\hline Outlet total pressure & $\mathrm{p}_{02}$ & 8.50 & 2.90 & barA & 2.90 & barA \\
\hline Outlet total temperature & $\mathrm{T}_{02}$ & 89.78 & 57.91 & ${ }^{\circ} \mathrm{C}$ & 60.47 & ${ }^{\circ} \mathrm{C}$ \\
\hline Mass flow rate & $\mathrm{m}$ & 140.00 & 140.00 & $\mathrm{~kg} / \mathrm{s}$ & 140.00 & $\mathrm{~kg} / \mathrm{s}$ \\
\hline Isentropic enthalpy drop & $\mathrm{Dh}_{\mathrm{s}}$ & 26.14 & 20.86 & $\mathrm{~kJ} / \mathrm{kg}$ & 46.52 & $\mathrm{~kJ} / \mathrm{kg}$ \\
\hline Inlet volume flow & $Q_{00}$ & 0.338 & 3.106 & $\mathrm{~m}^{3} / \mathrm{s}$ & 0.338 & $\mathrm{~m}^{3} / \mathrm{s}$ \\
\hline Outlet volume flow & $\mathrm{Q}_{02}$ & 3.108 & 9.344 & $\mathrm{~m}^{3} / \mathrm{s}$ & 9.536 & $\mathrm{~m}^{3} / \mathrm{s}$ \\
\hline Inlet compressibility factor & $Z_{0}$ & 0.392 & 0.824 & - & 0.392 & - \\
\hline Outlet compressibility factor & $Z_{2}$ & 0.824 & 0.928 & - & 0.929 & - \\
\hline Rotating speed & $\mathrm{N}$ & 6400 & 3100 & RPM & 3600 & RPM \\
\hline Stage efficiency & $\mathrm{h}_{\mathrm{s}}$ & 0.885 & 0.904 & - & 0.820 & * \\
\hline Wheel diameter & $D_{1}$ & 475 & 875 & $\mathrm{~mm}$ & 1080 & $\mathrm{~mm}$ \\
\hline Power & W & 3238 & 2639 & kW & 5340 & kW \\
\hline Power (tot) & $\mathrm{W}_{\text {TOT }}$ & 5877 & & & 5340 & \\
\hline \multirow[t]{2}{*}{ Gear } & $\mathrm{h}$ & 0.98 & & & & \\
\hline & & 5759 & $\mathrm{~kW}$ & & & \\
\hline
\end{tabular}


Table 25. Comparative cost analysis at $5 \mathrm{MWe}$.

\begin{tabular}{|c|c|c|c|c|c|c|c|}
\hline \multirow[b]{2}{*}{ Item } & \multicolumn{2}{|c|}{ Axial } & \multicolumn{2}{|c|}{ Radial integrally geared } & \multicolumn{3}{|c|}{ Radial overhung } \\
\hline & Cost (€) & Notes & Cost $(€)$ & Notes & Cost $(€)$ & & tes \\
\hline Total cost & $1.31 \times$ & - & $1.23 x$ & - & $1.48 x$ & & - \\
\hline Gas & \multicolumn{7}{|c|}{ New Fluid } \\
\hline P1 (Bar-A) & \multicolumn{7}{|c|}{47} \\
\hline $\mathrm{T} 1\left({ }^{\circ} \mathrm{C}\right)$ & \multicolumn{7}{|c|}{182} \\
\hline P2 (Bar-A) & \multicolumn{7}{|c|}{2.9} \\
\hline Enthalpy drop (KJ/Kg) & \multicolumn{7}{|c|}{47} \\
\hline Flow Kg/sec) & \multicolumn{7}{|c|}{140} \\
\hline Efficiency & \multicolumn{4}{|c|}{$88 \%$} & & $88 \%$ & $82 \%$ \\
\hline Power at generator shaft $(\mathrm{Kw})$ & \multicolumn{4}{|c|}{5,690} & & 5,617 & 5,296 \\
\hline$€ / \mathrm{Kw}$ & \multicolumn{4}{|c|}{416} & & 394 & 504 \\
\hline
\end{tabular}

Table 26. Comparative cost analysis at $15 \mathrm{MWe}$.

\begin{tabular}{|c|c|c|c|c|c|c|}
\hline \multirow[b]{2}{*}{ Item } & \multicolumn{2}{|c|}{ Axial } & \multicolumn{2}{|c|}{ Radial integrally geared } & \multicolumn{2}{|c|}{ Radial overhung } \\
\hline & Cost $(€)$ & Notes & Cost $(€)$ & Notes & Cost $(€)$ & Notes \\
\hline Total cost & $1 X$ & & $1.25 \mathrm{X}$ & & $1.09 X$ & \\
\hline Gas & \multicolumn{6}{|c|}{ New Fluid } \\
\hline P1 (Bar-A) & \multicolumn{6}{|c|}{47} \\
\hline $\mathrm{T} 1\left({ }^{\circ} \mathrm{C}\right)$ & \multicolumn{6}{|c|}{182} \\
\hline P2 (Bar-A) & \multicolumn{6}{|c|}{2.9} \\
\hline Enthalpy drop (KJ/Kg) & \multicolumn{6}{|c|}{47} \\
\hline Flow Kg/sec) & \multicolumn{6}{|c|}{364} \\
\hline Efficiency & \multicolumn{2}{|c|}{$88 \%$} & \multicolumn{2}{|c|}{$88 \%$} & \multicolumn{2}{|c|}{$85 \%$} \\
\hline Power at generator shaft $(\mathrm{Kw})$ & \multicolumn{2}{|c|}{14,955} & \multicolumn{2}{|c|}{14,603} & \multicolumn{2}{|c|}{14,442} \\
\hline$€ / \mathrm{Kw}$ & \multicolumn{2}{|c|}{222} & \multicolumn{2}{|c|}{284} & \multicolumn{2}{|c|}{251} \\
\hline
\end{tabular}

Table 27 presents the performance comparison of various designs completed in the current study. Combining the cost and performance numbers presented above, the overall impact of the turbine on the power block is presented in Table 28.

In terms of pure capital cost, of the radial machines for novel fluid and power cycle combination presented here, radial designs provide the lowest CAPEX at $5 \mathrm{MWe}$ while axial designs are more attractive at $15 \mathrm{MWe}$. However, considering the high capital investment in the EGS system, from an LCOE optimization perspective, it is best to have highly efficient axial machines as the power turbine for geothermal power plants. In conclusion, at a $15 \mathrm{MWe}$ or higher power rating, multi stage axial turbine for supercritical new fluid power block is most suitable providing the best performance and cost. However at lower power ratings in the $5 \mathrm{MWe}$ range, the expander technology to be chosen depends on the application of the power block. For EGS power blocks, it is most optimal to use multi-stage axial machines. 
Table 27. Comparison of various designs completed in the current study.

\begin{tabular}{|c|c|c|c|c|}
\hline Machine type & $\begin{array}{l}\text { Axial } \\
\text { three-stages }\end{array}$ & $\begin{array}{c}\text { Axial } \\
\text { four-stages }\end{array}$ & $\begin{array}{c}\text { Radial } \\
\text { two-stages }\end{array}$ & $\begin{array}{l}\text { Radial } \\
\text { single-stage }\end{array}$ \\
\hline P1 (Bar-A) & \multicolumn{4}{|c|}{47} \\
\hline $\mathrm{T} 1\left({ }^{\circ} \mathrm{C}\right)$ & \multicolumn{4}{|c|}{182} \\
\hline P2 (Bar-A) & \multicolumn{4}{|c|}{2.9} \\
\hline Flow $(\mathrm{Kg} / \mathrm{sec})$ & \multicolumn{4}{|c|}{140} \\
\hline Inlet volume $\left(\mathrm{m}^{3} / \mathrm{h}\right)$ & \multicolumn{4}{|c|}{1,220} \\
\hline Isentropic enthalpy drop $(\mathrm{KJ} / \mathrm{Kg})$ & \multicolumn{4}{|c|}{47} \\
\hline Exhaust temperature $\left({ }^{\circ} \mathrm{C}\right)$ & 56 & 55 & 58 & 64 \\
\hline Exhaust volume $\left(\mathrm{m}^{3} / \mathrm{h}\right)$ & 33,200 & 33,120 & 33,640 & 34,330 \\
\hline RPM & 3,600 & 3,600 & $6,400 / 3,100$ & 3,600 \\
\hline Thermodynamic power without mech. losses $(\mathrm{Kw})$ & 6,015 & 6,094 & 5,877 & 5,340 \\
\hline Power at generator shaft & 5,985 & 6,064 & 5,730 & 5,300 \\
\hline
\end{tabular}

Table 28. Impact of the turbine on the power block.

\begin{tabular}{l|c|c} 
& Cost $(\$ / \mathrm{KW})$ & Cost $(\$ / \mathrm{KW})$ \\
\hline Two-stage radial & $\mathbf{5} \mathbf{~ M W e}$ & $\mathbf{1 5} \mathbf{M w e}$ \\
\hline Single-stage radial & 394 & 284 \\
\hline Three-stage axial & 504 & 251 \\
\hline Four-stage axial & 416 & 222 \\
\hline
\end{tabular}




\section{Conclusions}

The main focus of Phase 3 was to experimentally validate the thermodynamic properties that formed the basis of the thermo-economic model built in Phase 2, and thus build confidence that the predictions of the model could be used reliably for process downselection and preliminary design at a given set of geothermal (and/or waste heat) boundary conditions.

The fluid and cycle downselected was based on a new proprietary fluid from a vendor in a supercritical ORC cycle at a resource condition of $200^{\circ} \mathrm{C}$ inlet temperature. The team devised and executed a series of experiments to prove the suitability of the new fluid in realistic ORC cycle conditions. Furthermore, the team performed a preliminary design study for a MW-scale turbo expander that would be used for a supercritical ORC cycle with this new fluid. The following summarizes the main findings in the investigative campaign that was undertaken:

1. Chemical compatibility of the new fluid with common seal/gasket/Oring materials was found to be problematic. Neoprene, Viton, and silicone materials were found to be incompatible, suffering chemical decomposition, swelling and/or compression set issues. Of the materials tested, only TEFLON was found to be compatible under actual ORC temperature and pressure conditions.

2. Thermal stability of the new fluid at $200^{\circ} \mathrm{C}$ and 40 bar was found to be acceptable after 399 hours of exposure - only $3 \%$ of the initial charge degraded into by products. The main degradation products being an isomer and a dimer.

3. In a comparative experiment between R245fa and the new fluid under subcritical conditions, it was found that the new fluid operated at 1 bar lower than R245fa for the same power output, which was also predicted in the Aspen HSYSY model. As a drop-in replacement fluid for R245fa, this new fluid was found to be at least as good as R245fa in terms of performance and stability. Further optimization of the subcritical cycle may lead to a significant improvement in performance for the new fluid.

4. For supercritical conditions, the experiment found a good match between the measured and model predicted state point property data and duties from the energy balance. The largest percent differences occurred with densities and evaporator duty (see Figure 78). It is therefore reasonable to conclude that the state point model was experimentally validated with a realistic ORC system.

5. The team also undertook a preliminary turbo-expander design study for a supercritical ORC cycle with the new working fluid.

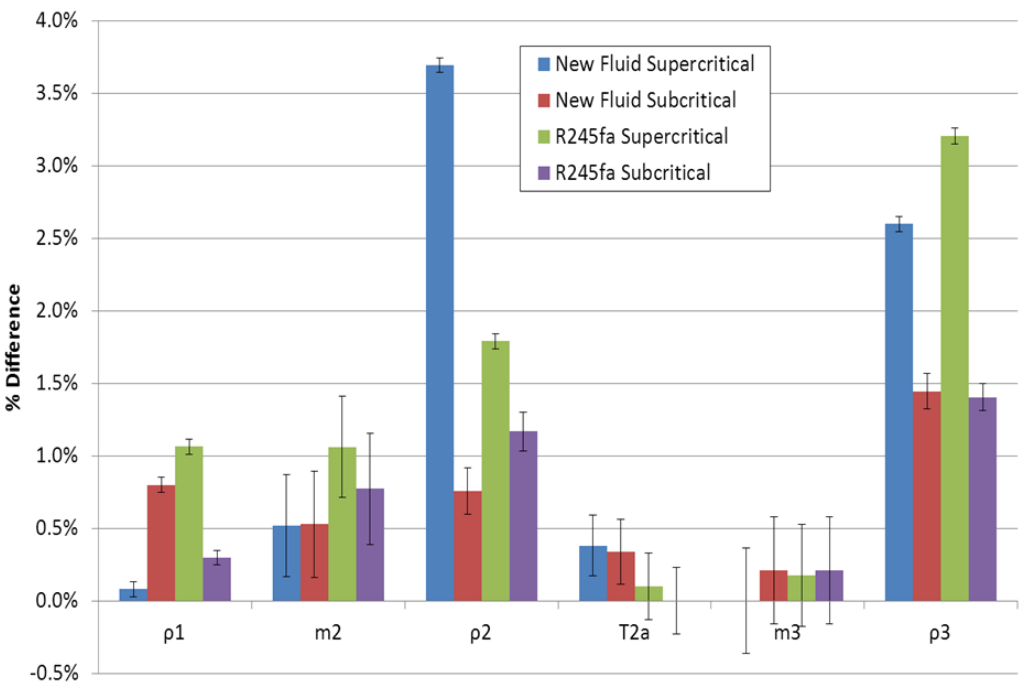

Figure 78. Graphical summary of percent difference between measured and predicted state points. Variants of radial and axial turbo expander geometries went through preliminary design and rough costing. It was found that at $15 \mathrm{MWe}$ or higher power rating, a multi-stage axial turbine is most suitable providing the 
best performance and cost. However, at lower power ratings in the 5MWe range, the expander technology to be chosen depends on the application of the power block. For EGS power blocks, it is most optimal to use multi-stage axial machines.

In conclusion, the predictions of the LCOE model that showed a supercritical cycle based on the new fluid to be most advantageous for geothermal power production at a resource temperature of $200^{\circ} \mathrm{C}$ have been experimentally validated. Table 29 shows a comparison of the net power output and LCOE of a supercritical cycle based on the new fluid with a supercritical R245fa based cycle. It is seen that the cycle based on the new fluid is lower in LCOE and higher in net power output (for the same boundary conditions). The project, therefore has found a new optimal configuration for low temperature geothermal power production in the form of a supercritical ORC cycle based on a new vendor fluid.

Table 29. Comparison of model predictions for supercritical R245fa versus the new fluid.

\begin{tabular}{lr|r}
\hline & \multicolumn{2}{c}{ Tresource $=200^{\circ} \mathrm{C}$} \\
\hline Component & New Fluid & R245fa \\
\hline Evaporator cost & $\$ 4,629,876.07$ & $\$ 3,403,747.50$ \\
\hline Condenser cost & $\$ 7,231,734.61$ & $\$ 6,491,828.42$ \\
\hline Recuperator cost & $\$ 124,069.44$ & $\$ 1,499,168.78$ \\
\hline Expander cost & $\$ 5,134,471.15$ & $\$ 5,005,539.91$ \\
\hline Circulation pump cost & $\$ 713,577.00$ & $\$ 443,469.92$ \\
\hline Reinjection pump cost & $\$ 564,865.98$ & $\$ 570,630.95$ \\
\hline Well Field Cost & $\$ 46,910,624.25$ & $\$ 46,910,624.25$ \\
\hline Total & $\$ 65,309,218.51$ & $\$ 64,325,009.73$ \\
\hline Site Net Power (KW) & $\$ 16,533.74$ & $\mathbf{\$ 1 6 , 0 0 1 . 4 3}$ \\
\hline LCOE (/kWh) & & $\mathbf{1 6 . 8 4}$ \\
\hline
\end{tabular}




\section{Acknowledgements}

This material is based upon work supported by the Department of Energy-under Award Number DE-EE0002769.

In addition to the Geothermal Technologies Program office, the authors would like to acknowledge the following colleagues in the associated business units of GE for the help and for sharing valuable information:

- Robert Moreau (Director Renewable Energy Solutions, GE O\&G)

- Gabriele Mariotti (Turboexpander Design Manager, GE Rotoflow)

- Andrea Burrato (Oregen Product Leader)

- Damiano Menichetti (GE O\&G)

- Randy Wu (GE O\&G)

- Michele Gambinotti (Aircoolers Commercial Manager, GE Vibo)

- Lance Woolley (GE Heat Recovery Solutions)

In addition to the different GE businesses, the authors would also like to thank Altarock Energy Inc. for their key support of this project. 


\section{References}

1. World Energy Outlook 2010, International Energy Agency, (2010)

2. http://altarockenergy.com/media/AltaRock_Stimulation_Release_Final_1_21_13.pdf

3. NREL/TP-6A20-51946, July 2012

4. J. Pickett, J. Silva, and T. Frey, "Organic Rankine Fluids Part 2. Stability. 2008 GRC080.

5. D.M. Ginosar, L.M. Petkovic, and D.P. Guillen, "Thermal Stability of Cyclopentane as an Organic Rankine Cycle Working Fluid, Energy and Fuels, 25, 4138-4144 (2011).

6. J. Zia, G. Becquin, H. Chen, A. Hardy, P. Huck, C. Kalra, T. Kirsten, J. Jackson, A. Laursen, K. Myers, "High-potential Working Fluids for Next Generation Binary Cycle Geothermal Power Plants: Cost-Performance Modeling," 2012 GRC648.

7. X. Zhang, K. Xeng, M. He, "New Technology of Thermodynamic Cycle for Waste Heat Recovery of Vehicle Gasoline Engine, IEEE Power and Energy Engineering Conference 2731 March 2009. http://ieeexplore.ieee.org/xpls/abs_all.jsp?arnumber=4918519\&tag=1

8. G.I. MacKay and R.E. March, "Thermal decomposition of cyclopentene," Can. J. Chem., 48, 913-916 (1970).

9. D.W. Vanas and W.D. Walters, “The Thermal Decomposition of Cyclopentene," J. Amer. Chem. Soc., 70, 4035-4039 (1948).

10. D.A. Knecht, "Thermal Decomposition of Cyclopentene and Cyclopentene -d8 in the Gas Phase,” J. Amer. Chem. Soc., 95, 7933-7938 (1973).

11. K.D. King, "Very Low-Pressure Pyrolysis (VLPP) of Cyclopentene," Int. J. Chem. Kinetics, 10, 117-123 (1978).

12. P.J. Lalonde, and M.H. Back, "A Concerted Hydrogen-Transfer Reaction in the Gas Phase," Int. J. Chem. Kinetics, 12, 301-313 (1980).

13. D.K. Lewis, J. Bergmann, R. Manjoney, R. Paddock, and B.L. Katra, "Rates of reactions of cyclopropane, cyclobutane, cyclopentene, and cyclohexene in the presence of boron trichloride," J. Phys. Chem. 88, 4112-4116 (1984).

14. F.O. Rice, and M.T. Murphy, "The thermal decomposition of five-membered rings," J. Amer. Chem. Soc., 64 896-899 (1942).

15. D.F. Van Sickle, F.R. Mayo, and R. M. Arluck, "The liquid phase oxidation of cyclopentene," J. Amer. Chem. Soc., 87, 4832-4837 (1965).

16. W.M. Kelly, N. J. Taylor, and S. Collins, "Polymerization of cyclopentene using metallocene catalysts: polymer tacticity and properties," Macromolecules, 27 4477-4485 (1994).

17. J.M. Smith and H.C. Van Ness, Introduction to Chemical Engineering Thermodynamics, McGraw Hill, 1959.

18. Authentic spectrum from the Japanese National Institute of Advanced Industrial Science and Technology (AIST) at http://riodb01.ibase.aist.go.jp/sdbs/cgi-bin/direct_frame_top.cgi

19. G.E. Goheen, “The synthesis of multicyclopentyls," J. Amer. Chem. Soc., 63, 744-749 (1942). 20. http://honeywell.com/sites/JP/Products-Services/Consumer-Home/Documents/Acrobat\% 20Document.pdf

21. L. R. G. Treloar, The Physics of Rubber Elasticity, Oxford: Clarendon Press, 2, 1975 (ISBN 978-0-1985-1355-1).

22.http://www.honeywell-orc.com/wp-content/uploads/2011/09/next-generation-ORC-workingfl uid-presentation-2011.pdf

23. NIST Standard Reference Database 23 version 7.0, 2002

24. GE Heat Recovery Solutions Clean Cycle Manual.

25. Heat Transfer Information: GE Heat Recovery Solutions (Email: Chen, June: "HX U Value", 
$06 / 17 / 2013)$.

26. Heat exchanger sizing: http://www.lafipa.lv/files/gea/WP_siltummaini.pdf.

27. NIST Technical Note 1297: Guidelines for Evaluating and Expressing the Uncertainty of NIST Measurement Results, Barry N Taylor and Chris E. Kuyatt

28. AIAA S-071A-1999: AIAA Guide to Assessing Experimental Uncertainty

29. US DOE Award DE-EE0002769, Phase I Milestone Report, 2011

30. US DOE Award DE-EE0002769, Phase II Milestone Report, 2012 